\title{
Essays in financial asset pricing in the European Monetary Union
}

Citation for published version (APA):

Fazlioglu, S. (2020). Essays in financial asset pricing in the European Monetary Union. [Doctoral Thesis, Maastricht University]. Maastricht University. https://doi.org/10.26481/dis.20201029sf

Document status and date:

Published: 01/01/2020

DOI:

10.26481/dis.20201029sf

Document Version:

Publisher's PDF, also known as Version of record

\section{Please check the document version of this publication:}

- A submitted manuscript is the version of the article upon submission and before peer-review. There can be important differences between the submitted version and the official published version of record.

People interested in the research are advised to contact the author for the final version of the publication, or visit the DOI to the publisher's website.

- The final author version and the galley proof are versions of the publication after peer review.

- The final published version features the final layout of the paper including the volume, issue and page numbers.

Link to publication

\footnotetext{
General rights rights.

- You may freely distribute the URL identifying the publication in the public portal. please follow below link for the End User Agreement:

www.umlib.nl/taverne-license

Take down policy

If you believe that this document breaches copyright please contact us at:

repository@maastrichtuniversity.nl

providing details and we will investigate your claim.
}

Copyright and moral rights for the publications made accessible in the public portal are retained by the authors and/or other copyright owners and it is a condition of accessing publications that users recognise and abide by the legal requirements associated with these

- Users may download and print one copy of any publication from the public portal for the purpose of private study or research.

- You may not further distribute the material or use it for any profit-making activity or commercial gain

If the publication is distributed under the terms of Article $25 \mathrm{fa}$ of the Dutch Copyright Act, indicated by the "Taverne" license above, 
Essays in financial asset pricing in the EMU 
(c) Seher Fazlıŏlu, Maastricht 2020

All rights reserved. No part of this publication may be reproduced, stored in a retrieval system, or transmitted in any form, or by any means, electronic, mechanical, photocopying, recording or otherwise, without the prior permission in writing from the author.

This book was typeset by the author using $\mathrm{ATEX}_{\mathrm{E}}$ 


\title{
Essays in financial asset pricing in the European Monetary Union
}

\author{
DISSERTATION \\ to obtain the degree of Doctor at Maastricht University, \\ on the authority of the Rector Magnificus, \\ Prof. dr. Rianne M. Letschert, \\ in accordance with the decision of the Board of Deans, \\ to be defended in public \\ on Thursday, 29 October 2020, at 14:00 hrs
}

by

Seher Fazlığlu 


\section{Supervisors:}

Prof. dr. Bertrand Candelon

Prof. dr. Tom Van Veen

Assessment Committee:

Prof. dr. Clemens Kool (Chair)

Prof. dr. Ivo Arnold (Erasmus University Rotterdam)

Dr. Nalan Baştürk

Prof. dr. Vincent Bodart (Université Catholique of Louvain-La-Neuve)

Dr. Stefan Straetmans 
for

Adem,

Meryem,

Safeta,

Meka \& Sadriya 


\section{Acknowledgements}

"We'll always have Paris."

Casablanca (1942)

Writing a thesis is a magical process of self-actualization, as the Italian philosopher and novelist Umberto Eco put it once. Every PhD journey is unique in its own way. You discover wisdom for yourself after this journey that no one else could have given you. Yet, your interactions with your supervisors, co-authors, colleagues set the tone and make this whole experience possible.

I would like to thank everyone who has helped me write this dissertation. Without your inputs this book would not have been completed. In particular, Bertrand Candelon, Tom Van Veen, Hande Karabıyı, Lennart Freitag, Jean Pierre Urbain, Ayşe Müge Yüksel, Merve Nezihe Özer, Dominik Blatt, Adam Kuczynski, Olaf Sleijpen, Jaap Bos, Murat Öztürk and our graceful ladies, Fleur Roemers, Silvana de Sanctis, Marion Muitjens and Sylvia Beenen.

A special thank you to the honourable members of my assessment committee, Professors Clemens Kool, Ivo Arnold, Nalan Baştürk, Vincent Bodart, Stefan Straetmans for reading and evaluating the thesis.

To all my friends, colleagues, I am grateful for your support and for your companionship during this time. Special thanks to my writing squad, Inge, Kim, Sanne, Maja, Raginee, Charlotte, Julia who has brought joy and efficiency into my life at the time most needed. My Wyck companions, Burcu and Esra, thank you.

At last, but not least to my dear family... Ve sevgili ailem: Fazlıŏlular, Erdenler and Çemberciler, koşulsuz sevgi ve destek için teşekkür ederim. 


\section{Contents}

Acknowledgements vii

Contents $x$

1 Introduction 1

2 Determinants of sovereign yield spreads in the EMU: a pairwise approach $\quad \mathbf{5}$

2.1 Introduction . . . . . . . . . . . . . . . . 5

2.2 Literature review: What explains government debt yield spreads? 7

2.3 Classification of determinants of sovereign yield spreads . . . . 11

2.4 Methodology . . . . . . . . . . . . . . . . 14

2.4.1 Measuring adjusted sovereign debt yield spreads . . . . 14

2.4.2 Econometric issues . . . . . . . . . . . . . . . 16

2.5 Estimation and results . . . . . . . . . . . . . . . . . . . . 18

2.5.1 The data set . . . . . . . . . . . . . . 18

2.5.2 Benchmark results ............... 20

2.5.3 Robustness analysis . . . . . . . . . . . . . . 28

2.6 Conclusion . . . . . . . . . . . . . . . . . . . . 32

2.7 Appendices . . . . . . . . . . . . . . . . . . 35

2.7.1 The long-run sovereign yield spreads . . . . . . . . . 35

2.7.2 Descriptive statistics . . . . . . . . . . . . . 36

2.7.3 Pairwise correlation of all variables . . . . . . . . . 36

3 Interdependence of sovereign yield spreads: the spatial dimension

3.1 Introduction . . . . . . . . . . . . . . . . . . 39

3.2 Literature review: Measuring interdependence . . . . . . . . . . 41

3.3 How to model interdependence of sovereign debt yield spreads . 44

3.4 Econometric framework . . . . . . . . . . . . . 45

3.4.1 Time series panel estimation: the long-run dynamics . . 46

3.4.2 Testing for spatial autocorrelation . . . . . . . . . 48

3.5 Preliminary data analysis . . . . . . . . . . . . . . . 51

3.6 Results . . . . . . . . . . . . . . . 56 
3.6.1 Step 1: establishing the long-run determinants of sovereign yield spreads . . . . . . . . . . . . . 56

3.6.2 Step 2: testing for spatial autocorrelation . . . . . . . . 60

3.7 Robustness analyses .................... 63

3.7.1 Sensitivity to the normalization techniques . . . . . 63

3.7.2 Sensitivity to the first step methods . . . . . . . . . . 64

3.7.3 Sensitivity to the sample of countries, the EMU members 66

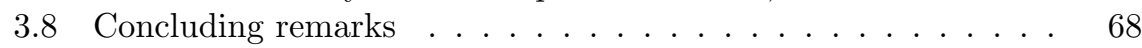

3.9 Appendices . . . . . . . . . . . . . . . 70

3.9.1 The long-run sovereign yield spreads for selected countries 70

3.9.2 Data construction and descriptive statistics . . . . . . 70

3.9.3 Panel unit root tests results . . . . . . . . . . . 71

4 Price discovery of European equities traded on multiple mar$\begin{array}{ll}\text { kets: Is the home market still dominant? } & \mathbf{7 5}\end{array}$

4.1 Introduction . . . . . . . . . . . . . . . . . . 75

4.2 Discussion of price discovery . . . . . . . . . . . . . . . 78

4.3 Empirical literature on the price discovery of stocks . . . . . . 80

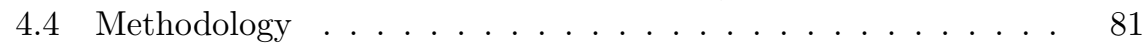

4.4.1 Error Correction Model . . . . . . . . . . . . . . 81

4.4.2 Price discovery measures . . . . . . . . . . . . 83

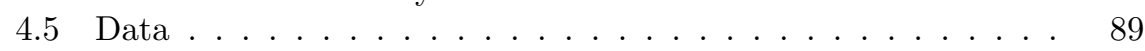

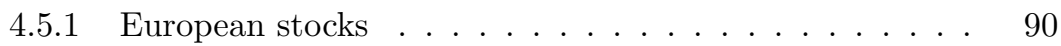

4.5.2 European equity market places . . . . . . . . . . 91

4.6 Empirical results . . . . . . . . . . . . . . . . . . 94

4.6.1 Cross-sectional dependence, unit root and cointegration tests ...................... 94

4.6.2 Estimation of price discovery parameters . . . . . . 100

4.7 Conclusion . . . . . . . . . . . . . . . 106

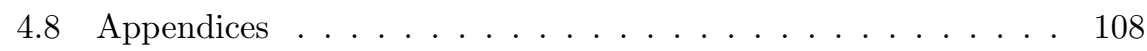

4.8.1 Pairwise correlation coefficients . . . . . . . . . 108

4.8.2 Panel unit root tests . . . . . . . . . . . . 109

5 Summary and conclusions $\quad 113$

$\begin{array}{ll}\text { Bibliography } & 117\end{array}$

$\begin{array}{lr}\text { The impact statement } & 127\end{array}$

$\begin{array}{lr}\text { Curriculum vitae } & 129\end{array}$ 


\section{Chapter 1}

\section{Introduction}

According to the Bank for International Settlements (BIS), the outstanding stock of total debt securities has jumped from 135\% of world GDP in 2000 to $188 \%$ of world GDP in 2012. This increase was mainly driven by the private sector, more specifically financial corporations, until the financial crisis in 2008. Then, the public sector picked up the bill to reduce the economic consequences of the crisis. International investments are liable to risks. To diminish exchange rate risk and to prepare for the introduction of the single currency, the European Economic Community has introduced the European Exchange Rate Mechanism (ERM). With the European Monetary Union (EMU) and the single currency, the euro, exchange rate risks among members were eliminated. This has also reduced default risks and increased access to borrowing channels for its members. Consequently, sovereign interest rate spreads have decreased in the 2000s. In addition, global liquidity conditions have supported this decrease.

After the 2008 financial crisis, there was a drastic change in market perception on default risks and the financial crisis turned into a sovereign debt crisis for the EMU members in 2010. The European Central Bank cooled down the liquidity crisis and sovereign interest rates have declined from high levels (ranging from $15 \%$ to $10 \%$ ) to lower levels (around 7\%-9\%) for some members. The default risks among members remain divergent in this new period.

In this thesis, we treat of price determination and price movements in financial markets. We focus on government bonds and equity markets. First, we analyze what country-specific risks matter for government bond yield spreads and second, we check the interdependence of government bond spreads. Third, we study the competitiveness of European equity markets within the common currency union. The aim is to gain more insight into price determinaion in these markets in the light of more integrated financial markets. The thesis consists of five chapters, the first being an introduction and the last providing a conclusion. The other three chapters evaluate aspects of bond markets as well 
as equity markets within the union. All of them are of empirical studies.

In Chapter 2, we investigate the fundamental drivers of adjusted government bond yield spreads in Europe. The spread is defined as long-run government bond yield differentials between pairs of countries. We correct for exchange rate risks, thus, sovereign spreads are adjusted. We analyze the effects of economic indicators, liquidity indicators, global risk factors as well as governance indicators on these spreads. We use a data set of pairwise combinations in a panel of 14 European economies, 11 EMU members and 3 non-EMU members over the period 1996-2011. We analyze which risk indicators matter in the market perception of default risks and whether the start of the EMU and the introduction of the euro in 1999 and the financial crisis in 2008 have had a significant impact on sovereign debt yield spreads. We find that adjusted sovereign yield spreads are sensitive to the relative government debt ratio, the relative economic growth rate, the liquidity of the debt market as well as governance quality. Interestingly, the relative debt ratio is the only factor that determines long-run yield spreads before the emergence of the EMU, while markets seem to ignore economic fundamentals after the introduction of the euro. After the financial crisis, the markets revalued other economic indicators, liquidity and governance indicators. Among EMU members, the marginal effects of the debt ratio are significant and higher. This indicates that markets price fiscal indebtedness higher among EMU members than among non-EMU members.

The empirical analysis of the determinants of sovereign yield spreads in Chapter 2 indicates that country-specific default risks and illiquidity are insufficient to justify the spreads. This is referred to as a "credit spread puzzle": spreads on sovereign bonds are much larger than can be explained by the country's relative economic fundamentals. The difference is often attributed to international interdependence of the yield spreads. In Chapter 3, we investigate how this interdependence is propagated across countries and how the domestic yield spreads (defined now as the difference between the long-run interest rate on a domestic sovereign bond and the long-run interest rate for a similar US sovereign bond) are affected by the spreads of foreign countries. We investigate the interdependence of sovereign yield spreads in a panel of 21 countries (11 European Monetary Union (EMU) members prior to the 2004 expansion and 10 non-EMU countries) over the period 1996 Q1 until 2016 Q4. Empirical methodologies to evaluate interdependence range from non-parametric techniques such as correlations and principal components to parametric methods such as OLS regressions, VARs, event studies, ARCH and GARCH models and non-linear regressions. Non-parametric methods are not a direct measure of interdependence across countries while parametric methods are. Both methods neglect the country-specific risks as well as the identification of transmission channels. We adopt a semi-parametric approach to address these issues to investigate the interdependence of the spreads. We find a highly significant spatial dependence in the sovereign yield spreads. This implies that the domestic yield spreads are affected by the spreads of foreign countries. Regarding 
transmission channels, economic connections between countries shape spatial dependence. Economic distance measured by trade volume shows the highest estimated degree of spatial dependence, followed by FDI flows and cross bank lending while geographical distance turns out to be insignificant for spatial dependence.

In Chapter 4, we shift from bonds to equities. We study the price discovery of European equities traded on multiple markets by using a panel econometric approach. Price discovery is a market-based pricing process for assets. Trading of the same assets on multiple markets raises the question of each market's contribution to the discovery process. Empirical studies are mainly US-market centric, focus on two markets and adopt an asset-by-asset approach. There is little information on European equities. We address these gaps in the literature. We find that pan-European equity markets operated by the Chicago Board Options Exchange (CBOE) and the London Stock Exchange Group (LSEG), contribute more than the home market to the price discovery process. Among the two pan-European markets, the CBOE contributes more to the price discovery process than the LSEG. With these findings, we contribute to the literature by showing that the mainstream consensus that the home market dominates the pricing process does not hold anymore for assets that are traded on multiple markets. In the case of European equities, the introduction of pan-European markets not only spreads trading volume across the markets in the European Union but also shifts the price discovery dominance.

The last chapter provides the conclusion of our research, the main results from each chapter are summarized and policy implications are discussed.

Our main contribution to the empirical literature is as follows. From a methodological perspective, more integrated financial markets make macroeconomic and financial variables vulnerable to the common shocks/factors such as a change in global risk appetite or a change in the oil price. Econometric techniques are required to incorporate the common factors to improve estimation for structural models. Throughout the thesis, we work with existing methodologies such as the pairwise approach from the trade literature (in Chapter 2) and spatial econometrics (in Chapter 3) which are rarely used in financial research to investigate price determination in bond markets. Also, we propose a new modeling approach (in Chapter 4 ) to capture the price discovery process of European equities.

Main takeaways from these studies are that despite the fact that financial markets have become more integrated, country-specific fundamentals still matter for bond markets. Among the country-specific fundamentals, relative real economic growth is the most robust across different estimations. Further, interdependence of bond markets is propagated via economic connections, particularly bilateral trade connections, FDI flows and cross-bank lending. Finally, the integration of equity markets has had the effect that home market dominance no longer holds in Europe. 
CHAPTER 1. INTRODUCTION 


\section{Chapter 2}

\section{Determinants of sovereign yield spreads in the EMU: a pairwise approach}

\subsection{Introduction}

What are the main drivers of sovereign interest rate spreads? ${ }^{1}$ Yield spreads are mainly determined by (expectations of) exchange rate fluctuations, differences in default/credit risk and differences in bond market liquidity. But what is behind these factors? Are these spreads mainly determined by global risk factors or by country specific economic fundamentals such as differences in fiscal strength, public debt ratios and relative economic growth performance? What has been the effect of monetary integration as well as the 2008 financial crisis on sovereign interest rate spreads? After the introduction of the common currency in 1999, members of the European (Monetary) Union (E(M)U) experienced stable and integrated bond markets until the start of the financial crisis. Monetary integration succeeded in eliminating exchange rate risks, reducing credit risk premiums and increasing access to borrowing channels for its members. Hence, sovereign interest rate spreads decreased in the 2000s, supported by amenable global liquidity conditions. Secondly, country specific economic fundamentals were neglected for a while. The 2008 financial crisis then triggered a revaluation process of individual members' default risks and changing market perceptions are reflected in diverging spreads.

There have been extensive, yet inconclusive empirical studies on the determinants of sovereign interest rates and yield spreads. The studies aim to trace out the effects of risk factors such as default risk, liquidity risk and global risk

\footnotetext{
${ }^{1}$ There are many definitions for yield spreads. In this chapter, we define the spread as the difference in yield on government bonds between two countries.
} 
factors. Early studies are based on time series analysis for sovereign bonds from single countries, mainly the US, since the US has the largest and most developed bond markets. Research into sovereign interest rates in the EMU has provided cross-country evidence. The analyses differ in terms of methodologies, explanatory variables, sample countries as well as sample periods and even in the definition of the dependent variable.

This study aims to provide an empirical analysis of long-term determinants of sovereign debt yield spreads of 14 countries: 11 EMU member states (Austria, Belgium, Finland, France, Germany, Greece, Ireland, Italy, the Netherlands, Portugal, Spain) and 3 non-EMU member states (Denmark, Sweden, the United Kingdom). We use annual data covering the period from 1996 to 2011 for the analysis. We define the sovereign yield spread as the spread of a 10-year benchmark government bond yield of country $i$ over the corresponding yield of the same 10-year maturity bond of country $j$. In accordance with the literature, we categorize common factors that are likely to affect sovereign debt yield spreads into economic indicators, liquidity indicators, global risk factors and governance indicators.

Our main contributions to the existing literature are twofold: we use a pairwise approach and a non-linear dynamic panel analysis. The conventional way to research yield spreads is to adopt the base country approach and to calculate the spread compared with a benchmark country. This approach is sensitive to the choice of the base country and neglects information that could be obtained from cross-country comparisons. For example, it could be that the interest rate differentials between a pair of countries, such as Italy and Greece, are largely driven by countries' fiscal discipline and competitiveness of the economies, while their spreads if computed separately against Germany, are affected by global financing conditions. Therefore, in this study, we define the dependent variable as the long-term interest rate differential between pairs of countries and analyze these in a dynamic panel framework in line with Beine and Candelon (2011). For each country pair, we investigate which factors impact the yield spreads. The pairwise approach is adopted from the gravity model that is widely used in the empirical trade literature. Beginning with Huang et al. (2006) who implemented the model to explain stock market correlations, the model has been used in financial research. Despite the fact that it has been used in explaining the development of cross-market correlations, to our knowledge this is the first empirical study employing the pairwise approach in the bond market literature. Furthermore, the non-linear dynamic panel analysis explores potential structural breaks in the coefficients by time and by country. In our research, the explanatory variables are interacted with an EMU dummy and a Crisis dummy to test for structural breaks in the coefficients after the introduction of the EMU and after the 2008 crisis. Due to the bilateral nature of the data, cross section dependence is likely to be present. We work with Feasible Generalized Least Square (FGLS) to treat cross sectional dependence.

The results of our study suggest that the differential government debt ratio, dif- 
ferential economic growth rates, liquidity and governance quality significantly explain sovereign yield spreads. We identify a significant positive effect for the differential government debt ratio and a significant negative effect for relative economic growth rates. The more liquid the public bond markets are, the lower the liquidity risk premiums are. A positive market perception of governance effectiveness reduces sovereign yield spreads. Moreover, the non-linear dynamic panel estimates indicate that markets seemed to have ignored country-specific economic fundamentals after the emergence of the EMU while the markets revalued the said risk factors after the 2008 financial crisis. We also investigate whether the relations between independent variables and bond yield spreads change with membership of the EMU. The results show that markets price fiscal indebtedness higher among EMU members than among non-EMU members. Finally, the results of the dynamic panel model are robust to different estimation techniques (such as GMM) and to sample selection.

The chapter is organized as follows: Section 2 presents a literature review on yield spreads while a number of potential determinants of these spreads are discussed and identified in Section 3. Section 4 defines our econometric framework whereas Section 5 discusses the data set used and presents the estimations and the results. Conclusions are presented in Section 6 .

\subsection{Literature review: What explains government debt yield spreads?}

There has been extensive research into what drives sovereign debt yield spreads. Economic theory suggests that worsening fiscal positions push interest rates up, causing a decrease in investment and GDP growth in the long-run (Elmendorf and Mankiw (1999)) while an increase in private savings or in international capital flows might reverse these effects (Faini (2006), Linnemann and Schabert (2010)). Standard IS-LM analyses emphasize budget deficits as the determinant of interest rates whereas micro-founded general equilibrium models tend to see the debt stock as playing a more central role. While many studies formalize a model of sovereign borrowing costs within a maximization problem of an open economy, other studies derive a reduced-form equation from a simple meanvariance portfolio model through introducing default, liquidity as well as other country specific risks.

Early empirical studies focus on fiscal responsibility and investigate whether flow fiscal variables such as the budget deficit and government expenditure ratio determine long-term borrowing conditions, or whether stock variables such as the debt stock ratio determine yields. The introduction of the common currency in the Euro area and the sovereign default risks triggered by the 2008 financial crisis have expanded the literature. Researchers have generally found some evidence for the explanatory power of these risk factors but the results and conclusions vary drastically across studies. The analyses differ in terms 
of methodologies, explanatory variables, sample countries as well as sample periods and the dependent variable. Below, we discuss the research into which indicators matter for default risk premiums, financial crises and revaluations of EMU members' risk premiums. A flow variable for fiscal outlook

A first line of research aims to trace out the effects of fiscal imbalances, in particular budget deficits, on sovereign borrowing costs. Both flow variables and stock variables are used to explain sovereign borrowing costs. Moreover, due to the endogeneity of fiscal positions to the business cycle, views differ on what fiscal variable (actual or forward projected public consumption or deficit or debt) should be employed as proxy fiscal positions. Balassone et al. (2004) conclude that expected deficits affect long-term interest rates positively for the US, and Laubach (2009) and Thomas and Wu (2009) confirm this result. Furthermore, Canzoneri et al. (2002) show that expected deficits affect the spread between long and short-term interest rates in the US. Heppke-Falk and Hüfner (2004) study whether expected budget deficits have an impact on interest rate swap spreads in France, Germany and Italy and find a positive impact. In a panel analysis of 19 OECD countries over the period 1988-2007, Gruber and Kamin (2012) find a robust and significant effect of fiscal performance (which is measured by projected budget deficit series) on long-term bond yields. Finally, Ardagna et al. (2004) use a panel of 16 OECD countries covering the period 1960-2002 and find a positive effect of primary deficits as well as the accumulated public debt on long-term interest rates. They use static as well as dynamic econometric models. Ardagna et al.'s paper stresses the non-linear effect of government debt on interest rates: The non-linear effect becomes stronger as a country's debt stock grows. In the robustness check, when the spread of 10-year government bond interest rate over the swap interest rate is used as the dependent variable, the primary deficit and government debt ratio coefficients become statistically insignificant. Since in the literature this measurement is considered as the default risk measurement, the authors argue that the impact of fiscal policy on interest rates is not likely to be via default risk directly, but could be through expected inflation or the demand for loanable funds which have the potential to affect swap markets.

\section{A stock variable for fiscal outlook}

A second line of research analyzes interest rate spreads between government bonds and suitable benchmark assets and focuses on the stock of sovereign debt as a measure of fiscal performance. There are many papers investigating subnational government bond markets. ${ }^{2}$ They find the government debt-toGDP ratio to be significantly positively related to yield spreads, but they fail

\footnotetext{
${ }^{2}$ Bayoumi et al. (1995) and Poterba and Rueben (1999) study the yield differentials of 39 US states relative to New Jersey and find the positive effects of the debt level on the differentials. Lemmen et al. (1999) investigate yield of bonds issued by subnational governments in Austria, Canada and Germany and find the yield spreads over central government bond yields depend positively on the ratio of government debt-to-GDP. Booth et al. (2007) show that bond yields of Canadian provinces over the federal government yield respond positively to measures of subnational indebtedness.
} 
to address how the sovereign risks of national government bonds are priced. Balassone et al. (2004) show that yield spreads of EU countries against Germany depend positively on the change in the government debt-to-GDP ratio over the period 1980-2003. However, one main drawback of this approach is that this cannot decompose credit and exchange rate risks since all variables are denominated in local currencies. Gomez-Puig (2008), Lemmen and Goodhart (1999) and Codogno et al. (2003) study the adjusted spreads of the yields on bonds, where the appropriate interest rate swap rates are subtracted from the yields in local-currency to eliminate the exchange rate risk, and find that the differentials depend positively on the level of public debt. Alesina et al. (1992) focus on 12 OECD countries and show that the differential between public and private bond yields is positively related to the level of public debt. Looning (2000) studies the yields of a very small sample of German Mark Bonds issued by 11 EU governments compared to German government bonds in the mid-1990s and indicates a positive, however not always significant, impact of government debt and deficits.

The introduction of the EMU has stimulated a considerable amount of empirical literature on the determinants of government bond yield spreads in Europe and the literature has expanded substantially following the global financial crisis in 2008. While the earlier literature indicates some similarities on the determinants of sovereign yield spreads, there is no consensus on the key drivers. Bernoth et al. (2012) study 14 EU countries over the period 1993-2005 and find that debt-to-GDP ratio, deficit-to-GDP ratio, debt service on revenues, US corporate bond spreads, an EMU dummy, the short-term US rate and liquidity of the bond to be statistically significant. Schuknecht et al. (2009) detect debt-to-GDP ratio, fiscal balance to GDP, US corporate bond spreads, region dummies, liquidity and maturity and the short-term US interest rate as significant determinants of sovereign yield spreads. Hagen et al. (2011) confirm these results, but also conclude that crisis dummies are significant. Codogno et al. (2003) point out that only debt-to-GDP ratio, US swap spread and US corporate bond spreads are significant. Manganelli and Wolswijk (2009) find country risk ratings and short-term interest rates as crucial yield spread drivers. Given high uncertainty about the "true" empirical model, Dominik (2012) suggests to use a Bayesian Model Averaging (BMA) approach to account explicitly for high uncertainty by considering the entire model space of explanatory variables. By considering 10 EMU member countries over the period 1999-2009, Dominik concludes that budget balance to GDP ratio, terms of trade, trade balance and countries' openness are main drivers of sovereign yield spreads in the Eurozone.

\section{Financial crises and yield spreads}

Finally, there is a growing body of literature which addresses the question of how the 2008 financial crisis has affected bond pricing and yields in the Eurozone. This literature underlines the impact of macroeconomic fundamentals based on cash flow determinants, risk determinants and the interaction of the 
two. Haugh et al. (2009) analyze the yield spreads between 10 EU countries and Germany in the period December 2005-June 2009. They conclude that expected budget deficits and the debt service ratio have important roles in explaining bond yield spreads in the Eurozone. They further argue that the importance of each fiscal variable increases with lower global risk appetite. Barrios et al. (2009) study a panel of 7 EMU countries covering the period 2003q1-2009q2. They find that domestic factors like liquidity and credit risks strongly influence the Euro area spreads and that this effect intensifies in a distressed economic environment. Sgherri and Zoli (2009) estimate a panel model covering monthly government bond yield spreads between 10 EU countries and Germany over the period January 2003-March 2009. They conclude that a significant deterioration in the fiscal position after the financial crisis was priced severely by the markets. Oliveira et al. (2012) study yield spreads of Euro-denominated government bonds for $8 \mathrm{EMU}$ countries covering the period $2000 q 1$ to $2010 q 4$. They find that macroeconomic country-specific variables became important after the financial crisis while market-related factors mainly determined yield spreads during the pre-crisis period. Bernoth and Erdogan (2012) analyze foreign-currency denominated long-term bond yields for $14 \mathrm{EU}$ countries including 3 non-EMU members over the period 1993-2009. They conclude that the yield spreads were sensitive to the government indebtedness both before and after the introduction of the EMU. Furthermore, after the EMU's introduction, markets seemed to pay less attention to government debt levels than before, while deficits and debt service ratios continued to be monitored just as attentively.

The relationship between sovereign debt spreads and the country-specific fundamentals is nonlinear, incorporating changes in the risk pricing (Bernoth and Erdogan (2012) ), contagion (Favero and Missale $(2010,2012)$ ) and changes in the markets' sentiments of risk (De Grauwe and Ji (2013)). Favero and Missale $(2010,2012)$ find that the default risk is an important factor for determining yield spreads for EMU members while the liquidity risk premium became important during the global financial crisis. The authors extend the model with considering a euro break-up factor in Favero and Missale (2016). They conclude interdependence of sovereign yield spreads, however countries with low interest rates along with sounder fiscal outlook are more exposed to the risk of euro break-up, rather than countries with weaker fiscal outlook. De Grauwe and Ji (2013) argue that the sovereign yields in the Eurozone are more vulnerable to self-fulling liquidity crises than in a country with monetary independence and find evidence that economic fundamentals such as the government debt ratio and the debt-to-total budget revenue ratio become important during crises but still negative market sentiments are more important. Further, De Grauwe and Ji (2014) find the evidence that sharp declines in the spreads after Outright Monetary Transaction programme in 2012 are due to positive market sentiment and liquidity provided. It is important that the European Central Bank is active in providing liquidity in time of crises (De Grauwe and Ji (2015)) while the convergence in the government spreads is attributed to positive market 
sentiments rather than fundamentals (De Grauwe et al. (2017)).

From the literature review, we draw the conclusion that empirical evidence on the determinants of sovereign yield spreads is sensitive to sample countries and sample periods, whereas there is no consensus on how to measure fiscal outlook, a flow variable versus a stock variable. Studies focusing on the early stage of the EMU's introduction which overlapped with favorable global liquidity conditions conclude that global risk indicators are the main drivers of the yield spreads among the EMU members. Studies focusing on the period after the financial crisis discuss the importance of fiscal outlook. Our second conclusion is that a difficulty of empirical analysis of the research question at hand is the mismatch between the dependent variable (yield spreads) and the explanatory variables (macroeconomic fundamentals for risk indicators). Yields are financial variables, very sensitive to expectations, quickly anticipate future expectations and are available at high frequency. Macroeconomic fundamentals are available at low frequency. In this empirical study, we use inclusive sample periods (pre-EMU, post-EMU and the crisis period) and sample countries (EMU countries and non-EMU countries) for annual data to determine the main drivers fo yields. The classification of these determinants is explained in the following section.

\subsection{Classification of determinants of sovereign yield spreads}

As discussed in the previous section, empirical studies on the determinants of sovereign yield spreads indicate a large number of risk factors as their main drivers. Many factors are in line with credit rating agencies' country risk assessment schemes which include the exchange rate risk, default/credit risk and liquidity risk. Rating agencies such as Moody's and S\&P spell out a list of numerous economic, political and social factors that underlie sovereign credit ratings. Based on earlier studies, we focus on those variables that have explanatory power as potential drivers of sovereign debt yield spreads. We classify the variables into economic indicators, liquidity indicators, global risk indicators and governance indicators. These indicators are discussed in detail below.

Economic indicators: We consider variables that reveal the ability of a country to fulfill its debt services in the long-run. Economic indicators cover default/credit risk components of risk premiums. We use these concepts interchangeably. The indicators include a country's fiscal strength, its economic growth performance as well as its openness and external sector features. In line with other studies, possible drivers are:

- Budget balance/GDP ratio: This is a flow fiscal variable and one of the main convergence criteria for EMU member states (the budget deficit must not exceed $3 \%$ of GDP). A large fiscal deficit indicates that government finances its current expenditure by borrowing rather than by generating revenue via taxation. Chronic fiscal deficits lead to accumulation of public debt. Thus, the higher the budget deficit is, the higher 
the market perception of default risk is.

- Government debt/GDP ratio: This is a stock fiscal variable and another convergence criteria for EMU member states (the gross government debt ratio must be below $60 \%$ of GDP). Since this is a stock variable, its maturity structure and yields paid on this debt reveal more information on the debt service burden of a country. In general, higher indebtedness increases default risk, putting upward pressure on yield spreads.

- Real GDP growth: Higher economic growth leads to greater tax revenue for government, lower expense due to lower welfare spending and thus a decrease in the default risk. From a theoretical point of view the debt becomes unsustainable when the real rate on the debt exceeds real GDP growth rate.

- Inflation: Inflation is expected to put upward pressure on nominal interest rates. Increasing inflation differentials push nominal interest rates up via the Fisher effect. Moreover, inflation differentials become more important under the common currency framework. As the nominal exchange rate is fixed, higher inflation compared to other members leads to an appreciation of the real exchange rate, deteriorating the competitiveness of a country and increasing default risk.

- Gross fixed capital formation as \% of GDP: This measure aims to test how investments influence default risk. Higher capital formation can lead to higher productivity and higher economic growth. Thus, the ability of an economy to deliver its debt service payments improves, reducing its default risk.

- Trade balance as \% of GDP: Several studies find external sector indicators to be statistically significant in explaining sovereign yield spreads. One indicator is the trade balance ratio, the difference between exports and imports over GDP. A positive trade balance lowers default risk since this is an indication of the ability to service debts. A negative trade balance can be considered as a long-term or solvency issue, leading higher interest rates.

- Openness as \% of GDP: Another external sector indicator is openness which is measured as the sum of exports and imports over GDP. There are two different approaches on how the openness of an economy can influence yield spreads. A country that does not serve its payment obligations bears the consequences of trade and capital flows disruptions. Thus, more open countries are more likely to pay their dues, having lower default risks. On the other hand, spillover literature argues that more open economies are more vulnerable to sudden shifts in global risk appetite or external shocks in the world economy. This increases their default risks and yield spreads in times of crisis.

- Terms of Trade: A third variable related to the external sector is the 
change in the terms of trade. An increase (decrease) in the terms of trade means that (average) export prices increase (decrease) in relation to (average) import prices. An increase in the ToT has two sides. On the one had it may decrease a deficit on the balance of payment, on the other hand a country loses competitiveness which might make debt finance and debt servicing more difficult.

Liquidity indicators: Liquidity of individual bond markets is also an important determinant of sovereign yield spreads. The influence of liquidity for the EMU bond markets is controversial in the literature. Some authors emphasize the importance of liquidity, while others find it to be insignificant for the assessment of risk. Several indicators are used in the literature. For single bond issues, one can observe bid-ask-spreads and the face value of outstanding debt. On the aggregate level, the entire outstanding debt can serve as an indicator for the depth of the country's bond market. Note that Ejsing and Sihvonen (2009), and Korajczyk and Sadka (2008) show that bid-ask-spreads and other liquidity measures are closely related. In this study we propose two aggregated measures to measure liquidity:

- Total outstanding debt: A high level of outstanding debt points at deeper and more liquid markets for bonds. The more liquid the individual bond market is, the lower the liquidity risk premium is.

- Total government debt as \% of total government debt in the sample: Similarly with the previous indicator, if this share increases, then the risk premium decreases.

Global risk indicators: Empirical studies suggest that in addition to country specific variables, global monetary conditions as well as the general market sentiment are the main drivers of bond yield spreads. In this sense, the US interest rate is considered as an indicator of international financing conditions and reflects global financing costs. A low interest rate points at easy financing conditions and lowers the market perception of default risk and spreads. We use the spread between risky US corporate bonds and the US treasury bond to measure the global risk perception of investors.

- US interest rate with 1 year maturity: A higher US rate is likely to increase yield spreads $^{3}$.

- Market sentiment: US corporate bond (BBB rated) spreads to US treasury bonds ${ }^{4}$. Higher corporate bond spreads are likely to lead to higher sovereign yield spreads.

\footnotetext{
${ }^{3}$ We use the US interest rate instead of a European equivalent such as Euribor (Euro Interbank Offered Rate), as the US interest rate is a better measure for the global financing conditions as the US financial market is the most liquid and largest one in the globe. Second, Euribor is available as of January 1999. We cover the period before 1999 and our sample countries include non-EMU members.

${ }^{4}$ The 'BBB' rating category is the largest among outstanding U.S. investment-grade corporate bonds, accounting the $53 \%$ of the investment-grade bonds in the U.S.
} 
Governance indicators: Including only macroeconomic fundamentals to explain spreads does not capture the whole picture regarding the determinants of sovereign yield spreads. Political risk indicators are also found to be significant for the default risk premium, especially for developing countries. Gupta et al. (2008) find the political risk index as one of the determinants of sovereign yields. Moreover, Kamin and von Kleist (1999) use ratings produced by Institutional Investor as an indicator while Eichengreen and Mody (1998) use ratings by Moody's and S\&P and find both the political risk indicators significant. This study focuses on developed economies and for these economies, market perception of risk focuses on governance/government effectiveness and regulatory quality. To measure this, the Worldwide Governance Indicators (WGI) ${ }^{5}$ are used.

- Government effectiveness: This reflects perceptions of the ability of a government to come up and implement sound policies and regulations that promote private sector development. The governance indicators are expected to have a negative relation to sovereign bond yields. Higher governance quality indicates better institutions, political regime and economic development and social stability and this decreases default probability.

- Regulatory quality: This reflects perceptions of the quality of public services, the quality of civil service and the degree of its independence from political pressures, the quality of policy formulation and implementation, and the credibility of the government's commitment to such policies. The hypothesis is that better regulatory quality decreases sovereign risk.

\subsection{Methodology}

In this section, we first define how sovereign debt yield spreads are measured in the pairwise approach. We correct for exchange rate risks, thus, sovereign spreads are adjusted to focus primarily on the effects of economic indicators, liquidity indicators, global risk factors as well as governance indicators. Then, we present the dynamic panel framework to analyze the yield spreads between pairs of $N$ countries in detail.

\subsubsection{Measuring adjusted sovereign debt yield spreads}

Two issues need to be addressed to study determinants of yield spreads: (1) How to measure the spreads and (2) how to extract exchange rate risk premiums on the yields to focus on other risk factors. The conventional way to

\footnotetext{
${ }^{5}$ The report compiles aggregate and individual governance indicators for 213 economies over the period 1996-2010, for six dimensions of governance:1) voice and accountability 2) political stability and absence of violence 3) government effectiveness 4) regulatory quality 5) rule of law 6) control of corruption. The individual data sources underlying the aggregate indicators are collected from a variety of survey institutes, think tanks, non-governmental organizations, and international organizations.
} 


\subsection{METHODOLOGY}

measure yield spreads is to adopt the base country approach, calculating the spread with respect to a benchmark country. For our sample countries, given the size of its economy, long-term interest rates on German government bonds can be considered as the benchmark rates. However, this approach is sensitive to the choice of the base country and neglects information in cross-country comparisons. Pesaran (2007a) adopts a pair-wise approach in his test for economic output convergence and he argues that this approach is applicable when $N$, the number of panels, is larger than $T$, the time dimension of the panel. In line with his study, we consider all $N(N-1) / 2$ possible pairs of yield spreads across $N$ countries in our panel to focus on cross-country comparisons. In our empirical study, sample countries consist of 11 EMU member states and 3 non-EMU members, 14 countries in total, thus 91 pairs of yield spreads. The sample covers the period 1996-2010, thus 15 years. Moreover, the main motivation of our study is to check the robustness of empirical evidence on the determinants of sovereign yield spreads by adopting the pairwise approach. The conventional method of measuring spreads, the base country approach, is suitable when composing a portfolio: ranking relative returns with respect to a base country.

The exchange rate risk premium is eliminated among the EMU member states with the common currency. However, we need to correct the foreign exchange component for the pre-EMU period as well as for the non-EMU members to focus primarily on other risk premiums. Arnold and Lemmen (2001), Blanco (2001), Codogno et al. (2003), Favero et al. (1998) use interest rate swap (IRS) differentials to correct for exchange rate risk premiums. More specifically, the fixed interest rate swap contracts are considered proxies for the measurement of exchange rate risk. Financial intermediaries in the swap markets in different currencies are the same and regulation standards and collateral requirements are also high, indicating similar credit risks across swap markets.

In line with Gomez-Puig (2008), we define the adjusted yield spread as the difference between the yield differential and interest rate swap rate differential $^{6}$ :

$$
\operatorname{AdjSpread}_{i j, 10}=\left[I_{i, 10}-I_{j, 10}\right]_{t}-\left[I R S_{i, 10}-I R S_{j, 10}\right]_{t}
$$

where $I_{i, 10}$ is the 10-year yield of country $i$ and $I R S_{i, 10}$ is the 10-year interest rate swap on the corresponding government bond of country $i$. The first terms on the right-hand side of $((2.1))$ is the 10-year yield differential of country $i$ over country $j$ at time $t$ :

$$
\left[I_{i, 10}-I_{j, 10}\right]_{t}=\text { Yieldspread }_{i j, t}
$$

And the interest rate swap differential (which is a proxy for exchange rate risk) is defined as:

\footnotetext{
${ }^{6}$ We take 10-year interest rate swap rates for the corresponding currency as calculated by Datastream.
} 


$$
\left[I R S_{i, 10}-I R S_{j, 10}\right]_{t}=\left[\text { Interest Rate } \operatorname{Swap}_{i, 10}-\text { Interest Rate } \operatorname{Swap}_{j, 10}\right]_{t}
$$

where the interest rate swap rate is determined on government bonds of the same maturity. In the remaining part of this chapter, we use the adjusted spread as our dependent variable.

\subsubsection{Econometric issues}

We investigate the determinants of sovereign debt yield spreads by using a dynamic panel data framework. The methodology is based on the procedure developed by Beine and Candelon (2011). Their paper suggests estimating a gravity-type model with a combination of cross-sectional and time-series dimension. The way we construct the adjusted yield spreads in our pairwise approach also fits the bilateral nature of a gravity model. Moreover, the crosssectional effects and period-specific effects are explicitly accounted for. The general model can be defined as:

$$
y_{i j t}=\alpha+\beta^{\prime} X_{i j t}+\delta_{t}+\mu_{i j}+\epsilon_{i j t}
$$

where $y_{i j t}$ is the adjusted yield spread of country $i$ over country $j, X_{i j t}$ is a vector of explanatory variables including our indicators for default risk, liquidity, global risk and governance quality. $\alpha$ represents the constant term in the model, $\delta_{t}$ stands for the time-specific effects while $\mu_{i j}$ is the cross-sectional effect and $\epsilon_{i j t}$ is the error term. Both time-specific and cross-sectional effects can be random or fixed. Our setup is identified as a micro-panel framework ${ }^{7}$ since the cross-sectional dimension (pairs of countries) is larger than the time dimension $(\mathrm{T})$.

The aim of introducing cross-sectional effects, $\mu_{i j}$, is to capture the non-time varying effects while time-specific effects, $\delta_{t}$, control for the common shocks disturbing all countries. For instance, several studies suggest the importance of global risk factors. Codogno et al. (2003), Schuknecht et al. (2009) include US interest rate spreads as a control variable. We also include a global risk factor explicitly, rather treating the time-specific effects as nuisance parameters.

To estimate this model, there are two issues to be addressed: cross sectional dependence and endogeneity. We work with Feasible Generalized Least Square (FGLS) to control for cross sectional dependence. Regarding endogeneity, fiscal variables are cyclically responsive to interest rates. For instance, during a recession, the fiscal deficit increases while long-term interest rates fall either due to monetary easing or due to a decline in credit demand. So, there is spurious reverse correlation between fiscal variables and long-term interest rates.

\footnotetext{
${ }^{7}$ Micro panel methods are based on assumptions like stationary data over time (T), crosssectional independence across panels $(\mathrm{N})$ and homogeneity in the coefficient parameters.
} 


\subsection{METHODOLOGY}

The literature suggests either working with projected fiscal variables to anticipate forward looking behavior of the markets or to estimate the model with Generalized Methods of Moments (GMM). We opt to use GMM.

To account for potential dynamics, model (2.4) is extended to include the lagged dependent variable. Given the persistence of yield spreads, the dynamic model can provide further insights on indicators in determining spreads. Accordingly, model (2.4) is expressed as

$$
y_{i j t}=\alpha_{0}+\rho_{0} y_{i j t-1}+\beta_{0}^{\prime} X_{i j t}+\delta_{t}+\mu_{i j}+\epsilon_{i j t}
$$

The dynamic panel model with individual effects induces the Nickell (1981) bias. Note that Nickell (1981) argues the bias increases with the ratio of $\mathrm{N}$ over T. Given the number of pairs (91) compared to the period of 15 years, potential bias should be limited in our empirical study.

We suggest two model specifications to explore potential structural breaks in the coefficients in terms of time and country. First, we examine possible structural breaks in the coefficients to capture the effects of monetary integration and financial crises on sovereign yield spreads. Model (2.5) then becomes,

$$
y_{i j t}=\alpha_{0}+\rho_{0} y_{i j t-1}+\beta_{0}^{\prime} X_{i j t}+\operatorname{EMU}\left(\alpha_{1}+\beta_{1}^{\prime} X_{i j t}\right)+\operatorname{Crisis}\left(\alpha_{2}+\beta_{2}^{\prime} X_{i j t}\right)+\lambda_{t}+\mu_{i j}+\epsilon_{i j t}
$$

where EMU is the dummy variable for the period after the EMU's introduction and Crisis is a dummy for the period after the default of the Lehman Brothers investment bank in September 2008. Interacting these two dummies with the explanatory variables allows testing for structural breaks due to the introduction of the Euro and the 2008 financial crisis. $X_{i j t}$ is a set of explanatory variables (the same as in model (2.4)).

The second specification aims to address the question whether the sensitivity of sovereign yield spreads to different risk factors changes when both paired countries are members of the EMU: Do EMU members pay higher or lower borrowing cost? Model 2.5 is redefined as:

$$
\begin{array}{r}
y_{i j t}=\alpha_{0}+\rho_{0} y_{i j t-1}+\beta_{0}^{\prime} X_{i j t}+\text { EMU-member }\left(\alpha_{1}+\beta_{1}^{\prime} X_{i j t}\right) \\
+ \text { non-EMU-member }\left(\alpha_{2}+\beta_{2}^{\prime} X_{i j t}\right)+\lambda_{t}+\mu_{i j}+\epsilon_{i j t}
\end{array}
$$

where EMU-member is a dummy variable for the pairs of two EMU members while non-EMU-member is a dummy for pairs of non-EMU members. The aim of this analysis is to test for structural breaks due to EMU membership. 


\subsection{Estimation and results}

\subsubsection{The data set}

Since our main motivations are to investigate the effects of European monetary integration on sovereign yield spreads and the effects of the 2008 financial crisis on the spreads, we use a European data set. Given the bilateral nature of our analysis, the data set contains data on all pairwise combinations in a panel of 14 countries. The cross section consists of 11 EMU member states, Austria, Belgium, Finland, France, Germany, Greece, Ireland, Italy, the Netherlands, Portugal, Spain which are already members prior to the 2004 expansion and 3 non-EMU members, Denmark, Sweden and the United Kingdom. The annual data set covers the period from 1996 to 2011. The sample period is chosen due to availability of derivative markets, interest rate swaps data, from 1996 onward. The period covers the pre-EMU era (1996-1999), the clam period (1999-2007) and the financial crisis (2007-2009) and the euro-debt crisis period (2009-2011) which are characterized by high fluctuations of the spreads across time and across countries ${ }^{8}$.

Table 2.1: Description of variables

\begin{tabular}{|c|c|c|c|}
\hline Variable & Definition & Source & Expected sign \\
\hline \multicolumn{4}{|l|}{ Dependent variables } \\
\hline$\overline{\text { Bond yields }}$ & 10-year maturity sovereign debt issued at the primary markets & Ameco* & \\
\hline Interest swap rates & 10-year interest rate swap rate of corresponding currency & Datastream & \\
\hline \multicolumn{4}{|l|}{ Independent variables } \\
\hline \multicolumn{4}{|l|}{$\overline{\text { Economic Indicators }}$} \\
\hline Budget balance ratio & Budget balance as \% of GDP & Ameco & - \\
\hline Primary budget balance ratio & Budget balance excluding interest payments as \% of GDP & Ameco & - \\
\hline Primary budget expenditure ratio & Budget expenditure excluding interest payments as $\%$ of GDP & Ameco & - \\
\hline Total government debt ratio & Total government debt as \% of GDP & Ameco & + \\
\hline GDP growth rate & Real GDP growth & Ameco & - \\
\hline Inflation & Annual CPI change & Ameco & + \\
\hline Capital formation & Gross fixed capital formation as \% of GDP & Ameco & - \\
\hline Trade balance & $(\mathrm{X}-\mathrm{M}) / \mathrm{GDP}$ & Ameco & $-/+$ \\
\hline Openness & $(\mathrm{X}+\mathrm{M}) / \mathrm{GDP}$ & Ameco & $-/+$ \\
\hline Terms of trade growth ${ }^{++}$ & Annual growth in ToT & Ameco & + \\
\hline \multicolumn{4}{|l|}{ Liquidity indicators } \\
\hline Total outstanding debt & Total government debt(in million $€)$ & Ameco & - \\
\hline Total outstanding debt ratio & Total government debt as $\%$ of total government debt in the sample & Ameco & - \\
\hline \multicolumn{4}{|l|}{ Global risk indicators } \\
\hline US interest rate & Bond yield from US treasury yield curve for one-year maturity & Datastream & + \\
\hline Market sentiment & BBB-rated US corporate bond spread to US treasury & Datastream & + \\
\hline \multicolumn{4}{|l|}{ Governance indicators } \\
\hline Government effectiveness & Measurement of the ability of government to implement sound policies*** & $\mathrm{WB}^{* *}$ & - \\
\hline Regulatory quality & Measurement of the quality of policy formulation and implementation & WB & - \\
\hline
\end{tabular}

*Annual Macroeconomic Database of the European Commission.

**The World Bank/Worldwide Governance Indicators.

++ ToT is the relative price of exports in terms of import prices.

***Estimate of governance ranges from approximately -2.5 (weak) to 2.5 (strong) governance performance.

Table 2.1 summarizes the definition of each variable and their source. The

\footnotetext{
${ }^{8}$ The mismatch between the dependent variable, yield (spreads) which are available at high frequency (daily) and the independent variables, macro fundamentals which are available at low frequency (quarterly) raises the question of what data frequency is right for this research. We work with annual data which is line with other studies adapting the pairwise approach(Beine and Candelon (2011), Pesaran (2007a)). The higher data frequency increases the number of observations while its time series properties dominate the process and requires different methodologies.
} 
dependent variable is the adjusted yield spread as the difference between the yield differential and interest rate swap rate differential. The yield differential is calculated by the yield on 10-year government bonds (denominated in local currency) of country $i$ over country $j$. The 10-year interest rate swap rate differential of corresponding pairs is a proxy for the exchange rate risk. The sovereign yield spreads are determined by a large number of variables and we have already discussed the main indicators in Section 2.3. The independent variables of the model comprise economic, liquidity, global risk as well as governance indicators.

Yield spreads among 14 countries over the past three decades are presented in Figure 2.1 in the appendix. The graph on the left side shows yield spreads over time while the graph on the right side shows the adjusted yield spreads. Figure 2.1 indicates that exchange rate risks dominate the fluctuations in the yields during the 1990s. In order to focus primarily on default and liquidity risks, it is vital to exclude exchange rate risks. Secondly, there is a clear pattern among sample countries: convergence right after the introduction of the common currency in 1999 and divergence triggered by Greece, Portugal, and Ireland after the 2008 financial crisis. The adjusted sovereign yield spreads range from $-13 \%$ to $+13 \%$ with near zero mean (Table 2.9 in the appendix). The bond markets start to price macro fundamentals after the 2008 crisis when high spreads are observed. In other words, the divergence in yield spreads among 14 countries after the 2008 financial turmoil (as shown in Figure 2.1), is mainly driven by spreads between the so-called soft-currency and the hard-currency economies. In the literature, soft-currency countries refer to countries which have weaker fiscal outlook, lower economic growth performance and a higher debt stock ratio while hard-currency stands for countries with stronger economic indicators. For instance, the long-run interest rates on Greek bonds jumped to $15.75 \%$ in 2011 while the second highest rate for 2011 was recorded by Portuguese bonds at $10.24 \%$. These were followed by Irish long-term interest rates at $9.6 \%$ in 2011. Finally, Spain and Italy stand out with higher borrowing cost differentials compared with other sample countries with $5.42 \%$ and $5.44 \%$ respectively in 2011, while the borrowing cost differentials for the rest of sample countries range from $2 \%$ to $4 \%$ for 2011 (See Figure 2.2). We also check whether the estimation results are sensitive to sample country selection by excluding PIIGS (Portugal, Italy, Ireland, Greece and Spain) in the robustness analysis.

Finally, pairwise correlation supports the expected relations between adjusted sovereign debt yield spreads and explanatory variables, as shown in Table 2.10 in the appendix. All explanatory variables are calculated as the difference between these variables for pairs of countries. For example, government debt ratio spread corresponds to the differential of these variables for a pair of countries. Table 2.10 reveals that yield spreads are negatively related to the differential budget balance ratio and positively related to the differential government debt ratio. A reduction in budget balance (larger budget deficit) leads to an increase in yield spreads. The differential real GDP growth rate as well as the differential gross fixed investment ratio appear to have significantly negative correlations 
with yield spreads which is in line with prior expectations. External sector indicators, the differential trade balance ratio and openness are significant with negative correlation signs. The literature points out the possibility of both sign directions for these indicators. Another external sector indicator, annual terms of trade change, is not significantly related to yield spreads. The liquidity indicators are also significantly related to spreads: As the liquidity increases, spreads decrease. Interestingly, global risk indicators, US short-term interest rates as well as market sentiment indicators are not related to yield spreads. Thus, we expect these variables to be not significant in the regression analysis despite the fact that many studies suggest the opposite. Finally, governance indicators are highly correlated with yield spreads with negative signs. Better quality in the governance pays off in terms of lower borrowing cost differentials in the bond markets.

\subsubsection{Benchmark results}

We first estimate equations (2.4) and (2.5) for the sample period and further investigate the effects of the EMU and the financial crisis on risk pricing in sovereign bond markets through the non-linear dynamic model in equation (2.6). Finally, we study the possible non-linearity in the coefficients to trace out the effects of being a EMU member on sovereign borrowing cost differentials.

Table 2.2 and 2.3 report the estimation results of our static and dynamic panel models. Table 2.2 summarizes the results of the static model. Relevant details on the estimation techniques are reported at the bottom of the table. We report R-squared, whether cross-sectional effects and time-specific effects are random or fixed, types of GLS weights as well as the coefficient covariance method for GLS estimation. Since standard panel estimators become inconsistent with the presence of cross sectional dependence, we work with an implementable version of GLS, the Feasible GLS (FGLS) approach. We use different methods for GLS weights and coefficient covariance matrices. Cross-section weights for FGLS estimation anticipate different variances for each cross-section while the White cross-section method for coefficient covariance estimation is robust to cross-section heterogeneity and contemporaneous correlation among individual units.

The first three columns of Table 2.2 present different measurements for fiscal outlook such as budget balance ratio, primary budget balance ratio, primary budget expenditure ratio while the public debt ratio is present in all three models. Each flow measurement turns out to be insignificant in determining the long-term sovereign yield spreads. On the budget balance ratio, a reduction in budget balance (decreasing surplus/increasing deficit) is more likely to put upward pressure on yield spreads. However, the estimation results indicate a positive, rather than a negative relation. In the second column, the primary budget balance ratio is included to avoid potential endogeneity bias in the estimation results, that might occur because current budget balance or 
expenditure figures include government interest payments. The third column shows the primary expenditure ratio with a counter-intuitive sign. One possible explanation of this spurious positive correlation is due to cyclical responses of fiscal variables to interest rates. If automatic fiscal stabilizers raise budget deficits during recessions, while at the same time long-term interest rates fall due to monetary easing or due to declining credit demand, deficits and interest rates may be negatively correlated. In line with our expectations, in all specifications the public debt ratio differentials are statistically significant and positively related to adjusted yield spreads. In line with other studies, the public debt ratio differential is a good indicator for the fiscal outlook of an economy (Balassone et al. (2004), Lemmen and Goodhart (1999)).

Other potential underlying determinants show results that are in line with our expectations. In terms of statistical significance, the inflation differential, openness differential as well as government effectiveness and the global risk factor turn out be insignificant. While many studies on the determinants of the EMU-zone sovereign yield spreads find global financing conditions to be significant, in this empirical setup the US short-term interest rate does not have any effect on yield spreads. One explanation is the sample period as well as data frequency. Studies such as Barrios et al. (2009), Schuknecht et al. (2009) focus on the sample period covering the first decade of the EMU during which global liquidity conditions were very good. Other studies work with higher frequency data such as quarterly or monthly data and find global market conditions to be more important in their analyses. Our empirical setup analyzes annual data for the period 1996-2011, covering the period of calm as well as the financial distress period for the EMU economies.

In column (6) of Table 2.2, we re-estimate the static model with differential public debt ratio, real GDP growth rates, gross fixed capital formation ratio and liquidity. We drop the variables that had no effects on the yield spreads in previous estimations. The results suggest that public debt ratio differential of $50 \%$ among the counties results in an increase of $1.30 \%$ in yield spreads. A $1 \%$ higher economic growth relative to the reference country decreases yield spreads by $0.075 \%$. The gross fixed capital formation ratio is the only measure to indicate whether the use of funds influences the borrowing cost. A gross fixed capital formation ratio differential of $10 \%$ causes a decline in yield spreads of $0.540 \%$. Finally, an increase in the bond market size by 100 million euro causes a reduction of the yield spreads by $0.120 \%$.

We extend model 2.4 into a dynamic model by adding the auto-regressive component to deal with serial correlation. The results are listed in Table 2.3. Estimations in Table 2.3 introduce dynamics in yield spreads through the inclusion of an $\mathrm{AR}(1)$ component, which is not present in the models for Table 2.2. The auto-regressive components turn out to be statistically significant, with a value of less than one. Regardless of the specifications, economic indicators, more specifically the public debt ratio differential, relative economic growth performance and the liquidity indicator differential are the main drivers of sovereign 
Table 2.2: Estimation results for the static model (equation (2.4))

\begin{tabular}{|c|c|c|c|c|c|c|}
\hline & (1) & $(2)$ & (3) & (4) & (5) & (6) \\
\hline estimator & FGLS & FGLS & FGLS & FGLS & FGLS & FGLS \\
\hline dependent variable & AdjSpread & AdjSpread & AdjSpread & AdjSpread & AdjSpread & AdjSpread \\
\hline Budget balance/GDP spread & $\begin{array}{c}0.053 \\
(0.049)\end{array}$ & & & & & \\
\hline Public debt/GDP spread & $\begin{array}{c}0.034^{* *} \\
(0.016)\end{array}$ & $\begin{array}{c}0.032^{* *} \\
(0.014)\end{array}$ & $\begin{array}{c}0.037^{* * *} \\
(0.017)\end{array}$ & $\begin{array}{c}0.025^{* *} \\
(0.011)\end{array}$ & $0.026^{* * *}$ & $(0.009)$ \\
\hline Real GDP growth spread & $\begin{array}{c}-0.138^{* *} \\
(0.055)\end{array}$ & $\begin{array}{c}-0.139^{* * *} \\
(0.052)\end{array}$ & $\begin{array}{c}-0.153^{* * *} \\
(0.055)\end{array}$ & $\begin{array}{c}-0.106^{* * *} \\
(0.034)\end{array}$ & $\begin{array}{c}-0.113^{* * *} \\
(0.040)\end{array}$ & $\begin{array}{c}-0.075^{* *} \\
(0.034)\end{array}$ \\
\hline Inflation spread & $\begin{array}{c}0.061 \\
(0.039)\end{array}$ & $\begin{array}{c}0.052 \\
(0.035)\end{array}$ & $\begin{array}{c}0.042 \\
(0.036)\end{array}$ & $\begin{array}{l}0.065^{*} \\
(0.037)\end{array}$ & $\begin{array}{c}0.051 \\
(0.032)\end{array}$ & \\
\hline GFI/GDP spread & $\begin{array}{c}-0.100^{* * *} \\
(0.037)\end{array}$ & $\begin{array}{c}-0.098^{* * *} \\
(0.034)\end{array}$ & $\begin{array}{c}-0.088^{* * *} \\
(0.029)\end{array}$ & $\begin{array}{c}-0.088^{* * *} \\
(0.028)\end{array}$ & $\begin{array}{c}-0.119^{* * *} \\
(0.043)\end{array}$ & $\begin{array}{c}-0.054^{* * *} \\
(0.022)\end{array}$ \\
\hline Openness spread & $\begin{array}{l}-0.006 \\
(0.001)\end{array}$ & $\begin{array}{l}-0.006 \\
(0.006)\end{array}$ & $\begin{array}{l}-0.010 \\
(0.007)\end{array}$ & $\begin{array}{l}-0.009 \\
(0.006)\end{array}$ & $\begin{array}{r}-0.012^{*} \\
(0.007)\end{array}$ & \\
\hline Liquidity spread & $\begin{array}{c}-0.002^{* *} \\
(0.001)\end{array}$ & $\begin{array}{c}-0.002^{* *} \\
(0.000)\end{array}$ & $\begin{array}{c}-0.002^{* *} \\
(0.000)\end{array}$ & $\begin{array}{c}-0.001^{* *} \\
(0.001)\end{array}$ & $\begin{array}{c}-0.001^{* *} \\
(0.000)\end{array}$ & $\begin{array}{c}-0.001^{* * *} \\
(0.001)\end{array}$ \\
\hline Global risk indicator & $\begin{array}{c}0.007 \\
(0.016)\end{array}$ & $\begin{array}{c}0.01 \\
(0.016)\end{array}$ & $\begin{array}{c}0.007 \\
(0.014)\end{array}$ & $\begin{array}{c}0.006 \\
(0.012)\end{array}$ & $\begin{array}{c}0.004 \\
(0.012)\end{array}$ & \\
\hline Governance indicator spread & $\begin{array}{l}-0.394 \\
(0.284)\end{array}$ & $\begin{array}{l}-0.385 \\
(0.265)\end{array}$ & $\begin{array}{c}-0.439 \\
(0.273)\end{array}$ & $\begin{array}{c}-0.225 \\
(0.155)\end{array}$ & $\begin{array}{c}-0.143 \\
(0.122)\end{array}$ & \\
\hline Primary budget balance/GDP sprd & & $\begin{array}{c}0.054 \\
(0.041)\end{array}$ & & & & \\
\hline Primary budget expenditure/GDP spread & & & $\begin{array}{c}-0.063 \\
(0.042)\end{array}$ & & & \\
\hline$\Delta$ Public debt/GDP spread(log) & & & & & $\begin{array}{l}0.597 * * \\
(-0.245)\end{array}$ & \\
\hline Constant & $\begin{array}{c}-0.266^{*} \\
(0.159)\end{array}$ & $\begin{array}{c}-0.281^{*} \\
(0.160)\end{array}$ & $\begin{array}{c}-0.039 \\
(0.124)\end{array}$ & $\begin{array}{l}-0.101 \\
(0.108)\end{array}$ & $\begin{array}{c}0.115 \\
(0.115)\end{array}$ & $\begin{array}{c}-0.293 \\
(0.094)\end{array}$ \\
\hline Observations & 1,456 & 1,456 & 1,456 & 1,456 & 1,456 & 1,456 \\
\hline R squared & 0.596 & 0.598 & 0.601 & 0.568 & 0.522 & 0.472 \\
\hline \# of pairs & 91 & 91 & 91 & 91 & 91 & 91 \\
\hline Cross section FE & Yes & Yes & Yes & Yes & Yes & Yes \\
\hline Time FE & No & No & No & No & No & No \\
\hline Coef. covar. method & White CS & White CS & White CS & White CS & White CS & White CS \\
\hline
\end{tabular}

** $\mathrm{p}<0.01,{ }^{* *} \mathrm{p}<0.05,{ }^{*} \mathrm{p}<0.10$ and standard deviations in parenthesis.

Note: GLS weights are CSW-Cross section weights.

yield spreads. The models explain around $70 \%$ of the variance in the long-term yield difference. The goodness of fit, R-squared-s have improved to $69 \%$ and $78 \%$ from around $50 \%$ in the static model. Furthermore, the autoregressive components turn out be significant and less than one across the estimations. Only in the model with logarithmic presentation of debt ratio in the column (5), the coefficient exceeds unity. However, it is very close to one, indicating high persistence in the yield spreads. As in the static model, the fiscal strength related variables such as budget balance, primary budget balance and primary expenditure ratios have counter-intuitive correlation direction signs. Thus, we focus on debt outlook as an indicator of government fiscal performance. Global risk factors do not affect the borrowing cost differential for this period. Inflation differential shows insignificant relations. Openness differential shows mixed results, insignificant relation in the first model, significant relation in the model with logarithmic presentation of debt ratio in the column (5). However, governance indicators become significant in the dynamic model while the gross fixed capital formation ratio registers an insignificant coefficient.

In the last column (6) of Table 2.3, we re-estimate the dynamic model with the public debt ratio differential, relative real GDP growth rates, liquidity as well 
Table 2.3: Estimation results for the dynamic model (equation (2.5))

\begin{tabular}{|c|c|c|c|c|c|c|}
\hline & (1) & (2) & (3) & (4) & (5) & (6) \\
\hline $\begin{array}{l}\text { estimators } \\
\text { dependent variable }\end{array}$ & $\begin{array}{c}\text { FGLS } \\
\text { AdjSpread }\end{array}$ & $\begin{array}{c}\text { FGLS } \\
\text { AdjSpread }\end{array}$ & $\begin{array}{c}\text { FGLS } \\
\text { AdjSpread }\end{array}$ & $\begin{array}{c}\text { FGLS } \\
\text { AdjSpread }\end{array}$ & $\begin{array}{c}\text { FGLS } \\
\text { AdjSpread }\end{array}$ & $\begin{array}{c}\text { FGLS } \\
\text { AdjSpread }\end{array}$ \\
\hline Lagged adjSpread & $\begin{array}{c}0.967^{* *} \\
(0.393)\end{array}$ & $\begin{array}{c}0.960^{* *} \\
(0.401)\end{array}$ & $\begin{array}{c}0.952^{* *} \\
(0.401)\end{array}$ & $\begin{array}{c}0.994^{* *} \\
(0.417)\end{array}$ & $\begin{array}{l}1.014^{* *} \\
(0.457)\end{array}$ & $\begin{array}{c}0.963^{* *} \\
(0.407)\end{array}$ \\
\hline Budget balance/GDP spread & $\begin{array}{l}0.051^{*} \\
(0.030)\end{array}$ & & & & & \\
\hline Public debt/GDP spread & $\begin{array}{c}0.033^{* * *} \\
(0.010)\end{array}$ & $\begin{array}{c}0.029^{* * *} \\
(0.009)\end{array}$ & $\begin{array}{c}0.034^{* * *} \\
(0.010)\end{array}$ & $\begin{array}{c}0.024^{* * *} \\
(0.007)\end{array}$ & & $\begin{array}{c}0.023^{* *} \\
(0.006)\end{array}$ \\
\hline Real GDP growth spread & $\begin{array}{c}-0.065^{* * * *} \\
(0.021)\end{array}$ & $\begin{array}{c}-0.059^{* * *} \\
(0.019)\end{array}$ & $\begin{array}{c}-0.066^{* * * *} \\
(0.020)\end{array}$ & $\begin{array}{c}-0.044^{* * * *} \\
(0.014)\end{array}$ & $\begin{array}{c}-0.045^{* * *} \\
(0.016)\end{array}$ & $\begin{array}{c}-0.057^{* *} \\
(0.015)\end{array}$ \\
\hline Inflation spread & $\begin{array}{c}0.002 \\
(0.033)\end{array}$ & $\begin{array}{c}0.003 \\
(0.032)\end{array}$ & $\begin{array}{c}-0.002 \\
(0.030)\end{array}$ & $\begin{array}{c}0.023 \\
(0.033)\end{array}$ & $\begin{array}{c}0.018 \\
(0.033)\end{array}$ & \\
\hline GFI/GDP spread & $\begin{array}{c}-0.023 \\
(0.021)\end{array}$ & $\begin{array}{l}-0.019 \\
(0.021)\end{array}$ & $\begin{array}{l}-0.011 \\
(0.006)\end{array}$ & $\begin{array}{l}-0.008 \\
(0.017)\end{array}$ & $\begin{array}{l}-0.036^{*} \\
(0.018)\end{array}$ & \\
\hline Openness spread & $\begin{array}{c}-0.009 \\
(0.006)\end{array}$ & $\begin{array}{l}-0.010^{*} \\
(0.006)\end{array}$ & $\begin{array}{l}-0.011^{*} \\
(0.006)\end{array}$ & $\begin{array}{l}-0.010^{*} \\
(0.004)\end{array}$ & $\begin{array}{c}-0.012^{* *} \\
(0.005)\end{array}$ & \\
\hline Liquidity spread & $\begin{array}{c}-0.002^{* * *} \\
(0.000)\end{array}$ & $\begin{array}{c}-0.002^{* *} \\
(0.000)\end{array}$ & $\begin{array}{c}-0.002^{* *} \\
(0.000)\end{array}$ & $\begin{array}{c}-0.001^{* *} \\
(0.000)\end{array}$ & $\begin{array}{c}-0.001^{* *} \\
(0.000)\end{array}$ & $\begin{array}{c}-0.001^{* *} \\
(0.000)\end{array}$ \\
\hline Global risk indicator & $\begin{array}{c}0.024 \\
(0.017)\end{array}$ & $\begin{array}{c}0.022 \\
(0.017)\end{array}$ & $\begin{array}{c}0.017 \\
(0.015)\end{array}$ & $\begin{array}{c}0.012 \\
(0.014)\end{array}$ & $\begin{array}{c}0.014 \\
(0.015)\end{array}$ & \\
\hline Governance indicator spread & $\begin{array}{c}-0.431^{* *} \\
(0.202)\end{array}$ & $\begin{array}{c}-0.397^{* *} \\
(0.188)\end{array}$ & $\begin{array}{c}-0.440^{* *} \\
(0.187)\end{array}$ & $\begin{array}{c}-0.276^{* *} \\
(0.130)\end{array}$ & $\begin{array}{l}-0.215^{*} \\
(0.110)\end{array}$ & $\begin{array}{c}-0.266^{* *} \\
(0.115)\end{array}$ \\
\hline Primary budget balance/GDP spread & & $\begin{array}{c}0.039 \\
(0.026)\end{array}$ & & & & \\
\hline Primary budget expenditure/GDP spread & & & $\begin{array}{c}-0.045^{*} \\
(0.024)\end{array}$ & & & \\
\hline$\Delta$ Public debt/GDP spread(log) & & & & & $\begin{array}{l}0.583^{*} \\
(0.342)\end{array}$ & \\
\hline Constant & $\begin{array}{c}-0.264^{*} \\
(0.136)\end{array}$ & $\begin{array}{c}-0.237^{*} \\
(0.130)\end{array}$ & $\begin{array}{c}-0.072 \\
(0.139)\end{array}$ & $\begin{array}{l}-0.124 \\
(0.099)\end{array}$ & $\begin{array}{c}0.023 \\
(0.099)\end{array}$ & $\begin{array}{c}-0.207^{* *} \\
(0.049)\end{array}$ \\
\hline Observations & 1,431 & 1,431 & 1,431 & 1,431 & 1,431 & 1,431 \\
\hline R squared & 0.773 & 0.762 & 0.766 & 0.731 & 0.687 & 0.72 \\
\hline \# of pairs & 91 & 91 & 91 & 91 & 91 & 91 \\
\hline GLS weights++ & CSW++ & CSW & CSW & CSW & CSW & CSW \\
\hline Coef. covar. method & White CS & White CS & White CS & White CS & White CS & White CS \\
\hline
\end{tabular}

as government effectiveness spreads. Compared to column (6) of Table 2.2, the public debt ratio differentials, relative economic growth rates and liquidity indicators are robust to the model specification. The model explains $72 \%$ of the variance in yield differentials, increasing from $47 \%$ in the corresponding static model. The coefficients can be interpreted as follows: a debt ratio differential of $50 \%$ among the pairs of countries results in an increase of $1.15 \%$ in adjusted yield spreads, while if a country has $1 \%$ higher economic growth compared to the reference country, adjusted yield spreads decrease by $0.057 \%$. Furthermore, an increase in the bond market size by 100 million Euro leads to a reduction in yield spreads of $0.10 \%$. One unit increase in the differential governance indicator between two countries decreases the yield spreads between the countries by $0.266 \%$.

The results of these estimations suggest that economic indicators, in particular, the public debt ratio, real GDP growth differentials, the liquidity indicator and the governance indicator are the main drivers of long-term borrowing cost differentials for the public sector. These results are in line with the findings of Lemmen and Goodhart (1999) and Codogno et al. (2003) who find debt ratios to have significant influence on yield spreads. Also, Rowland and Torres (2004) 
indicate a negative relation between economic growth and yield spreads for developing countries over the period 1998-2002. Regarding the liquidity indicator, the deeper and the more liquid the public bond markets are, the lower their liquidity risk premiums are. Schuknecht et al. (2009) and Hagen et al. (2011) also point at the importance of the liquidity (size) of the public debt for EU countries in reducing their relative borrowing costs. Finally, the market perception of governance effectiveness is important in determining yield spreads. This is also in line with studies for developing countries in which credit ratings stand for quality measures on government effectiveness. Eichengreen and Mody (1998) have found the ratings by Institutional Investor to be significant for the yield spreads for developing countries while Kamin and von Kleist (1999) also analyze the effects of ratings of $\mathrm{S} \& \mathrm{P}$ and Moody's on the borrowing costs for developing countries.

\section{The EMU and the crisis-period}

The introduction of the Euro and the 2008 financial crisis have affected yield spreads in the Eurozone. For instance, Bernoth et al. (2012) find that markets paid less attention to fiscal outlook for Eurozone countries following the EMU's introduction and became more sensitive to fiscal policies after the 2008 crisis. Also, liquidity premiums seemed to disappear after the emergence of the EMU. In addition, Hagen et al. (2011) find empirical evidence on the shifts in the nature and magnitude of default risk premiums before and after the EMU's introduction. Schuknecht et al. (2009) also argue that markets have penalized fiscal imbalances far more strongly since Lehman Brothers' default in September 2008. In light of these studies, we further investigate the presence of such patterns in our empirical study.

Table 2.4 presents the results of equation ((2.6)). The lower panel of Table 2.4 shows the variables that are interacted with the EMU dummy and the Crisis dummy to test for structural breaks in the coefficients. The first column of Table 2.4 summarizes the benchmark results while the second column checks robustness of the results as we estimate the model without EMU effects. The third column uses the budget balance ratio variable instead of the public debt ratio to analyze fiscal performance. A comparison between Table 2.3 and Table 2.4 reveals that while the pricing direction of risks related to relevant factors remains unchanged with the (EMU and the crisis period, the relation between the risk factors and bond yield spreads change significantly across the sub-periods. The public debt ratio differential becomes the only factor that moves the long-term sovereign debt yield spreads, but with much lower marginal effects during the pre-EMU period, whereas other variables turn out to be insignificant.

The marginal effects of the differential real GDP growth rates on the sovereign yield spreads intensify with the crisis period ( -0.204 percentage points during the crisis versus -0.057 percentage points during the whole sample period (column (6) of Table 2.3) while the marginal effects of government effectiveness differentials almost double during the crisis (-0.404 units during the crisis ver- 
sus -0.266 units for the entire sample period). The most important point of the non-linear dynamic model estimation is that all risk factors become insignificant with the EMU's introduction. After the 2008 financial crisis, relative real GDP growth and governance indicators are revalued by the markets while the liquidity indicator and the public debt ratio differential are also statistically significant, but with economically limited effects. Apart of avoiding the exchange rate risk, reducing country-specific credit risks was another fundamental motivation for forming the monetary union. At early stages, markets priced the convergence among the EMU countries as their borrowing costs declined drastically. The financial crisis in 2008 was a wake-up call for the investors to focus more closely on the country-specific risks.

\section{The EMU membership}

Finally, the panel structure of the data gives us an opportunity to check another non-linearity in the coefficients: does the sensitivity of yield spreads to risk variables change due to the EMU membership? The aim of this analysis is to investigate whether the relation between indicators for risks and adjusted sovereign yield spreads changes when both pair-countries are members of the EMU. Table 2.5 summarizes the results of non-linear dynamic model of equation (2.7).

The lower panel of Table 2.5 shows the variables that are interacted with the EMU membership dummy and the non-EMU membership dummy to test for structural breaks in the coefficients. The first column of Table 2.5 summarizes the benchmark results while the second column checks robustness of the results by re-estimating the model, excluding statistically insignificant interactive variables (with the EMU membership dummy). The third column includes the budget balance ratio variable instead of the public debt ratio to analyze fiscal performance in the presence of structural breaks. The public debt ratio is a more appropriate tool for fiscal performance measurement since the coefficient of the budget ratio turns out be insignificant. The estimation results confirm a positive relation for the public debt ratio, a negative relation for real GDP growth rate and a negative relation for the liquidity risk. Also an increase in the governance quality indicator leads to a deterioration in sovereign yield spreads. All is in line with the previous analysis. Furthermore, the results indicate a structural break in the public debt ratio coefficients in both categories: among EMU members and non-EMU members. Among EMU members, pricing risk related to increasing public debt ratio remains unchanged since its sign is positive and thus its marginal effects intensify. Whereas the relation between the debt ratio and bond yield spreads has changed significantly for non-EMU members since it has a negative sign . Thus, the markets price the deterioration in the debt outlook among non-EMU countries far less than among EMU members.

One needs to be cautious when interpreting this claim. The individual significance of the differential debt ratio interacted with the non-EMU members is statistically significant with a negative sign. In order to generate statisti- 
Table 2.4: Estimation results for non-linear dynamic model-time (equation $(2.6))$

\begin{tabular}{|c|c|c|c|}
\hline & (1) & $(2)$ & (3) \\
\hline \multirow{2}{*}{$\begin{array}{l}\text { estimators } \\
\text { dependent variable }\end{array}$} & FGLS & FGLS & FGLS \\
\hline & AdjSpread & AdjSpread & AdjSpread \\
\hline \multirow[t]{2}{*}{ Lagged adjSpread } & $0.789^{* *}$ & $0.775^{* *}$ & $0.979^{* *}$ \\
\hline & $(0.372)$ & $(0.341)$ & $(0.405)$ \\
\hline \multirow[t]{2}{*}{ Budget balance/GDP spread } & & & -0.016 \\
\hline & & & $(0.077)$ \\
\hline \multirow[t]{2}{*}{ Public debt/GDP spread } & $0.016^{* * *}$ & $0.017^{* * *}$ & \\
\hline & $(0.004)$ & $(0.005)$ & \\
\hline \multirow[t]{2}{*}{ Real GDP growth spread } & 0.020 & 0.007 & $0.05^{* * *}$ \\
\hline & $(0.020)$ & $(0.016)$ & $(0.015)$ \\
\hline \multirow[t]{2}{*}{ Liquidity spread } & -0.001 & $-0.001 * * *$ & $-0.001^{* *}$ \\
\hline & $(0.000)$ & $(0.000)$ & $(0.000)$ \\
\hline \multirow[t]{2}{*}{ Governance indicator spread } & 0.025 & -0.021 & 0.456 \\
\hline & $(0.001)$ & $(0.111)$ & $(0.339)$ \\
\hline \multirow[t]{2}{*}{ Constant } & $-0.159^{* * *}$ & $-0.170^{* * *}$ & $0.050^{* *}$ \\
\hline & $(0.056)$ & $(0.063)$ & $(0.025)$ \\
\hline \multicolumn{4}{|l|}{ EMU effect } \\
\hline \multirow[t]{2}{*}{ Budget balance/GDP spread } & & & 0.023 \\
\hline & & & $(0.075)$ \\
\hline \multirow[t]{2}{*}{ Public debt/GDP spread } & 0.002 & & \\
\hline & $(0.003)$ & & \\
\hline \multirow[t]{2}{*}{ Real GDP growth spread } & -0.014 & & $-0.014^{* * *}$ \\
\hline & $(0.017)$ & & $(0.015)$ \\
\hline \multirow[t]{2}{*}{ Liquidity spread } & -0.000 & & -0.000 \\
\hline & $(0.000)$ & & $(0.000)$ \\
\hline \multirow{2}{*}{ Governance indicator spread } & -0.059 & & -0.443 \\
\hline & $(0.398)$ & & $(0.376)$ \\
\hline \multicolumn{4}{|l|}{ Crisis effect } \\
\hline \multirow[t]{2}{*}{ Budget balance/GDP spread } & & & 0.01 \\
\hline & & & $(0.019)$ \\
\hline \multirow[t]{2}{*}{ Public debt/GDP spread } & $0.014^{* * *}$ & $0.014^{* * *}$ & \\
\hline & $(0.003)$ & $(0.004)$ & \\
\hline \multirow[t]{2}{*}{ Real GDP growth spread } & $-0.204^{* * *}$ & $-0.209^{* * *}$ & $-0.220 * * *$ \\
\hline & $(0.005)$ & $(0.005)$ & $(0.054)$ \\
\hline \multirow[t]{2}{*}{ Liquidity spread } & $-0.000^{* * *}$ & $-0.000^{* * *}$ & $-0.001^{* * *}$ \\
\hline & $(0.000)$ & $(0.000)$ & $(0.000)$ \\
\hline \multirow[t]{2}{*}{ Governance indicator spread } & $-0.404^{* * *}$ & $-0.409^{* * *}$ & $-1.056^{* * *}$ \\
\hline & $(0.162)$ & $(0.166)$ & $(0.310)$ \\
\hline Observations & 1431 & 1431 & 1431 \\
\hline $\mathrm{R}$ squared & 0.793 & 0.791 & 0.739 \\
\hline Number of pairs & 91 & 91 & 91 \\
\hline GLS weights ++ & $\mathrm{CSW}++$ & CSW & CSW \\
\hline Coef. covar. method & White CS & White CS & White CS \\
\hline
\end{tabular}

++ CSW-Cross-sectional weights and ${ }^{* *} \mathrm{p}<0.01,{ }^{* *} \mathrm{p}<0.05,{ }^{*} \mathrm{p}<0.10$ and standard deviations in parentheses. Note: Cross-sectional Fixed effects- Yes; Time fixed effects- No.

cal inference, we conduct Wald tests on the hypotheses that the sum of the coefficients of one independent variable and its corresponding non-linear coefficient is equal to zero. Given that the interactive variables are additive, Wald tests on the sum of coefficient significance are relevant. Corresponding Wald tests are reported in Table 2.6 with their p-values. The hypothesis that the 
Table 2.5: Estimation results for the non-linear dynamic model-country (equation $(2.7))$

\begin{tabular}{|c|c|c|c|}
\hline & $(1)$ & $(2)$ & $(3)$ \\
\hline $\begin{array}{l}\text { estimators } \\
\text { dependent variable }\end{array}$ & $\begin{array}{c}\text { FGLS } \\
\text { AdjSpread }\end{array}$ & $\begin{array}{c}\text { FGLS } \\
\text { AdjSpread }\end{array}$ & $\begin{array}{c}\text { FGLS } \\
\text { AdjSpread }\end{array}$ \\
\hline Lagged adjSpread & $\begin{array}{c}0.922^{* * *} \\
(0.402)\end{array}$ & $\begin{array}{c}0.928^{* * *} \\
(0.398)\end{array}$ & $\begin{array}{c}1.032^{* * *} \\
(0.462)\end{array}$ \\
\hline Budget balance/GDP spread & & & $\begin{array}{c}-0.004 \\
(0.016)\end{array}$ \\
\hline Public debt/GDP spread & $\begin{array}{c}0.021^{* * *} \\
(0.007)\end{array}$ & $\begin{array}{c}0.018^{* * *} \\
(0.005)\end{array}$ & \\
\hline Real GDP growth spread & $\begin{array}{c}-0.049^{* * *} \\
(0.022)\end{array}$ & $\begin{array}{c}-0.064^{* * *} \\
(0.018)\end{array}$ & $\begin{array}{c}-0.056^{* * *} \\
(0.024)\end{array}$ \\
\hline Liquidity spread & $\begin{array}{c}-0.001^{* * *} \\
(0.000)\end{array}$ & $\begin{array}{c}-0.001^{* * *} \\
(0.000)\end{array}$ & $\begin{array}{l}-0.000 \\
(0.000)\end{array}$ \\
\hline Governance indicator spread & $\begin{array}{c}-0.252^{*} \\
(0.141)\end{array}$ & $\begin{array}{l}-0.329 \\
(0.132)\end{array}$ & $\begin{array}{c}-0.355^{*} \\
(0.214)\end{array}$ \\
\hline Constant & $\begin{array}{c}-0.172^{* * *} \\
(0.055)\end{array}$ & $\begin{array}{c}-0.166^{* * *} \\
(0.043)\end{array}$ & $\begin{array}{l}-0.020 \\
(0.025)\end{array}$ \\
\hline EMU members & & & \\
\hline Budget balance/GDP spread & & & $\begin{array}{l}-0.009 \\
(0.016)\end{array}$ \\
\hline Public debt/GDP spread & $\begin{array}{c}0.007^{* * * *} \\
(0.003)\end{array}$ & $\begin{array}{c}0.01^{* * *} \\
(0.004)\end{array}$ & \\
\hline Real GDP growth spread & $\begin{array}{l}-0.022 \\
(0.024)\end{array}$ & & $\begin{array}{c}-0.030 \\
(0.033)\end{array}$ \\
\hline Liquidity spread & $\begin{array}{l}-0.000 \\
(0.000)\end{array}$ & & $\begin{array}{l}-0.000 \\
(0.000)\end{array}$ \\
\hline Governance indicator spread & $\begin{array}{l}-0.114 \\
(0.134)\end{array}$ & & $\begin{array}{c}0.222 \\
(0.175)\end{array}$ \\
\hline Non- EMU members & & & \\
\hline Budget balance/GDP spread & & & $\begin{array}{l}-0.020 \\
(0.034)\end{array}$ \\
\hline Public debt/GDP spread & $\begin{array}{c}-0.025^{* * *} \\
(0.012)\end{array}$ & $\begin{array}{c}-0.022^{* * *} \\
(0.012)\end{array}$ & \\
\hline Real GDP growth spread & $\begin{array}{c}0.039 \\
(0.052)\end{array}$ & $\begin{array}{c}0.054 \\
(0.063)\end{array}$ & $\begin{array}{c}0.08 \\
(0.069)\end{array}$ \\
\hline Liquidity spread & $\begin{array}{c}0.001^{* * * *} \\
(0.001)\end{array}$ & $\begin{array}{c}0.001^{* * *} * \\
(0.001)\end{array}$ & $\begin{array}{l}-0.000 \\
(0.000)\end{array}$ \\
\hline Governance indicator spread & $\begin{array}{c}0.037 \\
(0.613)\end{array}$ & $\begin{array}{c}0.113 \\
(0.590)\end{array}$ & $\begin{array}{c}0.393 \\
(0.610)\end{array}$ \\
\hline Observations & 1431 & 1431 & 1431 \\
\hline $\mathrm{R}$ squared & 0.72 & 0.72 & 0.64 \\
\hline Number of pairs & 91 & 91 & 91 \\
\hline GLS weights ++ & $\mathrm{CSW}++$ & CSW & CSW \\
\hline Coef. covar. method & White CS & White CS & White CS \\
\hline
\end{tabular}

++ CSW-Cross-sectional weights and ${ }^{* * *} \mathrm{p}<0.01,{ }^{* *} \mathrm{p}<0.05,{ }^{*} \mathrm{p}<0.10$ and standard deviations in parentheses. Note: Cross-sectional Fixed effects- Yes; Time fixed effects- No.

sum of the coefficients on debt ratio and debt ratio*non-EMU is zero is not rejected at $10 \%$ significance level through the Wald test. The marginal effects of an increase in the differential debt ratios on the sovereign yield spreads among the non-EMU members become statistically insignificant. On the other hand, the result of a Wald test of the hypothesis that sum of the coefficients 
on debt ratio and debt ratio ${ }^{*} E M U$ is zero, is rejected at $1 \%$ significance level. The bottom line is that markets seem to price fiscal indebtedness among the EMU members more than among the non-EMU members. This finding must be related to the monetary union. EMU members gave up their own national currencies for the common currency. The European Central Bank does not serve as lender of last resort for individual states, increasing risk premiums for the members in times of crisis. Another explanation is the lack of nominal exchange rate adjustments to increase members' competitiveness to cope with a crisis. With a fixed nominal exchange rates, a EMU member can increase its competitiveness, depreciating its real exchange rate, via domestic price or wage adjustments which are more painful and longer processes compared to nominal exchange rate adjustment.

Table 2.6: Hypotheses tests

\begin{tabular}{lc}
\hline & Wald Test (p-values) \\
\hline$H_{0}:$ the sum of coefficients on debt_ratio and debt_ratio*EMU member is equal to zero & 0.00 \\
$H_{0}:$ the sum of coefficients on gdp_growth and gdp_growth*EMU member is equal to zero & 0.00 \\
$H_{0}:$ the sum of coefficients on liquidity and liquidity*EMU member is equal to zero & 0.00 \\
$H_{0}:$ the sum of coefficients on governance and governance*EMU member is equal to zero & 0.00 \\
$H_{0}:$ the sum of coefficients on debt_ratio and debt_ratio*Non-EMU member is equal to zero & 0.71 \\
$H_{0}:$ the sum of coefficients on gdp_growth and gdp_growth*Non-EMU member is equal to zero & 0.86 \\
$H_{0}:$ the sum of coefficients on liquidity and liquidity*Non-EMU member is equal to zero & 0.69 \\
$H_{0}:$ the sum of coefficients on governance and governance*Non-EMU member is equal to zero & 0.70 \\
\hline
\end{tabular}

\subsubsection{Robustness analysis}

In this section, we discuss robustness tests. First, we investigate whether the estimation results are sensitive to the choice of econometric technique. We estimate the dynamic panel model with Generalized Methods of Moments (GMM). Note that our benchmark estimation tool, FGLS, allows presence of heteroscedasticity across panels, which are country pairs in our sample, while GMM deals with endogeneity in estimation. Endogeneity indicates a situation in which an explanatory variable is correlated with the error term, thus undermining the consistency of estimation. Secondly, we also investigate whether the main drivers of long-term borrowing cost differentials are robust to sample country selection given that structural breaks in coefficients are detected in the previous analysis. Conducting such analysis for a subsample of countries excluding PIIGS (Portugal, Italy, Ireland, Greece and Spain) can provide empirical evidence on the determinants of sovereign yield spreads. Both tests are explained in detail below.

\section{GMM estimation}

The panel structure of our data enables to analyze determinants of sovereign yield spreads. However, each econometric method tracks a particular aspect of this structure while neglecting another. For instance, FGLS deals with crosssectional dependence among panels/individual units whereas GMM controls for endogeneity. In the benchmark analysis of FGLS estimations, we use the 
lagged independent variables to take the endogeneity issue into account. In this section, we treat endogeneity explicitly by using the GMM estimation. GMM assumes that there is a set of $\mathrm{L}$ moment conditions that $\mathrm{K}$ parameters of interest $\beta$, need to satisfy. Moment conditions are defined as an orthogonality condition between the residuals of an equation and a set of $\mathrm{K}$ instruments. Standard GMM solves the set of $\mathrm{L}$ equations for the parameters $\beta$. If the number of moment restrictions, L equals the number of unknown parameters, then GMM estimator becomes an Ordinary Least Square (OLS) estimation. When there are more $\mathrm{L}$ moment conditions than parameters, $\mathrm{K}$, the system of equations may be over-identified and may not have an exact solution. GMM is an estimator that minimizes the system of equations with respect to the parameters $\beta$.

How to weight the various moment conditions is an important aspect of GMM estimation. The GMM weights in this study follow from a Arellano-Bond 2step estimation $^{9}$ as the techniques developed by Arellano and Bond (1991), and Arellano and Bover (1995) ${ }^{10}$ suit our data set: dynamic panel structure with the small $\mathrm{T}$ dimension and large $\mathrm{N}$ panels. For computing the coefficient covariance matrix, the heteroskedasticity-consistent White estimator is used.

Table 2.7 reports the estimation results of the models for equation (2.5). Specification tests for each estimation are presented in the lower panel of Table 2.7. We report the specifications on the choice of weighting matrix estimation, coefficient covariance calculation and J-statistics and Sargan tests to check for overidentification. The first column shows the original benchmark results from the dynamic panel model, using FGLS (see Table 2.3, Column (6)) while columns (2-4) present the empirical results for the same model, but estimated using the GMM method. The primary differences among the last three columns are the choice of instrumental variables. Note that the column (2) model treats the lagged dependent variable as predetermined while all other regressors are assumed to be exogenous. The column (3) model assumes the lagged dependent variable, debt ratio and real GDP growth rate to be endogenous and the others to be exogenous. Finally, the last model assumes that all regressors are endogenous.

Under the null hypothesis that the instruments are valid, the Sargan-test statistic has a $\chi^{2}$ with $(\mathrm{p}-\mathrm{k})$ degrees of freedom where $\mathrm{p}$ is the number of instrumental rank (the number of linearly independent instruments) and $\mathrm{k}$ is the number of estimated coefficients. Rejecting the null hypothesis indicates overidentification while failing to reject it supports the validity of instruments. The p-values

\footnotetext{
${ }^{9}$ In the first step, the residual variance is obtained from the initial parameter estimation. In the second step, the GMM objective function with weighting matrix from the first step variance is minimized to obtain the parameter estimations.

${ }^{10}$ The Arellano and Bond (1991) and Arellano and Bover (1995) dynamic panel estimators are based on the assumptions of small $\mathrm{T}$ and large $\mathrm{N}$ panel structure, linear functional relation, dynamic single left-hand variable, possible endogeneity in the independent variables, fixed individual effects and heteroskedasticity and autocorrelation within individuals, but not across units.
} 
of the Sargan tests are reported in the last line of Table 2.7. The second GMM specification (Column (3)) fails to reject the null hypothesis while both other two models reject the null hypothesis, indicating overidentification. The Sargan test (p-value of 0.66 ) fails to reject the null hypothesis at $1 \%$ significance level. Therefore, we work with the second GMM specification. Note that the third GMM specification where all regressors are treated as endogenous rejects the null hypothesis of the corresponding instruments' validity. Also its J statistic in which the GMM objective function is evaluated with the GMM estimator is very high, indicating that the instruments do not satisfy orthogonality conditions.

Table 2.7: Dynamic approach with GMM estimation of equation (2.5)

\begin{tabular}{|c|c|c|c|c|}
\hline & (1) & $(2)$ & $(3)$ & (4) \\
\hline estimators & FGLS & GMM & GMM & GMM \\
\hline dependent variable & AdjSpread & AdjSpread & AdjSpread & AdjSpread \\
\hline \multirow[t]{2}{*}{ Lagged adjSpread } & $0.963^{* *}$ & $0.590 * * *$ & $0.856^{* * *}$ & $0.900^{* *}$ \\
\hline & $(0.407)$ & $(0.142)$ & $(0.002)$ & $(0.135)$ \\
\hline \multirow{2}{*}{ Public debt/GDP spread } & $0.023^{* *}$ & $0.073^{* * *}$ & $0.044^{* * *}$ & $0.039 * *$ \\
\hline & $(0.006)$ & $(0.010)$ & $(0.000)$ & $(0.006)$ \\
\hline \multirow[t]{2}{*}{ Real GDP growth spread } & $-0.057^{* *}$ & $-0.152^{* * *}$ & $-0.107 * * *$ & $-0.116^{* *}$ \\
\hline & $(0.015)$ & $(0.021)$ & $(0.011)$ & $(0.027)$ \\
\hline \multirow[t]{2}{*}{ Liquidity spread } & $-0.001^{* *}$ & $-0.003^{* * *}$ & $-0.002^{* * *}$ & $-0.002^{* *}$ \\
\hline & $(0.000)$ & $(0.001)$ & $(0.001)$ & $(0.001)$ \\
\hline \multirow{2}{*}{ Governance indicator spread } & $-0.266^{* *}$ & 0.098 & $-0.525^{* *}$ & $-0.299^{* *}$ \\
\hline & $(0.115)$ & $(0.126)$ & $(0.003)$ & $(0.219)$ \\
\hline Constant & $\begin{array}{c}-0.207^{* *} \\
(0.049)\end{array}$ & & & \\
\hline Observations & 1431 & 1340 & 1340 & 1340 \\
\hline $\mathrm{R}$ squared & 0.72 & & & \\
\hline Number of pairs & 91 & 91 & 91 & 91 \\
\hline GMM weights & & AB-n-step & AB-n-step & AB-n-step \\
\hline Coef. covar. method & & White diagonal & White diagonal & White diagonal \\
\hline Instrument rank & & 49 & 92 & 196 \\
\hline J-statistics & & 76.9 & 81.3 & 2009.8 \\
\hline Sargan test (p-value) & & 0.00 & 0.66 & 0.00 \\
\hline $\begin{array}{l}* * * \mathrm{p}<0.01,{ }^{* *} \mathrm{p}<0.05, * \mathrm{p}<0.10 \text { ar } \\
\text { Column }(2) \text { model-Instrument spe } \\
\text { regressors. } \\
\text { Column (3) model-Instrument spe } \\
\text { to four lags along with liquidity as } \\
\text { Column (4) model-Instrument spe } \\
\text { Note: Constant added to instrum } \\
\text { GMM weights. }\end{array}$ & $\begin{array}{l}\text { ification: the } 1 \\
\text { well as governa } \\
\text { ification: All r } \\
\text { nt list. White p }\end{array}$ & $\begin{array}{l}\text { gged dependent va } \\
\text { gre indicator. } \\
\text { gressors up to four } \\
\text { riod-Arellano-Bon }\end{array}$ & $\begin{array}{l}\text { S. } \\
\text { iable up to four la } \\
\text { iable, debt_ratio as } \\
\text { ags. } \\
\text { 2-step estimator }\end{array}$ & $\begin{array}{l}\text { along with all oth } \\
\text { ell as gdp_growth } \\
\text { rate to converge) } \mathrm{f}\end{array}$ \\
\hline
\end{tabular}

The GMM estimation results confirm the benchmark results from previous analysis. The fundamental drivers of long-term borrowing cost differentials are robust to our estimation techniques. The government debt ratio differential puts upward pressure on adjusted sovereign yield spreads while relatively better economic growth performance brings them down. On top of country specific economic indicators, liquidity of individual sovereign bond markets also matters in determining its long-term dynamics. The more liquid the individual markets, the lower the liquidity risk premiums. Finally, for government ef- 
fectiveness, measured as the ability to execute sound policies to support the private sector, having better institutions, is also likely to reduce sovereign default risks.

\section{Subsample analysis for sample countries: Hard-currency versus soft-currency countries}

The last two decades were the best of times as well as the worst of times for EMU members. Their risks converged after the introduction of the Euro and stayed very low. The sovereign debt crisis triggered by the 2008 global financial turmoil became a test for the union. After the 2008 crisis, EMU members with weaker fiscal outlook, lower economic growth performance and higher debt stock ratio borrowed from international bond markets at higher costs than the EMU average. Moreover, the structural break analysis indicates that the relation between long-term government bond yield spreads and their risk premiums are sensitive to the sample country selection (see Table 2.5). It would be interesting to investigate whether the benchmark results are still valid among members which possess strong fiscal outlook, which are informally known as hard-currency economies.

Hard-currency countries refer to those members with stronger fiscal outlook, lower government debt, lower private debt stock ratios and more competitiveness in foreign trade. Figure 2.1 (in the appendix) shows sovereign yield spreads in Europe over the last two decades. Portugal, Italy, Ireland, Greece and Spain (PIIGS) drastically diverge from other EMU members after the 2008 financial crisis. Greek public borrowing cost spread reached $15.75 \%$ in 2011 and the Portuguese sovereign interest rate jumped to $10.24 \%$. These were followed by Irish long-term yield spreads at $9.60 \%$. Finally, Spain as well as Italy stand out with higher borrowing cost differentials compared to other member countries with $5.42 \%$ and $5.44 \%$ respectively in 2011 , while the borrowing cost differentials for the rest of sample countries range from $2.00 \%$ to $4.00 \%$ in 2011 (See Figure 2.2). We treat PIIGS as soft-currency countries. As shown in Figure 2.2, hard-currency countries are more alike in terms of risk premiums.

Table 2.8 reports results for the revaluation of the dynamic panel model with subsample countries excluding PIIGS. The first column summarizes the outcome estimated with our benchmark method, FGLS, while the other columns present the estimation with GMM. The main difference between two GMM estimations is the coefficient covariance method. The signs of coefficients remain the same and the magnitudes of the coefficients do not vary drastically, ranging within an interval. ${ }^{11}$

All in all, our main empirical results remain robust to sample country selection.

\footnotetext{
${ }^{11}$ The second column presents the results with white diagonal whereas the third column shows the outcome with white period. The white period is the standard Arellano-Bond 2step estimator standard errors (innovations have time series correlation structure that varies by the panels) whereas white diagonal is robust to cross-section heterogeneity as well as correlation among the panels. Note that there is evidence in the literature that the standard errors for the two-step estimator may not be reliable.
} 
Table 2.8: Dynamic approach with FGLS and GMM for subsample countries excluding PIIGS (equation (2.5))

\begin{tabular}{lccc}
\hline & $(1)$ & $(2)$ & $(3)$ \\
\hline \multicolumn{1}{c}{ estimators } & FGLS & GMM & GMM \\
AdjSpread & AdjSpread & AdjSpread \\
\hline Lagged adjSpread & $0.524^{* *}$ & $0.353^{*}$ & $0.353^{* * *}$ \\
& $(0.149)$ & $(0.084)$ & $(0.000)$ \\
Public debt/GDP spread & 0.002 & 0.003 & $0.003^{* * *}$ \\
& $(0.002)$ & $(0.019)$ & $(0.000)$ \\
Real GDP growth spread & $-0.017^{* * *}$ & -0.027 & $-0.027^{* * *}$ \\
& $(0.007)$ & $(0.163)$ & $(0.001)$ \\
Liquidity spread & -0.001 & -0.000 & $-0.000^{* * *}$ \\
& $(0.000)$ & $(0.002)$ & $(0.000)$ \\
Governance indicator spread & $-0.144^{* *}$ & -0.215 & $-0.215^{* * *}$ \\
& $(0.048)$ & $(1.098)$ & $(0.006)$ \\
Constant & 0.026 & & 540 \\
& $(0.028)$ & & \\
\hline Observations & 576 & 540 & 36 \\
R squared & 0.53 & & \\
Number of pairs & 36 & 36 & AB-n-step \\
Cross section FE & YES & & 38 \\
Time FE & NO & & 11 \\
GLS weights & CSW^++ & AB-n-step & 0.99 \\
GMM weights & & White diagonal & White period \\
Coef. covar. method & & 38 & 11 \\
Instrument rank & & 0.99 & J-statistics \\
Sargan test (p-value) & & & \\
\hline
\end{tabular}

++ CSW-Cross section weights and $* * * \mathrm{p}<0.01,{ }^{*} \mathrm{p}<0.05,{ }^{*} \mathrm{p}<0.10$ and standard deviations in parentheses

White period-Arellano-Bond 2-step estimator (iterate to converge) for GMM weights.

All regressors are treated as endogenous and instrumental space is composed of up to four lags.

The government debt ratio differences push the adjusted sovereign yield spreads up while relatively better economic growth performance brings them down. Along with these country-specific economic indicators, liquidity of individual sovereign bond markets continues to affect borrowing costs by reducing their liquidity risks. Finally, having better institutions also reduces sovereign default risk.

\subsection{Conclusion}

This paper contributes to the empirical literature on the fundamental drivers of long-term interest rate differentials by analyzing the effects of economic indicators, liquidity indicators, global risk factors as well as governance factors on adjusted sovereign bond yield spreads in Europe. We use a data set of pairwise combinations in a panel of 14 European economies, 11 EMU members and 3 non-EMU members, to check the robustness of well-documented empirical evidence over the period 1996-2011. We correct for exchange rate risks. We 
analyze which risk factors matter in the market perception of default risks and whether the EMU's introduction in 1999 and the financial crisis in 2008 have had a significant impact on sovereign debt yield spreads.

The results show that adjusted sovereign yield spreads are determined by the differential government debt ratio, relative economic growth performance, liquidity of the debt markets as well as governance quality in the country. Interestingly, the differential debt ratios are the only factor that determines long-term yield spreads before the emergence of the EMU, while markets seem to ignore economic fundamentals after the EMU's introduction. The markets revalued other economic indicators, liquidity and governance indicators after the financial crisis. We further investigate whether the relations between risk factors and bond yield spreads changed when both countries in a pair were members of the EMU. Among EMU members, pricing risk related to increasing debt ratios remains significant and its marginal effects increase. This indicates that markets price fiscal indebtedness higher among EMU members than among non-EMU members.

The results of the dynamic panel model are robust to different estimation techniques like GMM. The differential debt ratio, real GDP growth rates, liquidity as well as governance indicators are significantly and robustly correlated to adjusted sovereign yield spreads. The second robustness check involving the revaluation of the dynamic panel model for a subsample of countries (excluding PIIGS -Portugal, Italy, Ireland, Greece and Spain-) further supports the claim that sovereign yield spreads are positively related to differential government debt ratios and negatively related to relative economic growth performance, differential liquidity of individual debt markets as well as governance quality.

The European Monetary Union (EMU) had a successful launch and early history on the back of amenable global liquidity conditions. The sovereign debt crisis in 2010 was the first serious test for the monetary union. Market actors anticipated convergence expectations among its members as exchange rate risks were eliminated, credit risk premiums across members declined and more access to borrowing channels for all EMU members emerged. The 2008 financial crisis turned into a sovereign debt crisis for some EMU members in 2010. After the European Central Bank tempered the liquidity crisis in 2010, sovereign interest rates declined from high levels (ranging from 15\% to 10\%) to lower levels (around 7\%-9\%) for some members. But for some, life was never the same again. Risk premiums among members have remained divergent after 2010 .

The main implication of this study for policy makers is to keep prioritizing fiscal responsibility while introducing structural reforms to boost economic growth in the long-run. As the European Commission prioritizes investment, fiscal responsibility and structural reforms, promoting economic growth via reforms can thus reduce borrowing costs. Structural reforms refer to changes in the way an economy works. For instance, addressing the challenges facing the wel- 
fare state such as aging population, introducing more flexible labor markets and a simpler and fairer tax system can improve the overall business environment. Regarding fiscal responsibility, regulation to keep the debt stock ratio at a certain level or at least avoiding upward momentum in the public debt ratio is vital for strengthening the currency union. Finally, the perception of whether the government will implement sound policies that support the private sector is also important in shaping the trend of long-term borrowing cost differentials. This relation is captured via the governance indicator which measures government effectiveness in terms of its ability to implement policies that boost private sector development. The countries that have postponed taking such actions due to social and political opposition are likely to face higher risk premiums in the bond markets in the future. 


\subsection{Appendices}

\subsubsection{The long-run sovereign yield spreads}

Figure 2.1: Annual yield spreads

(a) Annual yield spreads

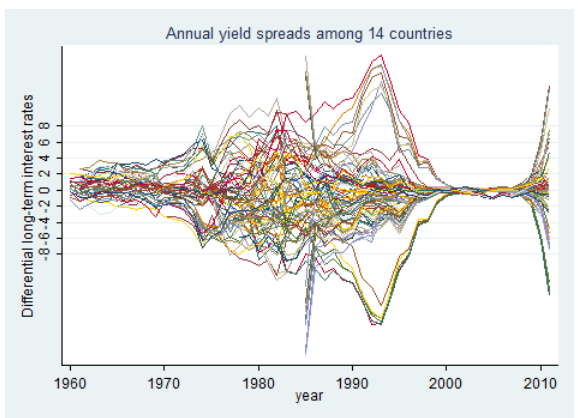

(b) Adjusted yield spreads

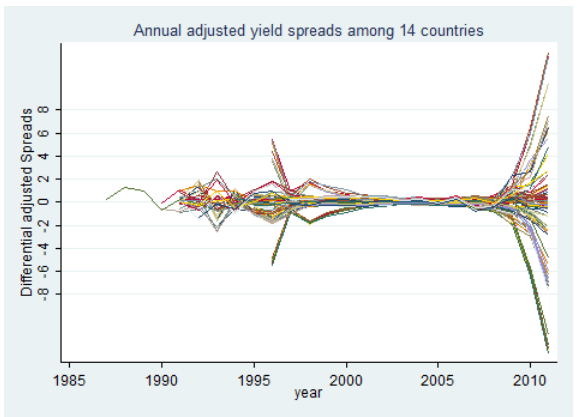

Source: AMECO

Figure 2.2: Adjusted yield spreads for subsample countries

(a) Adjusted yield spreads

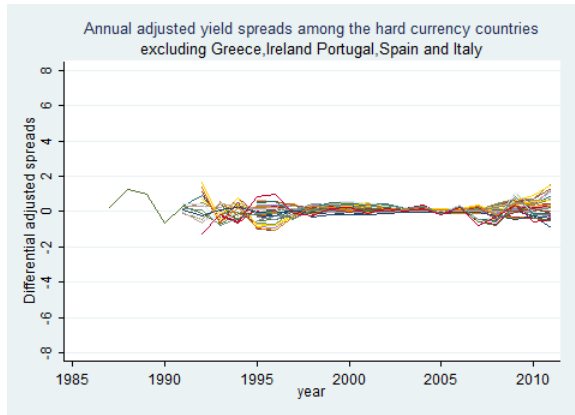

(b) Adjusted yield spreads

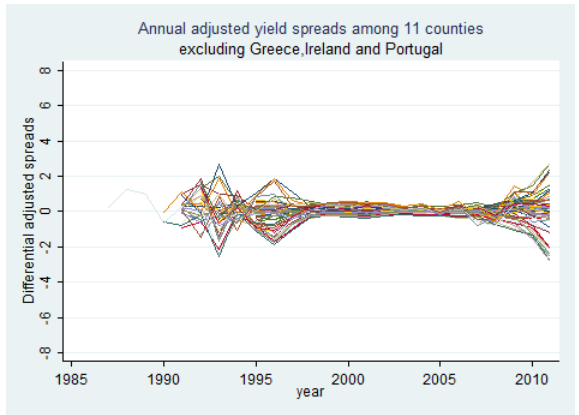

Source: AMECO 


\subsubsection{Descriptive statistics}

Table 2.9: Descriptive statistics

\begin{tabular}{|c|c|c|c|c|c|c|}
\hline Variable* & Unit & Obs & Mean & Std. Dev. & Min & Max \\
\hline Adjusted spreads & $\%$ & 1456 & -0.05 & 1.64 & -13.14 & 13.06 \\
\hline Yield spreads & $\%$ & 1456 & -0.16 & 1.80 & -13.14 & 13.14 \\
\hline \multicolumn{7}{|l|}{ Economic Indicators } \\
\hline Budget balance ratio & $\%$ & 1456 & 0.65 & 4.84 & -31.11 & 28.46 \\
\hline Primary budget balance ratio & $\%$ & 1456 & 0.96 & 4.41 & -29.10 & 27.58 \\
\hline Primary bud. expenditure ratio & $\%$ & 1456 & 2.67 & 7.77 & -23.65 & 22.10 \\
\hline Primary bud. expenditure ratio (log) & & 1456 & 0.06 & 0.18 & -0.57 & 0.54 \\
\hline Government debt ratio & $\%$ & 1456 & 5.71 & 35.47 & -118.83 & 126.96 \\
\hline Government debt ratio $(\log )$ & & 1456 & 0.09 & 0.51 & -1.46 & 1.47 \\
\hline GDP growth rate & $\%$ & 1456 & -0.19 & 2.51 & -10.84 & 10.11 \\
\hline Annual CPI change & $\%$ & 1456 & -0.11 & 1.54 & -7.61 & 7.72 \\
\hline Gross fixed investment ratio & $\%$ & 1456 & 0.34 & 4.37 & -12.81 & 13.51 \\
\hline Gross fixed investment ratio (log) & & 1456 & 0.02 & 0.21 & -0.75 & 0.83 \\
\hline Trade balance ratio & & 1456 & 6.83 & 28.70 & -81.10 & 76.35 \\
\hline Openness & $\%$ & 1456 & 12.19 & 51.15 & -134.34 & 130.84 \\
\hline Openness $(\log )$ & & 1456 & 0.14 & 0.54 & -1.26 & 1.25 \\
\hline Annual terms of trade change & $\%$ & 1456 & -0.15 & 1.84 & -6.33 & 7.18 \\
\hline \multicolumn{7}{|l|}{ Liquidity indicators } \\
\hline Liquidity indicator & million $€$ & 1456 & -65.52 & 748.00 & -1995.50 & 1938.00 \\
\hline Liquidity indicator (log) & & 1456 & -0.23 & 1.60 & -3.58 & 3.58 \\
\hline Liquidty indicator 2 & $\%$ & 1456 & -0.01 & 0.11 & -0.23 & 0.23 \\
\hline \multicolumn{7}{|l|}{ Global risk indicators } \\
\hline US short interest rate & $\%$ & 1456 & 3.47 & 2.12 & 0.34 & 6.53 \\
\hline Market sentiments & $\%$ & 1456 & 2.55 & 0.95 & 1.62 & 5.64 \\
\hline \multicolumn{7}{|l|}{ Governance indicators } \\
\hline Government effectiveness & Index** & 1456 & 0.14 & 0.69 & -1.68 & 2.04 \\
\hline Regulatory quality & Index & 1456 & 0.01 & 0.51 & -1.39 & 1.25 \\
\hline
\end{tabular}

*Note that each variable indicates pairwise difference among sample countries

**Estimate of governance ranges from approximately -2.5 (weak) to 2.5 (strong) governance performance

\subsubsection{Pairwise correlation of all variables}


2.7. APPENDICES

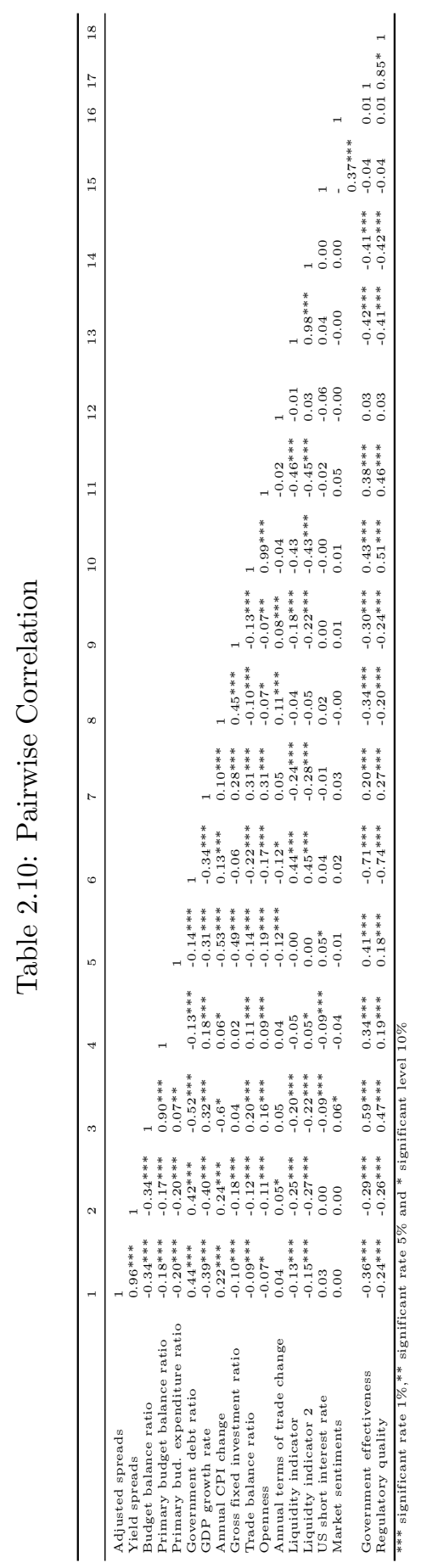


CHAPTER 2. DETERMINANTS OF SOVEREIGN YIELD SPREADS IN THE EMU: A PAIRWISE APPROACH 


\section{Chapter 3}

\section{Interdependence of sovereign yield}

\section{spreads: the spatial dimension}

\subsection{Introduction}

In Chapter 2, we concluded that adjusted sovereign yield spreads are determined by the relative government debt ratio, relative economic growth rate, liquidity of the debt market as well as governance quality. However, empirical analysis of the determinants of sovereign yield spreads indicates that their own country-specific default risks and illiquidity fall short of justifying the spreads. This is referred to as a "credit spread puzzle": spreads on sovereign bonds are much larger than can be explained by their own fundamentals. The difference is often attributed to the interdependence of yield spreads (Tsuji (2005),Amato and Remolona (2012)). In this chapter ${ }^{1}$, we investigate how this interdependence is propagated across countries and how the domestic yield spreads are affected by the spreads of foreign countries. We investigate the interdependence of sovereign yield spreads in a panel of 21 countries (11 European Monetary Union (EMU) members prior to the 2004 expansion and 10 non-EMU countries) over the period 1996 Q1 to 2016 Q4. In this chapter, the sovereign yield spread is defined in a conventional way as the difference between the long-run interest rate on a domestic sovereign bond and the long-run interest rate on a benchmark foreign sovereign bond.

One way of approaching the interdependence of economic variables is to mea-

\footnotetext{
${ }^{1}$ We are grateful to Lennart Freitag for his contributions. Also thanks to the seminar participants at Maastricht University in 2018.
} 


\section{CHAPTER 3. INTERDEPENDENCE OF SOVEREIGN YIELD SPREADS: THE SPATIAL DIMENSION}

sure co-movements using correlations or principal components. The magnitude of interdependence is estimated by the strength of the co-movement. Generally, spillover is the case when a shock from one country is transmitted to another, while if the co-movement intensifies during a crisis, this is called contagion. Note that the distinction between contagion and spillover is not crystal clear. Rigobon (2016), however, argues that most researchers agree on the definition of shift contagion and spillover contagion. Shift contagion, measures breaks in transmission channels after a certain event while spillover contagion investigates changes in the dynamics of transmission channels. Finally, measuring interdependence of economic variables is method dependent.

Following the standard classification in the literature, empirical methodologies to evaluate interdependence range from non-parametric techniques such as correlations and principal components to parametric methods such as OLS regressions, VARs, event studies, ARCH and GARCH models and non-linear regressions $^{2}$. Non-parametric methods are not a direct measure of interdependence across variables/countries. The measurement of co-movement via correlations and principal components addresses the question whether contagion is present. Empirical results are vulnerable to parameter instability and change in volatility of the variables during a crisis. On the other hand, parametric methods are a direct measure of interdependence, but they suffer from identification problems, endogeneity and omitted variable biases. Both methods neglect the country-specific risks as well as the identification of transmission channels.

We adopt a semi-parametric approach to address these issues and measure the spillover contagion of the sovereign yield spreads with a two-step procedure. First, we establish the long-run relation between the domestic sovereign yield spreads and the country-specific risks such as exchange rate, default and liquidity risks. In the second step, we investigate the interdependence of the yield spreads after extracting country-specific risks and common factors from domestic yield spreads. We fit a spatial lag model to investigate the presence of interdependence (see e.g. Holly et al. (2010)). The spatial econometric approach to measure interdependence of the yield spreads identifies the transmission channels. Using this method, we can look for an alternative way to assess the credit spread puzzle in sovereign bond markets.

In the first step, we find a significant positive effect of the short-run policy rate spread and a significant negative effect of the relative real GDP growth rate on changes in the long-run sovereign yield spreads. Among the EMU members, the budget balance ratio difference and the relative real GDP growth rate turn out to be significant in explaining the yield spreads. This finding indicates the importance of fiscal responsibility within a common currency union. In the second step, we fit a spatial autoregressive model (SAR) for yields that cannot be

\footnotetext{
${ }^{2}$ OLS-Ordinary Least Square, VAR- Vector Autoregressive Regression, ARCH- Autoregressive Conditional Heteroskedasticity, GARCH- Generalized Autoregressive Conditional Heteroskedasticity.
} 
explained by the country-specific default risks and illiquidity. We find a highly significant spatial dependence in sovereign yield spreads. This implies that the domestic yield spreads are affected by the spreads of foreign countries. Regarding the transmission channels, economic connections between countries shape such spatial dependence. Economic distance measured by trade volume shows the highest estimated degree of spatial dependence, followed by FDI flows and cross-bank lending, while geographical distance turns out to be insignificant for spatial dependence. On the policy implications, we find empirical evidence to support the introduction of a pan-European bond market. The existence of spatial dependence among EMU members indicates that even if an individual member takes care of its fiscal responsibility and economic policies successfully, national bond markets are vulnerable to adverse developments in other countries within the EMU.

The chapter is organized as follows. Section 2 provides more details on the methodological frameworks in the literature and where our methodology stands. Section 3 discusses how to model the interdependence of sovereign yield spreads. Section 4 reviews macro-panel models and our estimation methods. Section 5 introduces the data and provides a preliminary analysis. Section 6 reports on estimation results, followed by robustness analyses in section 7 . Section 8 concludes.

\subsection{Literature review: Measuring interdependence}

Different definitions of interdependence along with their own methodologies track a particular aspect of interdependence. Dungey et al. (2005) provide a compact framework for pointing out the key features of different approaches. In line with Dungey et al. (2005) and Rigobon (2016), one can further classify the literature into two distinct approaches: shift contagion, measuring breaks in transmission channels after a certain event and second, spillover contagion, investigating changes in the dynamics of transmission channels. Our methodology fits in the second category. Panel spatial regression analysis allows us to model the interdependence of all countries in the sample simultaneously and gives an average system-wide interdependence measure as a result. Via spatial weight matrices, we can identify transmission channels that propagate such network relations. The two broad strands of the literature on interdependence are introduced in more detail below.

\section{Shift contagion}

A first strand in the literature treats interdependence as a pairwise measure and mostly assumes linear and bilateral relations. To analyze interdependence after an initial shock, shift contagion measures breaks in contemporaneous correlations. A key contribution by Forbes and Rigobon (2002) suggests a correlation break test for the presence of shift contagion, after controlling for potential volatility changes. This method has two important shortfalls: It investigates 


\section{CHAPTER 3. INTERDEPENDENCE OF SOVEREIGN YIELD SPREADS: THE SPATIAL DIMENSION}

a possible linear relationship and imposes a crisis period exogenously. Interdependence between asset returns is likely to be non-linear during a period of extreme returns. Other papers model contagion as a range of asymmetrical adjustments, focusing on the tails of asset returns. For instance, Bae et al. (2003) identify exceedances of individual returns and co-exceedances across asset returns. Favero and Giavazzi (2002) model a VAR to detect the interdependence between asset returns. They use the properties of the residuals to identify unexpected shocks. They also endogenously determine crisis periods along with the extreme values and different parameters that are attached to each break period. Likewise, Metiu (2012) extends the Forbes and Rigobon (2002) approach by endogenously dating contagion events based on the method of Pesaran and Pick (2007). They analyze 10-year sovereign bond yields in the Eurozone and find evidence for significant contagion effects between January 2008 and February 2012. In addition, Manner and Candelon (2010) generalize the approach of Favero and Giavazzi (2002) by challenging the assumption of the simultaneity of structural breaks in volatility and correlations. By employing a copula-based approach, the authors find that during the Asian crisis of 1997, variance breaks mainly occurred before correlation shifts. Furthermore, Blatt et al. (2015) propose a sequential testing approach for contagion in multivariate systems by decomposing the mean, variance as well as correlation breaks.

\section{Spillover contagion}

A second approach aims to go beyond the pairwise measurement of interdependence to system-wide measurement. This is also called spillover contagion, investigating changes in the dynamics of transmission channels. We classify the main methodologies in this field into three groups. A first group of papers follows the Spillover Index approach developed by Diebold and Yilmaz (2012). Secondly, empirical studies to detect the interdependence use Global Vector Autoregressive (GVAR) models which are proposed by Favero (2013). A third group is the newly emerging spatial dependence literature on financial variables such as Keiler and Eder (2013) and Blasques et al. (2016). Our methodology fits in this category. The first two methods can be criticized as still consisting of pairwise measurements, since they are estimated by aggregating bilateral measurements. In addition, they neglect taking into account economic fundamentals. By using spatial econometric methods, one can trace out the spillover contagion via the spatial dimension after incorporating the country-specific risks and global risk factors (Holly et al. (2010)).

The Diebold and Yilmaz (2009) spillover index is based on the variance decomposition of a VAR model. A single index is calculated as the sum of cross variance shares relative to the total forecast error variation. In order to introduce the dynamics, the authors suggest a rolling window spillover index that sums the forecast error variation components, either from country $i$ to all other countries or from all other countries to country $i$. Diebold and Yilmaz (2012) further improve the spillover index by estimating variance decompositions within the generalized vector autoregressive model which is robust to 
variable ordering. Thus, a particular causal structure is imposed, rather than extracting causal relationships from the data itself. The generalized variance decomposition (GVD) framework of Koop et al. (1996) relies on a data-based identification scheme and allows for contemporaneously correlated shocks which are observed historically. Furthermore, Claeys and Vasicek (2014) enrich the spillover index by incorporating common principal components. They measure the linkages between 16 European Union sovereign bond markets using a factor-augmented version of the VAR model in the spillover index. In line with previous research results which indicate that the spreads are mainly determined by external developments such as global risk factors (Codogno et al. (2003), Bernoth and Erdogan (2012)) , Claeys and Vasicek (2014) extract common factors from sample countries, model the linkages and further check for breaks in coefficients to determine the presence of contagion. Spillovers between the EMU countries are detected while the increase in co-movement is mostly attributed to larger volatility rather than to contagion.

Favero (2013) uses a GVAR model to capture the time-varying interdependence of 10-year yield spreads. The author argues that this methodology brings two improvements to the market spillover literature: First, the measurement via a GVAR model does not require the identification of structural shocks which is the main criticism of the previous method. Secondly, it allows spillovers to affect the first moments (means) of the dependent variable. The standard spillover index methodologies consider the source of spillovers as unpredictable shocks and the shocks do not change parameters (particularly the first moments (means) of the dependent variable).

Spatial econometric approaches to measure interdependence of financial variables or markets have been receiving increasing attention in the literature. These methods provide an alternative way to assess the credit spread puzzle. Keiler and Eder (2013) use this methodology to analyze 5-year credit default swaps of 15 systematically important financial institutions in Europe. The monthly data cover the period 2004-2009. The authors conclude that the extent of spillover effects measured by the spatial autoregressive parameter is significant and considerable. Blasques et al. (2016) adopt a time-varying spatial dependence model to investigate the dependence between 8 European sovereign CDS spreads over the period 2009-2014. The authors find a timevarying degree of spatial dependence, propagated by cross-bank lending. The remainder of this chapter discusses the spatial econometric approach in more detail. 


\subsection{How to model interdependence of sovereign debt yield}

\section{spreads}

The theory underlying interest rate determination is based on no arbitrage conditions of the returns on corresponding assets. The no arbitrage condition asserts that the return on interest-bearing assets is the same given that their risks are the same. Returns are defined as net changes in an asset's value and liquidity measures how easily an asset can change hands. Based on this conceptual framework, we examine the determinants of the sovereign yield spreads. The yield spread is defined as the difference between the long-run interest rate on the domestic government bond and the long-run interest rate on a benchmark foreign government bond, $i_{D}-i_{B}$. For the rate, we use the yield-tomaturity rate which represents the average returns on a bond over its remaining term and use the US government bond as the benchmark government bond. Sovereign yield spreads are determined by country-specific risks: exchange rate risk $\left(E R_{i, t}\right)$, default risk $\left(D R_{i, t}\right)$ and liquidity risk $\left(L R_{i, t}\right)$.

\section{Spatial dimension}

Apart from the country-specific risks, global economy-wide common shocks also affect the yield spreads across countries. Common shocks/factors such as global business cycles, changes in the global risk appetite or oil price shocks change sovereign yields, but with different degrees across countries and thereby influence the spreads. The expansion in global debt financing during the 2000s is an example of such a common factor. According to the Bank for International Settlements (BIS), the outstanding stock of total debt securities jumped from $135 \%$ of World GDP in 2000 to $188 \%$ of World GDP in 2012. This increase was mainly driven by the private sector, more specifically financial corporations, until the financial crisis in 2008. During the credit boom cycle, it is likely that a number of economic variables are all affected by this common factor: sovereign yields are lower as credit channels improve for all parties, not only for the private sector but also for the public sector. Economies grow faster, more trade takes place, and domestic demand increases as access to lending facilities improves. Hence, common factors generate cross-sectional dependence across sovereign yields. However, Pesaran (2007b) shows in a panel analysis that the presence of cross-sectional dependence due to common factors causes inaccurate estimates and misleading inferences for structural models. Therefore, most studies (Barrios et al. (2009), Schuknecht et al. (2009)) incorporate observed common factors explicitly into their models, as explanatory variables, and find these to dominate over the country-specific risks. We argue that sufficiently flexible econometric models are needed to treat cross-sectional dependence explicitly in order to improve the estimation for country-specific risks.

Another source of dependence is the spatial dimension. The role of "distance" or "space" in economic processes is studied by spatial econometrics (Anselin et al. (2008)). We particularly emphasize interactions in "space" (spatial de- 
pendence/autocorrelation). Spatial autocorrelation ${ }^{3}$ represents the correlation between the values of an economic variable in a country and the values of the same economic variable in "closer" countries. Such dependence is propagated via trade and financial connections. For instance, consider the case of three countries: Germany, Italy and the Netherlands. Dutch yield spreads are affected by German yield spreads and Italian yield spreads and each is weighted by their bilateral connections with the Dutch economy in a so-called weighting matrix. The degree of the dependence decreases as the connections between countries get weaker.

\subsection{Econometric framework}

In this chapter, we investigate how the domestic sovereign yield spreads are affected by the yield spreads of foreign countries. The methodology is based on Holly et al. (2010) and involves two steps. The first step is to establish the long-run relations between domestic sovereign yield spreads and the countryspecific risks such as exchange rate, default and liquidity risks. Given the nature of macroeconomic data, we adopt a Macro-Panel approach in which non-stationarity over time, common factors and heterogeneity in the coefficient parameters are treated explicitly. Estimators that do not take these features into account generate inconsistent estimation results for structural models.

In the second step, we investigate the interdependence of yield spreads. For this, we first extract country-specific risks from domestic sovereign yield spreads. We also correct for common factors that influence sovereign yield spreads. Thereafter, we fit a spatial autoregressive model to trace out whether domestic yield spreads are affected by the spreads of foreign countries. This methodology also allows us to investigate the propagation mechanisms for spillovers. One can interpret such spillovers as a form of propagation across countries which are present at all times, regardless of the stages of the business cycle. We first explain how the long-run relations are estimated by time series panel models. Then, we use the estimators that are flexible to accommodate different forms of heterogeneity in the modeling to estimate coefficients. Thereafter, we introduce the spatial model to trace out the interdependence of sovereign yield spreads.

\footnotetext{
${ }^{3}$ Spatial autocorrelation is similar to serial autocorrelation in time series literature, with a big difference. Time order is unidimensional as it runs in one direction: the past affects present, but not the other way around. Spatial order can run in both directions and is determined using the spatial weighing matrix. For instance, country $i$ affects another one which affects other countries and in return others affect country $i$ etc.
} 


\subsubsection{Time series panel estimation: the long-run dynamics}

In our research, sovereign yield spreads (defined as the difference between the long-run interest rate on a sovereign bond for country $i$ and the interest rate for a corresponding US government bond) are determined by exchange rate risk $\left(E R_{i, t}\right)$, default risk $\left(D R_{i, t}\right)$ and liquidity risk $\left(L R_{i, t}\right)$. In order to establish the relations between the sovereign yield spreads and these risks, we use a common factor representation for a standard yield spread model:

$$
\begin{gathered}
y_{i t}=\boldsymbol{\beta}_{\boldsymbol{i}^{\prime}}^{\prime} \boldsymbol{x}_{i t}+u_{i t} \quad u_{i t}=\alpha_{1 i}+\boldsymbol{\lambda}_{i}^{\prime} \boldsymbol{f}_{t}+\epsilon_{i t}, \\
\boldsymbol{x}_{i t}=\alpha_{2 i}+\boldsymbol{\rho}_{i} \boldsymbol{f}_{t}+\nu_{i t} \\
i=1, \ldots . N, t=1, \ldots . T
\end{gathered}
$$

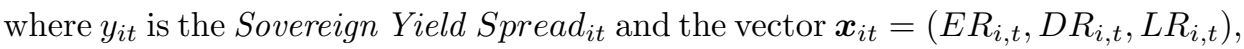
$i$ stands for a country and $t$ stands for time. This setup introduces heterogeneity in the coefficients, $\boldsymbol{\beta}_{\boldsymbol{i}}^{\prime}$, as well as in the factor loadings, $\boldsymbol{\lambda}_{i}$, of common factors. $\nu_{i t}$ in equation (3.2) is assumed to be independent of common factors, $\boldsymbol{f}_{t}$, and across countries and follows a stationary process. The common factors are present in both the explanatory variables, $\boldsymbol{x}_{i t}$ (equation (3.2)) and in the yield spreads, $y_{i t}$ (equation (3.1)) via the error terms, $u_{i t}$. The model assumes that $u_{i t}$ and $\boldsymbol{x}_{i t}$ follow a multi-factor structure in which $\boldsymbol{f}_{t}$ is an $m x 1$ vector of observed common factors such as global business cycles or unobserved common factors such as greater financial liberalization. Common factors are treated as nuisance parameters in this framework and in our analysis: we are not interested in them per se, but they need to be taken into account to improve the estimates. $\epsilon_{i t}$ is the country-specific errors assumed to be distributed independently of $y_{i t}$ and $\boldsymbol{f}_{t}$. However, $\epsilon_{i t}$ is allowed to be weakly dependent across countries, and serially correlated over time. In line with Pesaran and Tosetti (2011), this setup allows us to investigate spatial dependence and a spatial structure in the weakly dependent $\epsilon_{i t}$.

A time series panel framework provides a comprehensive toolkit for estimating the common factor model of equation (3.1). In advance, we do not know which estimators suit best for our analysis since the assumptions for each estimator are different. Therefore, we work with different estimators to establish the long-run dynamics and choose the one that has the highest goodness of fit, has statistically significant explanatory power and for which the coefficient signs are in line with our expectations. We use six different estimators. Four out of these estimators use the cross-sectional means of the dependent and the independent variables as proxies for the common factors and the other two estimators suggest a predicted proxy to measure the common factor. The estimators that use the cross-sectional means of the variables work with the 
extension of the following augmented regression:

$$
y_{i t}=a_{i}+\boldsymbol{\beta}_{\boldsymbol{i}}^{\prime} \boldsymbol{x}_{i t}+\lambda_{1 i} \bar{y}_{t}+\lambda_{2 i} \overline{\boldsymbol{x}}_{t}+\epsilon_{i t}
$$

where the cross-sectional means $\bar{y}_{t}$ and $\overline{\boldsymbol{x}}_{t}$ are proxies for the common factors, $\boldsymbol{f}_{\boldsymbol{t}}$, to soak up heterogeneities. We start with the Pesaran and Smith (1995a) Mean Group (MG) estimation which incorporates heterogeneity in risk parameters, but not in the factor loadings in order to get a first glimpse on the data structure. Second, the Pesaran (2006) Common Correlated Effects Mean Group (CMG) estimation accounts for heterogeneity in both the risk parameters and in the factor loadings, corresponding to equation (3.3). Third, the Common Correlated Effects Mean Pooled (CCEP) estimator from Pesaran (2006) considers the coefficients homogeneously to exploit commonality while treating the factor loadings heterogeneously.

Table 3.1: The estimation methods used

\begin{tabular}{ccccccc}
\hline Estimation methods & MG & CMG & CCEP & AMG & AMG-IMP & DCCE \\
\hline Risk parameters -heterogeneity $\left(\beta_{i}\right)$ & yes & yes & no & yes & yes & yes \\
Factor loadings- heterogeneity $\left(\lambda_{i}\right)$ & no & yes & yes & yes & yes & yes
\end{tabular}

Abbreviations: MG-Mean Group estimator from Pesaran and Smith (1995); CMG- Common Correlated Effects Mean Group estimator from Pesaran (2006); CCEP- Common Correlated Effects Mean Pooled from Pesaran (2006); AMG- Augmented Mean Group estimator from Eberhardt and Teal (2011) and AMG-IMP- in which estimated common factor is extracted from the dependent variable; DCCE- Dynamic Common Correlated Effects from Jan Ditzen (2016).

Two out of six estimators work with another proxy to track the common factors. Eberhardt and Teal (2011) estimate the common factor as the mean evolution of the factors over time. In order to get this estimated factor, we run a regression with the first difference along with a time dummy and this time dummy coefficient represents the mean evolution of the factors over time ${ }^{4}$. In order to estimate the Augmented Mean Group (AMG) model, we replace the cross-sectional means with this common dynamic process in equation (3.3) and reestimate it. As an alternative method, Eberhardt and Teal (2011) suggest subtracting the common dynamic process from the dependent variable to estimate the structural model. This is the AMG-IMP estimator. Both estimations treat risk parameters and the factor loadings heterogeneously.

Finally, we go back to equation (3.3) and add the lagged dependent variable as well as the lagged cross-sectional means as explanatory variables to get the last estimation, the Dynamic Common Correlated Effects (DCCE) estimation

\footnotetext{
${ }^{4}$ Eberhardt and Teal (2011)'s approach consists of two stages. In the first stage, the time dummy coefficients $\hat{\mu}_{t}^{*}$ are collected from the regression with T-1 year dummies in first differences. It represents an estimated mean evolution of common factors across countries over time. It is called the common dynamic process:

Stage (i): $\quad \Delta y_{i t}=\boldsymbol{b}^{\prime} \Delta \boldsymbol{x}_{i t}+\sum_{t=2}^{T} c_{t} \Delta D_{t}+\epsilon_{i t} \quad$ and $\quad \hat{\boldsymbol{c}}_{\boldsymbol{t}}=\hat{\mu}_{t}^{*}$ In the second phase, this process is explicitly augmented in the panel regression model: Stage (ii): $\quad y_{i t}=a_{i}+\boldsymbol{b}_{i}^{\prime} \boldsymbol{x}_{i t}+c_{i} t+\lambda_{i} \hat{\mu}_{t}^{*}+\epsilon_{i t}$ And AMG estimator is calculated as $\boldsymbol{b}_{\boldsymbol{A} \boldsymbol{M} \boldsymbol{G}}=N^{-1} \sum_{i} \hat{\boldsymbol{b}}_{\boldsymbol{i}}$.
} 
by Ditzen (2016). Since interest rates are highly persistent, depending on its own past values, the DCCE estimation is suitable for our data. This estimation also treats risk parameters and the factor loadings heterogeneously. Table 3.1 summarizes the main features of each estimation method in terms of parameter heterogeneity.

\subsubsection{Testing for spatial autocorrelation}

In our two-step approach, we first establish the relationship between domestic sovereign yield spreads and country-specific risks by estimating equation (3.1). Common factors $\left(\boldsymbol{f}_{t}\right)$ capture cross-sectional dependence explicitly. Pesaran and Tosetti (2011) formally discuss and define different forms of cross-sectional dependence. They define the common factors as strong forms of cross-sectional dependence since common factors such as changes in oil prices affect all countries and stretch out to its fullest extent. However, there might be remaining dependence across the yield spreads, embodied in the overall residuals, $u_{i t}$ in equation (3.1) via $\epsilon_{i t}$. This type of cross-sectional dependence assumed in spatial econometrics is an example of weak forms of cross-sectional dependence. In the weak forms of cross-sectional dependence measured by spatial autoregressive models, the degree of dependence gets sufficiently and quickly looser as the proximity (distance) between the countries decreases (increases). In the following, the term cross-sectional dependence refers to strong forms of dependence and spatial dependence refers to weak forms of dependence.

To investigate spatial patterns in the residuals, the common factors decomposition of $u_{i t}$ is required. Consider the residuals from equation (3.1)

$$
\hat{u}_{i t}=\boldsymbol{\lambda}_{i}^{\prime} \hat{\boldsymbol{f}}_{t}+\hat{\epsilon}_{i t}
$$

where $\hat{\boldsymbol{f}}_{t}$ is common factors, $\boldsymbol{\lambda}_{i}^{\prime}$ is corresponding factor loadings and $\hat{\epsilon}_{i t}$ is weakly dependent across countries, and serially correlated over time.

We can use the country-specific errors, $\hat{\epsilon}_{i t}$ to measure the spatial dependence. To investigate the spatial pattern in the error components, we estimate the following spatial autoregressive model (SAR) in $\hat{\epsilon}_{i t}$,

$$
\hat{\epsilon}_{i t}=\psi \sum_{j=1}^{N} w_{i j} \hat{\epsilon}_{j t}+v_{i t}
$$

where $\psi$ is the spatial autoregressive parameter, $w_{i j}$ is the element of $\mathrm{N} \times \mathrm{N}$ nonstochastic spatial weighting matrix $\mathbf{W}$ and $v_{i t} \sim N\left(0, \sigma_{v}^{2}\right)$ is a disturbance term. Prior to being used in the estimation, the $\mathbf{W}$ matrix needs to be normalized. This normalization guarantees that the spatial model is stationary as $\psi$ is bound to $\left(1 / \lambda_{\min }, 1\right)$ where $\lambda_{\min }$ is the smallest eigenvalue of $\mathbf{W}$. Then, equation (3.5) 


\subsection{ECONOMETRIC FRAMEWORK}

can be estimated using Maximum Likelihood techniques.

The weighted average of $\sum_{j=1}^{N} w_{i j} \hat{\epsilon}_{j t}$, on the right-hand side, is called a spatial lag since each country's variable is weighted via its bilateral trade or financial connections with country $i$. As an example, consider the case of three countries: Germany, Italy and the Netherlands. In order to explain Dutch yield spreads, German and Italian spreads are weighted by their bilateral trade or financial connections with the Dutch economy. If there is no trade between a country pair, then $w_{i j}$ becomes zero. This results in not taking into account country $j$ 's spread for country $i$ 's spread via this channel. In the SAR model, the $\hat{\epsilon}_{i t}$ values are determined simultaneously for all countries and the spatial lag measures the interdependence between sovereign yield spreads across countries. Statistically, we test whether $\psi$ is significant while its exact interpretation depends on the construction details of $\mathbf{W}$. If statistically significant, the domestic yield spreads are affected by yield spreads of foreign countries and this form of dependence decreases as the proximity (distance) between countries decreases (increases).

\section{Construction of the weighting matrices}

The spatial weighting matrix, $\mathbf{W}$ is central to spatial modeling. Each element in this matrix defines a network relation between any pair of countries in the sample. We need to specify "space" and we need to normalize W in order to obtain an intuitive interpretation of the spatial coefficient, $\psi$. To specify "space", we consider geographical distance as well as economic distance measurements. Geographical measure is standard in spatial econometrics. Possible options for this measure are binary metrics, continuous metrics or hybrid metrics $^{5}$. We work with continuous metrics which is measured by the Euclidean distance between countries where their coordinates are geo-spatial units (in terms of latitude and longitudes and with respect to capital cities) ${ }^{6}$. Given highly globalized financial markets, we do not expect geographic distance to be the main determinant of propagation and spatial dependence. However, this measurement fulfills the assumption of exogeneity of $\mathbf{W}$ while non-geographical measures are more economically relevant, but most likely less exogenous.

For the economic distance measures, we use the cross-country economic linkages. Claeys et al. (2012) provide economic measurements for financial linkages. By using spatial modeling, the authors investigate why increasing public debt does not lead to higher domestic interest rates. For their study, they consider the cross-country financial linkages in terms of stock markets, bond markets and Foreign Direct Investments (FDI). Among these channels, FDI is more stable and less subject to market fluctuations. Therefore, we include this bi-

\footnotetext{
${ }^{5}$ Binary metrics takes the $(i, j)$ elements of a weighting matrix to be 1 if the ith and jth countries have common border and zero otherwise. Continuous metrics defines a function of distance based on the longitudes and latitudes while hybrid metrics works with $\mathrm{k}$ nearest countries.

${ }^{6}$ Euclidean distance between units $\mathrm{s}$ and $\mathrm{t}$ is given as such $d_{s t}=\sqrt{\sum_{j=1}^{q}\left(x_{j}[s]-x_{j}[t]\right)^{2}}$ for observations s and $\mathrm{t}$.
} 


\section{CHAPTER 3. INTERDEPENDENCE OF SOVEREIGN YIELD SPREADS: THE SPATIAL DIMENSION}

lateral measure in our analysis. For more liquid assets, cross-bank lending seems more suitable. Blasques et al. (2016) apply cross-bank lending as the channel for spillovers among European sovereign credit default risk spreads. Kallestrup et al. (2016) also argue that these are relevant pricing factors for such spillovers. Finally, Forbes and Chinn (2004) claim that bilateral trade flows are vital drivers of linkages in both stock and bond markets. In the light of these studies, we use geographic distance, bilateral exposure in terms of trade, FDI and cross-bank lending to construct the weighting matrices in the estimations.

A second issue is the normalization of $\mathbf{W}$. This ensures that the spatial model is stationary, avoiding the possibility of a near-singular matrix and more importantly, obtaining an intuitive interpretation of $\psi$ as the weighted average impact of other countries on the domestic sovereign yield spreads. There are three ways to normalize the underlying matrix $\mathbf{W}$, where the elements are assumed to be nonnegative: row-normalization, min-max-normalization and spectral-normalization. Row-normalization gives a relative measure of distance while the spectral-normalization provides an absolute measure and the min-max-normalization falls in between. We denote the normalized matrix as $\tilde{\mathbf{W}}=\left(\tilde{w}_{i j}\right)$. We explain the relative and absolute measures first, then min-max normalization.

In a row-normalized matrix, the $(i, j)^{t h}$ element of $\tilde{\mathbf{W}}$ becomes $\tilde{w}_{i j}=w_{i j} / r_{i}$, where $r_{i}$ is sum of the $i^{\text {th }}$ row of $\mathbf{W}$. After row-normalization, each row of $\tilde{\mathbf{W}}$ sums up to 1 . With row-normalization, it is easy to interpret the spatial coefficient $(\psi)$ as the spatial lag, a weighted average of the variables of other countries connected to each country. On the other hand, in a spectral-normalized matrix, the $(i, j)^{t h}$ element of $\tilde{\mathbf{W}}$ becomes $\tilde{w}_{i j}=w_{i j} / v$, where $v$ is the largest of the moduli of the eigenvalues of $\mathbf{W}$. This gives the absolute distance (all elements sum to 1). Despite the fact that row-normalization is the most popular method, it has major drawbacks such as altering the internal weighting structure of $\mathbf{W}$ so that comparisons between rows become problematic.

Consider Germany, the largest economy in the EMU, and Greece, the smallest economy in the EMU, and bilateral trade as a weighting matrix. Given the differences in economic size, the impact of having $10 \%$ of the share of trade with the German economy must be different than having the same share of the trade with the Greek economy. Comparing this $10 \%$ share across the rows (countries) is not economically meaningful. In the spectral-normalized matrix, the whole trade volume of sample countries is standardized to 1 and each element gets a share. This way, the largest economy gets the greatest weight.

Kelejian and Prucha (2010) suggest the min-max-normalization method in their paper. In a min-max normalized matrix, the $(i, j)^{t h}$ element of $\tilde{\mathbf{W}}$ becomes $\tilde{w}_{i j}=w_{i j} / m$, where $m=\min \left\{\max _{i}\left(r_{i}\right), \max _{i}\left(c_{i}\right)\right\}$, with $\max _{i}\left(r_{i}\right)$ being the largest row sum of $\mathbf{W}$ and $\max _{i}\left(c_{i}\right)$ being the largest column sum of $\mathbf{W}$. For min-max normalization, $\psi$ indicates "global spillover". This means that changes in the domestic spreads in the study domain are affected not only di- 
rectly but also indirectly by other foreign spreads. As an example, consider the case of three countries, Germany, Italy, the Netherlands. For Dutch yield spreads, not only bilateral connections with each country but also the influence of German spreads via Italian spreads on Dutch yield spreads are considered in the analysis. This measurement is in between the relative measurement and the absolute measurement. In the benchmark analysis, we work with the min-max method.

\subsection{Preliminary data analysis}

We start our empirical investigation with a preliminary analysis of cross-sectional dependence in the data and with the time series properties of all variables. Table 3.2 lists the countries that we study. Table 3.3 defines the variables that we use in our analysis. Table 3.4 summarizes the correlation coefficients between yield spreads at country level to get a first glimpse of cross-sectional dependence. We also discuss the cross-sectional dependence tests formally and elaborate on the time series properties of the data.

The data set contains a panel of 21 countries: Australia, Austria, Belgium, Canada, Denmark, Finland, France, Germany, Greece, Ireland, Italy, Japan, the Netherlands, Norway, Portugal, South Africa, Spain, Sweden, Switzerland, the United Kingdom (UK) and the United States of America (USA). This represents 11 European Monetary Union (EMU) members prior to the 2004 expansion as well as 10 non-EMU countries (see Table 3.2). We examine quarterly data covering the period from 1996 Q1 to 2016 Q4. The dependent variable is the spread between the long-run interest rate on a sovereign bond with 10-year maturity for country $i$ and the long-run interest rate for the corresponding US government bond.

Table 3.2: List of countries

\begin{tabular}{ll}
\hline Euro area countries & Non-Euro area countries \\
\hline Austria & Australia \\
Belgium & Canada \\
Finland & Denmark \\
France & Japan \\
Germany & Norway \\
Greece & South Africa \\
Ireland & Sweden \\
Italy & Switzerland \\
Netherlands & UK \\
Portugal & USA \\
Spain & \\
\hline
\end{tabular}

In order to estimate equation (3.1), we use economic indicators for default risks and a liquidity indicator for liquidity risk. Table 3.3 summarizes the dependent variable and the explanatory variables which include not only economic and liquidity indicators but also the short-run interest rate, the exchange rate 


\section{CHAPTER 3. INTERDEPENDENCE OF SOVEREIGN YIELD SPREADS: THE SPATIAL DIMENSION}

indicator and global risk indicators. The expected depreciation of a domestic currency is a proxy for the exchange rate risk and short-run interest rates are included to indicate individual monetary policy stances across countries. As in Chapter 2, for default risks we take into account the economic indicators for fiscal outlook, state of the economy and external sector. However, the quality measure of governance effectiveness is not among the indicators, since we use data with quarterly frequency in this chapter and data for governance quality is not available on a quarterly basis.

Table 3.3: List of variables and their descriptions

\begin{tabular}{|c|c|c|}
\hline Variable* & Definition & Expected sign \\
\hline \multicolumn{3}{|l|}{ Dependent variable } \\
\hline Bond yields & \multicolumn{2}{|l|}{ Redemption yield on 10-year maturity sovereign bonds } \\
\hline \multicolumn{3}{|l|}{ Independent variables } \\
\hline \multicolumn{3}{|l|}{ Short-run interest rate } \\
\hline Policy rate & Short-run interest rate determined by the monetary authorities** & + \\
\hline \multicolumn{3}{|l|}{ Exchange rate indicator/risk } \\
\hline Exchange rate risk & The expected depreciation of the domestic currency*** & - \\
\hline \multicolumn{3}{|l|}{ Economic Indicators for default risks } \\
\hline Budget balance to GDP & Budget balance as \% of GDP & - \\
\hline Total government debt to GDP & Total government debt as \% of GDP & + \\
\hline GDP growth & Real GDP growth & - \\
\hline Inflation & Annual CPI change & + \\
\hline Openness & (Exports+Imports)/GDP & $-/+$ \\
\hline Current account ratio & $\mathrm{CA}$ as $\%$ of GDP & - \\
\hline \multicolumn{3}{|l|}{ Liquidity indicator for liquidity risk } \\
\hline Government debt to total sample debt & Share of government debt of country within the sample & - \\
\hline \multicolumn{3}{|l|}{ Global risk indicators/risks } \\
\hline Market Sentiment & the CBOE Volatility Index (VIX) & + \\
\hline Market Sentiment II & BBB-rates US corporate bond spread to Fed policy rate & + \\
\hline \multicolumn{3}{|c|}{$\begin{array}{l}\text { Source: Datastream, Factset. } \\
\text { Note: *US indicators are the benchmark values and all indicators are relative to the USA. } \\
\text { ** List of policy rates for each country: Main refinancing operation rate for Euro area countries, Target cash rate } \\
\text { (overnight) for Australia, Target rate (overnight) for Canada, Lending rate for Denmark, Policy rate for Japan, } \\
\text { Key sight deposit rate for Norway, Repo rate for Sweden, Target 3-month libor rate for Switzerland, Bank rate for } \\
\text { the UK, Federal funds target rate for the USA and Repo rate for South Africa. }\end{array}$} \\
\hline
\end{tabular}

We view Economic indicators as variables related to a country's long-run ability to pay its debt. First, we take two variables, Budget balance to GDP and Total government debt to GDP as indicators of fiscal strength. In line with Chapter 2, we expect a higher budget balance ratio to lower the borrowing cost differentials. The higher the debt stock, the higher the default risk and the yield spreads. Next, we anticipate higher economic growth to be supportive for the fiscal position of a country, so Real GDP growth rate is expected to have a negative relation with the yield spreads. Thirdly, Inflation might increase default risk. Purchasing power parity indicates that higher inflation leads to a depreciation of the local currency and via Fisher effects, nominal interest rates rise to keep real interest rate constant. Openness is considered as an external sector indicator. This variable may influence sovereign yield spreads and the market perception in both directions. For instance, a higher trade volume is expected to lead to lower default risk since it is an indication of the high competitiveness of an economy as well as of the ability to get more funding for debt servicing. A negative relationship can be considered as a long-run or solvency issue, since a more open economy can be vulnerable to sudden capital flights or a sharp drop in foreign demand. In addition to the variables related to the market perception of countries' default risk, market liquidity also may 
influence sovereign yield spreads. Government debt of a country as \% of total government debt in the sample can serve as an indicator for the depth of the country's bond market. The more liquid the individual bond market, the lower the liquidity risk.

In addition to country-specific variables, variables related to global monetary conditions as well as market sentiment are reported in the literature to be the main drivers of yield spreads. These variables are global risk indicators, affecting all sovereign spreads. Market sentiment is measured by fluctuations in the Chicago Boards Options Exchange (CBOE) Volatility Index (VIX). A second possible measure is the difference between private sector and public sector borrowing cost in US financial markets. Wider spread between private sector and public sector interest rate indicates an increase in global risk perception. Table 3.14 in appendix-A2 summarizes descriptive statistics for all variables in terms of sub-sample groups, EMU versus non-EMU members and in terms of the pre-crisis period and the post-crisis period. After the global financial crisis in 2008, sovereign yield spreads became more volatile. During the post-crisis period, policy interest rate spreads became positive and higher while during the pre-crisis period, they were negative and lower. The exchange rate risk is volatile over all periods. For fiscal outlook, both the budget balance ratio and the debt ratio became relatively more volatile after 2008. At the same time, they both improved. The main reason for this could be that the benchmark country's (USA) outlook had deteriorated significantly. Inflation also seemed stable while economic growth performance was better for the benchmark country. After 2008, other economies have grown less compared to the USA.

Figure 3.1 in appendix-A1 shows the course of sovereign yield spreads for the past two decades. The path taken by EMU members is very distinct: convergence right after the common currency introduction in 1999 and divergence after the sovereign debt crisis in 2010 triggered by Greece, Portugal, and Ireland. The spreads of advanced economies clearly move together.

\section{Correlation coefficients of yield spreads}

To give an initial impression of the interdependence of sovereign yield spreads between sample countries, we report correlation coefficients in Table 3.4. The average correlation coefficient between sample countries is 0.45 , ranging from 0.07 (Japan) to 0.68 (Belgium). Thus, Japan is a relatively closed economy while the Belgium economy seems to be the most integrated with other countries. Greece (0.21), Japan (0.07) and South Africa (0.11) register the lowest rates. Greece registers the lowest correlation (0.21) among the EMU countries. However, Greece has high correlation rates with Ireland, Japan, Portugal and Spain, three of which are EMU members most affected by the European sovereign debt crisis of 2010. As simply focusing on the overall correlations does not spell out the interdependence structure, we need to go into more detail. However, there is still evidence of possible interdependence in yield spreads in the raw data. 
Table 3.4: Correlation coefficients of sovereign yield spreads between sample countries

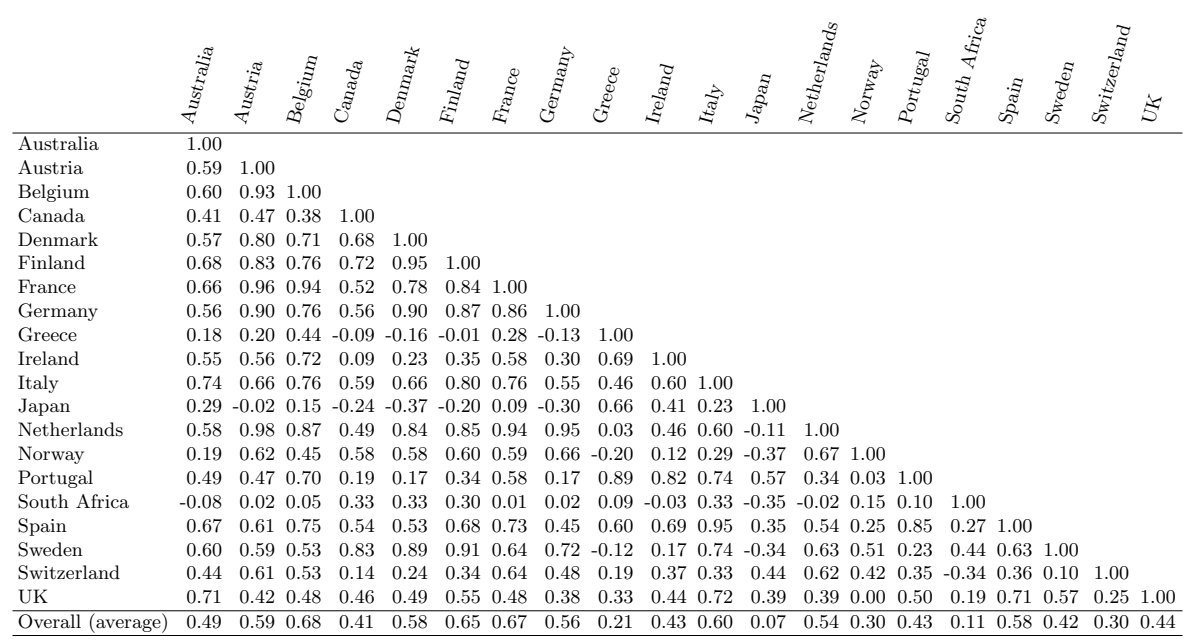

\section{Cross-sectional dependence tests}

The general common factor model assumes that the common factors, $\boldsymbol{f}_{t}$, drive the variations of yield spreads not only via the residuals, $u_{i t}$ in equation (3.1) but also via the explanatory variables in equation (3.2). We explore the presence of common factors in the data formally with the CD (cross-sectional dependence) test from Pesaran (2004). The CD test is based on the average of the pairwise correlation of series and follows the standard normal distribution as $N \rightarrow \infty$. The test is expressed as:

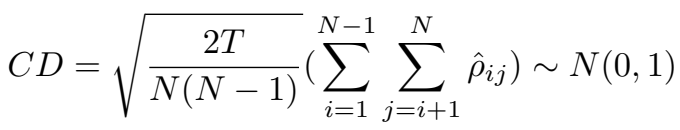

where $\hat{\rho}_{i j}$ is the sample estimate of the pair-wise correlation of the series ${ }^{7}$ and $i$ stands for country, $N$ for number of countries and $\mathrm{T}$ for the length of the period. The null hypothesis of no cross-sectional dependence (or cross-sectional independence) is presented as $\mathcal{H}_{0}: \rho_{i j}=\rho_{j i}=0$ for $i \neq j^{8}$.

Table 3.5 reports the results of the cross-sectional dependence tests for yield spreads and relative main indicators across 20 countries (the USA being the benchmark country) over the period 1996 Q1 to 2016 Q4. The average sample

${ }^{7} \rho_{i j}$ is the correlation coefficient of the corresponding series and it is given by

$$
\rho_{i j}=\rho_{j i}=\frac{\sum_{t=1}^{T} x_{i t} x_{j t}}{\sqrt{\sum_{t=1}^{T} x_{i t}^{2}} \sqrt{\sum_{t=1}^{T} x_{j t}^{2}}}
$$

${ }^{8}$ The higher the $\mathrm{CD}$, the higher the possibility that is $\mathcal{H}_{0}$ is rejected. 
estimates of the pair-wise correlations $(\rho)$ as well as their absolute values $(|\rho|)$ are reported along with the CD test statistics with corresponding p-values. The results indicate a large degree of correlation for each main indicator. For example, the estimation of $|\rho|$ ranges from 0.33 to 0.76 and the cross-sectional dependence across two fiscal outlook indicators is at around 50\%. Monetary policy stances show the highest dependence (0.75), since monetary policies usually accommodate the global economic business cycles. The CD test sums up positive and negative correlations. This might lead to a failure to reject the null hypothesis when it is false. Note that the CD test value follows $\mathrm{N}(0,1)$ under the null hypothesis of no cross-sectional dependence in the series. The CD test statistics in Table 3.5 clearly show that the common factors are statistically significant and need to be incorporated explicitly in the analysis. Alternatively, as we expected, there are common factors in the yield spreads and in the explanatory variables.

Table 3.5: Cross correlation tests for spreads and main indicators

\begin{tabular}{lccccccccc}
\hline & Yield spreads & Policy rates & $F I 1^{+}$ & $F I 2^{++}$ & GDP growth & Inflation & Openness & CA ratio & Liquidity \\
\hline average $\rho$ & 0.45 & 0.75 & 0.49 & 0.32 & 0.29 & 0.36 & 0.38 & 0.15 & 0.70 \\
average $|\rho|$ & 0.48 & 0.76 & 0.52 & 0.53 & 0.33 & 0.39 & 0.47 & 0.36 & 0.70 \\
CD & 57.49 & 96.35 & 63.70 & 41.51 & 36.79 & 46.29 & 48.89 & 18.73 & 90.15 \\
p-value & $0.00^{* * *}$ & $0.00^{* * *}$ & $0.00^{* * *}$ & $0.00^{* * *}$ & $0.00^{* * *}$ & $0.00^{* * *}$ & $0.00^{* * *}$ & $0.00^{* * *}$ & $0.00^{* * *}$ \\
\hline
\end{tabular}

Note: All indicators are calculated with respect to the USA indicators.

$* * * \mathrm{p}<0.01, * * \mathrm{p}<0.05, * \mathrm{p}<0.10$

+ FI (Fiscal indicator) 1-Budget balance to GDP

++ FI (Fiscal Indicator) 2-Total government debt to GDP

Panel unit root tests results

We next analyze the time series properties of the data to check whether the variables are stationary or non-stationary. Using non-stationary data undermines the consistency of estimations. Within the panel analysis framework, second generation panel unit root tests from Pesaran (2007) suit the data at hand where we have already documented the presence of cross-sectional dependence in each variable. The Pesaran (2007) test, CIPS, is the cross-sectionally augmented version of Im, Pesaran and Shin (1997, 2003), the IPS test.

The CIPS test results, summarized in Table 3.15 in appendix-A3, show that for the government debt ratio spreads and the liquidity indicator spreads, the unit root hypothesis cannot be rejected. For the other series, the unit root hypothesis is rejected. We continue by taking the government debt ratio and liquidity indicator spreads as integrated order of $\mathrm{I}(1)$ and the other series as stationary, $\mathrm{I}(0)$ variables. For the two variables that are non-stationary, we transform these into stationary series by using their first differences in our empirical analysis. 


\subsection{Results}

\subsubsection{Step 1: establishing the long-run determinants of sovereign yield spreads}

To establish the long-run relation between the sovereign yield spreads and the country-specific indicators, we estimate the general common factor model in equation (3.1):

$$
y_{i t}=\boldsymbol{\beta}_{\boldsymbol{i}}^{\prime} \boldsymbol{x}_{i t}+u_{i t} \quad u_{i t}=\alpha_{1 i}+\boldsymbol{\lambda}_{i}^{\prime} \boldsymbol{f}_{t}+\epsilon_{i t}
$$

This setup is flexible in incorporating heterogeneity in the parameters $\left(\boldsymbol{\beta}_{\boldsymbol{i}}^{\prime}\right)$ as well as in the factor loadings $\left(\boldsymbol{\lambda}_{i}^{\prime}\right)$, the coefficients of the common factors. We estimate the general factor model of equation 3.8 with different estimation techniques. The results are summarized in Table 3.6. The first two columns present the results of Pesaran and Smith (1995) MG estimations, without (MG) and with (CMG) treating the cross-sectional dependence in order to show the importance of allowing for heterogeneity in factor loadings $\left(\boldsymbol{\lambda}_{i}^{\prime}\right)$. The third column shows the results of the CCEP estimation, treating the coefficients $\left(\boldsymbol{\beta}^{\prime}\right)$ homogeneously and the factor loadings $\left(\boldsymbol{\lambda}_{i}^{\prime}\right)$ heterogeneously. The last three columns introduce the estimations with heterogeneous coefficients $\left(\boldsymbol{\beta}_{\boldsymbol{i}}^{\prime}\right)$ as well as heterogeneous factor loadings $\left(\boldsymbol{\lambda}_{i}^{\prime}\right)$.

The first column in Table 3.6 reports the output for the MG estimation (heterogeneity in the coefficients) without taking into account cross sectional dependence. The results indicate that the short-run policy rate spread, the public debt ratio spread, the current account ratio spread as well as the liquidity indicator spread are statistically significant and their signs are in line with our expectations. The results indicate that when the domestic short-run yield is $1 \%$ higher than the US monetary policy stance, this leads to 0.189 percentage points increase in domestic long-run yield spreads. Regarding the fiscal outlook, our estimation results indicate that the interpretations are sensitive to the benchmark country's public debt level as we work with natural log values ${ }^{9}$. For instance, a $10 \%$ difference in the public debt ratio drives the domestic sovereign yield by approximately 0.457 percentage points assuming that the benchmark country's debt ratio is at $100 \%$ on average. However, if the benchmark debt ratio is lower, around $50 \%$, then its sensitivity to the $10 \%$ difference in the public debt jumps up to 0.914 percentage points. If the benchmark country's debt ratio level is exceptionally high, around $200 \%$, then $10 \%$ difference in the debt ratios puts a pressure of 0.229 percentage points on the domestic long-run

\footnotetext{
${ }^{9}$ The linear-log model indicates that the effect of $\mathrm{X}$ (independent) on $\mathrm{Y}$ (dependent) is not constant, but decreases as (X) increases. An increase in (X) by one unit leads to an increase in $(\mathrm{Y})$ by $\left(\beta_{x} / \mathrm{X}\right)$ units.
} 
Table 3.6: Model estimation results (equation (3.8))

\begin{tabular}{lcccccc}
\hline & $(1)$ & $(2)$ & $(3)$ & $(4)$ & $(5)$ & $(6)$ \\
\hline \multicolumn{1}{c}{ deptimators } & MG & CMG & CCEP & AMG & AMG-IMP & DCCE \\
& Spreads & Spreads & Spreads & Spreads & Spreads & Spreads \\
\hline Policy rate spread & $0.189^{* * *}$ & 0.008 & $0.152^{* * *}$ & 0.038 & 0.047 & $0.068^{* * *}$ \\
& {$[0.034]$} & {$[0.168]$} & {$[0.029]$} & {$[0.046]$} & {$[0.037]$} & {$[0.02]$} \\
Budget balance/GDP spread & 0.061 & -0.062 & -0.048 & -0.056 & -0.101 & -0.012 \\
& {$[0.051]$} & {$[0.046]$} & {$[0.013]$} & {$[0.048]$} & {$[0.058]$} & {$[0.010]$} \\
$\Delta$ Public debt/GDP spread (log) & $4.570^{*}$ & -0.586 & 0.208 & $1.963^{*}$ & 0.989 & 0.366 \\
& {$[1.644]$} & {$[1.019]$} & {$[0.770]$} & {$[0.779]$} & {$[1.496]$} & {$[0.755]$} \\
Real GDP growth spread & 0.072 & -0.065 & $-0.271^{* * *}$ & 0.078 & -0.165 & 0.01 \\
& {$[0.202]$} & {$[0.055]$} & {$[0.037]$} & {$[0.077]$} & {$[0.151]$} & {$[0.031]$} \\
Inflation spread & 0.473 & 0.334 & $-0.352^{* *}$ & 0.172 & $0.634^{*}$ & 0.107 \\
& {$[0.261]$} & {$[0.177]$} & {$[0.088]$} & {$[0.124]$} & {$[0.175]$} & {$[0.065]$} \\
CA/GDP spread & $-0.031^{*}$ & 0.006 & $0.043^{* * *}$ & 0.026 & $0.051^{* *}$ & -0.006 \\
& {$[0.014]$} & {$[0.012]$} & {$[0.008]$} & {$[0.018]$} & {$[0.017]$} & {$[0.006]$} \\
$\Delta$ Liquidity indicator spread (log) & $-1.727^{*}$ & $-0.181^{*}$ & -0.239 & -0.936 & -0.916 & -0.184 \\
& {$[0.868]$} & {$[0.611]$} & {$[0.480]$} & {$[0.725]$} & {$[0.862]$} & {$[0.563]$} \\
Exchange rate risk & -0.015 & 0.0014 & -0.005 & -0.004 & -0.011 & $-0.012^{*}$ \\
& {$[0.011]$} & {$[0.014]$} & {$[0.009]$} & {$[0.007]$} & {$[0.009]$} & {$[0.006]$} \\
Lagged dependent variable & & & & & & $0.816^{* * *}$ \\
& & & & & & {$[0.531]$} \\
\hline dummies/trends & included & included & included & included & included & included \\
\hline \# of observations & 1700 & 1700 & 1700 & 1700 & 1700 & 1640 \\
\# of sign. Trends (at 5\%) & 13 & 16 & - & 13 & 10 & - \\
R-squared & 0.58 & 0.87 & 0.80 & 0.71 & 0.76 & 0.51 \\
RMSE & 1.03 & 0.48 & 0.76 & 0.57 & 0.87 & 0.39 \\
CD Test (p-value) & $0.03^{* *}$ & 0.17 & 0.23 & 0.45 & 0.20 & 0.18 \\
\hline
\end{tabular}

Notes: Standard deviations are in parenthesis. *** $\mathrm{p}<0.01$, $^{*} \mathrm{p}<0.05,{ }^{*} \mathrm{p}<0.10$. The CD test statistic follows $\mathrm{N}(0,1)$ under the null hypothesis of no cross-sectional dependence. The coefficients of the common factors are not reported. The $C D$ tests on the residuals for each estimation are to check whether the cross-sectional dependence is removed. Each estimation method is presented in detail below.

Standard Mean Group (MG) estimator

$\mathrm{N}$ Time series regressions: $\quad y_{i t}=a_{i}+\boldsymbol{b}_{\boldsymbol{i}}^{\prime} \boldsymbol{x}_{i t}++c_{i} t+\epsilon_{i t}$

Averaging: $\quad b_{M G}=N^{-1} \sum_{i} \hat{b}_{i}$

Common Correlated Effects Mean Groups (CCEMG) or (CMG)

Major insight: $\quad \boldsymbol{f}_{\boldsymbol{t}}=\bar{\gamma}^{-1}\left(\bar{y}_{t}-\bar{\alpha}-\overline{\boldsymbol{\beta}}^{\prime} \bar{x}_{t}\right)$ for $N \rightarrow \infty$ since $\bar{\epsilon}_{t}=0 \quad($ iff $\overline{\boldsymbol{\gamma}} \neq 0)$

Augmentation: $\quad y_{i t}=a_{i}+\boldsymbol{b}_{\boldsymbol{i}}^{\prime} \boldsymbol{x}_{i t}+d_{1 i} \bar{y}_{t}+d_{2 i} \overline{\boldsymbol{x}}_{t}+\epsilon_{i t}$

$\Rightarrow \boldsymbol{b}_{C M G}=N^{-1} \sum_{i} \hat{\boldsymbol{b}}_{\boldsymbol{i}}$ where the cross-sectional means $\bar{y}_{t}(T x 1)$ and $\bar{x}_{t}(T x 1)$ proxy for $\boldsymbol{f}_{\boldsymbol{t}}$ to soak up heterogeneities.

Common Correlated Effects Mean Pooled (CCEP)

Augmentation: $\quad y_{i t}=a_{i}+\boldsymbol{b} \boldsymbol{x}_{i t}+d_{1 i} \bar{y}_{t}+d_{2 i} \overline{\boldsymbol{x}}_{t}+\epsilon_{i t}$

Augmented Mean Group (AMG)

Stage (i): $\quad \Delta y_{i t}=\boldsymbol{b}^{\prime} \Delta \boldsymbol{x}_{i t}+\sum_{t=2}^{T} c_{t} \Delta D_{t}+\epsilon_{i t} \Rightarrow \hat{\boldsymbol{c}}_{\boldsymbol{t}} \equiv \hat{\mu}_{t}^{*}$

Stage (ii): $\quad y_{i t}=a_{i}+\boldsymbol{b}_{i}^{\prime} \boldsymbol{x}_{i t}+c_{i} t+d_{i} \hat{\mu}_{t}^{*}+\epsilon_{i t} \Rightarrow \boldsymbol{b}_{\boldsymbol{A} \boldsymbol{M} \boldsymbol{G}}=N^{-1} \sum_{i} \hat{\boldsymbol{b}}_{\boldsymbol{i}}$

Stage (i) represents a standard first-difference-OLS with T-1 year dummies in first differences, from which the time dummy coefficients $\hat{\mu}_{t}^{*}$ are collected. They represent an estimated cross-group average of the evolution of unobservables over time. This is referred to as 'common dynamic process'. In stage (ii), the group-specific regression model is then augmented with the estimated common dynamic process: either (a) as an explicit variable, or (b) imposed on each group member with unit coefficient by subtracting the estimated process from the dependent variable.

Dynamic Common Correlated Effects (DCCE)

$y_{i t}=\delta_{i} y_{i, t-1}+\boldsymbol{b}_{i}^{\prime} \boldsymbol{x}_{i t}++\sum_{l=0}^{p_{T}}{ }^{\prime}{ }^{\prime} \lambda_{i} \overline{\boldsymbol{z}}_{t-l}+\epsilon_{i t}$

where $\overline{\boldsymbol{z}}_{t}=\left(\bar{y}_{t}, \bar{y}_{t-1}, \bar{x}_{t}\right)$

borrowing rate differentials. Thus, the sensitivity of the spreads to the debt ratio difference declines as the debt stock level in the benchmark country increases. The current account balance indicates whether an economy consumes more than it produces. If this balance is positive, then the country produces 


\section{CHAPTER 3. INTERDEPENDENCE OF SOVEREIGN YIELD SPREADS: THE SPATIAL DIMENSION}

more than it consumes, indicating the accumulation of foreign assets abroad. Thus, its ability to pay its debt is higher and its borrowing cost would be lower. Finally, more liquid individual bond markets enable investors to buy or sell these bonds easily, thus lower liquidity premiums are required for the assets. The coefficients of the liquidity indicators are statistically significant and negative, as expected.

For the model specifications, we report the R-squared, the Root Mean Squared Error (RMSE) and the CD test for the residuals of regressions. The RMSE measures the absolute fit of the model to the data, interpreting the standard deviation fit of unexplained variance. The lower the value of the RMSE, the better its fit. The R-squared is a relative measure of fit. Both statistics are used to evaluate the model. The null hypothesis of the CD test is that there is no cross-sectional dependence in the residuals, $u_{i t}$, in other words the residuals are cross-sectional independent in equation (3.8). As expected, the CD test indicates the existence of cross-sectional dependence in the MG model since the null hypothesis is rejected. Furthermore, the MG estimation registers the highest RMSE among the estimation methods as well as the second lowest R-squared.

The estimation methods in column (2)-(6) include our common factors and thus take cross-sectional dependence into account. In the second column, we show the results of the CMG estimation. Compared to the MG estimation (the first column), the RMSE decreases to 0.48 while we fail to reject the null hypothesis of the no cross-sectional dependence. The fit of the model has improved as anticipated with the incorporation of cross-sectional dependence. However, the power of explanatory variables to explain yield spreads turns out to be weak. Only the liquidity risk indicator registers statistical significance in this specification.

The CCEP estimation in the third column is the only model in which we treat the coefficients $\left(\boldsymbol{\beta}^{\prime}\right)$ homogeneously. The CD test statistics fail to reject the null hypothesis of no cross-sectional dependence for the residuals. So, the crosssectional dependence is eliminated and the model explains $80 \%$ of the variance in long-run yield differences. Policy rate spreads and real GDP growth rates are crucial for determining the long-run borrowing cost spreads. When the domestic short-run yields are $1 \%$ higher than the USA monetary policy stance, this leads an approximately 0.152 percentage points increase in the domestic long-run sovereign borrowing cost. We expect higher economic growth to be supportive of the fiscal position, so economic growth is expected to have a negative relationship with the yield spreads. The estimation results show that if the domestic economic growth rate is $1 \%$ higher than the USA's economic growth, the domestic sovereign borrowing cost would be 0.271 percentage points lower than US yields. When the policy rate spreads increase, the sovereign yield spreads also move upward while higher economic growth indicates lower domestic borrowing cost.

The current account balance ratio and inflation differentials turn out to be 
statistically significant in determining sovereign yield spreads, but with opposite signs. As the current account balance increases, so does sovereign yield spread. A possible explanation could be that the current account balance is more closely related to short run or liquidity issues, whereas a negative sign is related to long-run or solvency arguments. A positive current account balance implies being a capital exporter and net capital exports might increase liquidity-related concerns, putting upward pressure on yields. Higher inflation rates lead to a loss in competitiveness especially for pegged currencies such as a common currency, which increases default risk. However, in this model, the empirical results point to a negative relationship: higher inflation leads to lower sovereign yield spreads for our sample of countries. One explanation for this result might be that the last two decades are considered as a disinflation period for economies. Inflation differences range from $2.4 \%$ at maximum to $-1.1 \%$ with a mean of $0 \%$. In a such low inflation period across countries, investors might consider an economy with relatively high inflation to be performing better , as a consequence of economic activity heating up and charge this country less, rather than more.

The next method is the Augmented Mean Group estimation (AMG), developed by Eberhardt and Teal (2010) as an alternative to the Pesaran (2006) CMG. In the CMG, the cross-sectional means are used as proxies for the common factors while the AMG estimation suggests an estimated proxy. The fourth column in Table 3.6 reports the results of the AMG estimation. Only fiscal outlook turns out to be statistically significant in determining sovereign debt yield spreads whereas other fundamentals are relatively less important, but still their relations with the yield spreads are in line with our preliminary expectations. Moreover, its fit is worse than the CCEP estimation, but better than the DCCE estimation. Note that the debt ratio spread has a negative sign in the CMG estimation while it is positive and statistically significant in the AMG estimation. The fifth column shows the results for another version of the AMG estimation, the AMG-IMP estimation. In this method, Eberhardt and Teal (2010) suggest extracting the common dynamic process from the dependent variable, to estimate the coefficients. However, the model fit, the RMSE, deteriorates from 0.57 to 0.87 . Thus, we prefer the AMG estimator over the AMG-IMP estimator.

The final method is the Dynamic Common Correlated Effects (DCCE) estimation which delivers a sound fit for modeling the sovereign debt yield spreads, but this is mainly due to the lagged dependent variable. Most of the coefficient signs are in line with our expectations. However, the model explains $51 \%$ of the variance in the long-run yield differentials. The short-run interest rate spreads, the exchange rate risk and the lagged long-run interest rate spreads turn out to be statistically significant while the economic and liquidity indicators are less vital in comparison. The standard upward sloping term structure of interest rates shows that investors require higher interest rates as the investment duration extends. The uncovered interest rate parity condition indicates that the expected depreciation of a domestic currency puts upward pressure on the 


\section{CHAPTER 3. INTERDEPENDENCE OF SOVEREIGN YIELD SPREADS: THE SPATIAL DIMENSION}

domestic interest rates. Since we use the indirect quotation, a decrease in the exchange rate (depreciation of domestic currency) pushes the sovereign yield spreads up. Finally, it is no surprise that the lagged dependent variable turns out to be statistically significant since the persistence property in interest rates is well-documented in the empirical literature.

Among the six estimation methods, we consider the CCEP estimation to deliver the best results. Four out of eight explanatory variables turn out to be statistically significant and in line with our expectations while the model explains $80 \%$ of the variance in the yield spreads. The residuals from this estimation are not cross-sectional dependent since the CD test statistics fails to reject the null of no cross-sectional dependence (see the diagnoses tests in Table 3.6). This implies that the common factors are successfully extracted from the residuals. Finally, we also check the simple correlation coefficients for the residuals from the CCEP estimation of the sovereign yield spreads. These correlation coefficients of sovereign yield spreads are calculated after the country-specific risks as well as the common factors are extracted from the spreads. The results in Table 3.7 indicate that the correlation coefficients between sample countries is 0.14, much lower than 0.51 in Table 3.4. We next investigate in this model the possible spatial patterns in this part of the yield spreads that cannot be explained by the country-specific default risks and illiquidity.

Table 3.7: Average residual correlation coefficients between sample countries (the CCEP model)

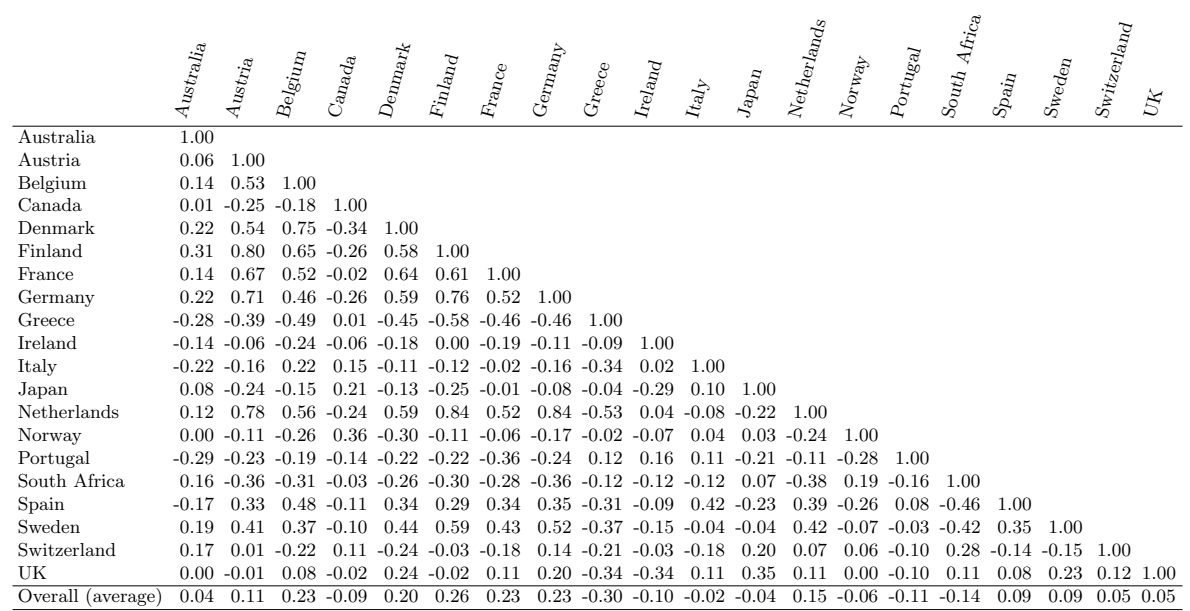

\subsubsection{Step 2: testing for spatial autocorrelation}

In the previous section, we provided consistent estimates between the sovereign debt yield spreads and the country-specific risks. We also corrected for crosssectional dependence with the common factors. In this section we investigate spatial patterns in the realized spreads on the government bonds that cannot 
be explained by its own country-specific risks and the common factors. We focus on the country-specific errors, $\hat{\epsilon}_{i t}$ which is $\hat{u}_{i t}$ in equation (3.8) after the common factors are extracted. Therefore, we estimate the following spatial autoregressive model (SAR) in $\hat{\epsilon}_{i t}$,

$$
\hat{\epsilon}_{i t}=\psi \sum_{j=1}^{N} w_{i j} \hat{\epsilon}_{j t}+v_{i t}
$$

where $\psi$ is the spatial autoregressive parameter, $w_{i j}$ is the element of $\mathrm{N} \times \mathrm{N}$ nonstochastic spatial weighting matrix $\mathbf{W}$ and $v_{i t} \sim N\left(0, \sigma_{v}^{2}\right)$ is a disturbance term. Statistically, we test whether $\psi$ is significant. This implies that the domestic yield spreads are affected by the spreads of foreign countries. Equation (3.9) can be estimated using Maximum Likelihood techniques after the $\mathbf{W}$ matrix is normalized. In this setup, spatial lag measures dependence between the sovereign yield spreads across countries and such dependence is propagated via a weighting matrix.

The spatial weighting matrix is imposed exogenously. We use the geographic distance, bilateral exposure in terms of trade, FDI and cross-bank lending to construct the weighting matrices. Table 3.8 presents the results of equation (3.9) for the CCEP model specification for each weighting matrix based on the min-max normalization method.

Table 3.8: Spatial coefficients based on the residuals from the CCEP estimation

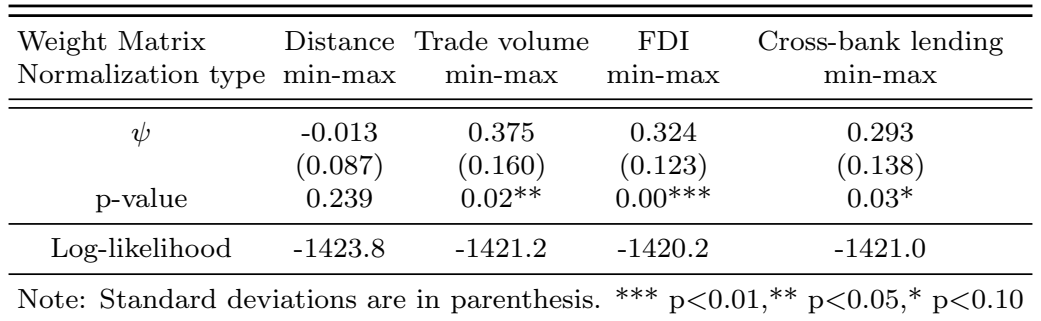

Table 3.8 shows that the spatial lag variable that uses the (geographical) distance as the weight among countries is statistically insignificant. This outcome is in line with our expectations. We did not expect geographical distance to be the main channel of propagating dependence among yield spreads given the high level of globalization of financial markets. Apart from being statistically insignificant, its sign is negative, indicating that the yield spreads move in opposite directions. An increase in one sovereign yield spread influences all yield spreads and decreases them at the aggregate level after the effects of the country-specific risks are left out ${ }^{10}$. We investigate this counter-intuitive find-

\footnotetext{
${ }^{10}$ Such negative relation is known as "flight to safety" in the literature. While stocks and higher-risk assets perform poorly during financial distress, lower-risk assets actually benefit. The dynamics indicate that investors are more concerned with protecting their principal
} 


\section{CHAPTER 3. INTERDEPENDENCE OF SOVEREIGN YIELD SPREADS: THE SPATIAL DIMENSION}

ing of the negative relation further by examining the residuals from two other models, the DCCE and the AMG models. The bottom-line is that geographical distance continues to be statistically insignificant across all models. It is not considered as a channel for spillovers among the interest rate differentials in our analysis.

All non-geographical distance measurements turn out to be statistically significant with the expected positive signs. The spatial lag parameter, $\psi$, ranges from $1 / \lambda_{\min }$ to 1 and the higher this value, the stronger the spatial dependence. The estimated degree of spatial dependence among yield spreads that is propagated by the trade volume is the highest whereas the coefficient for the spatial lag variable that uses the cross-bank lending as the weight is the lowest. Focusing on the model which uses the trade volume as the weight, a $1 \%$ increase in any sovereign yield spread is estimated to increase yield spreads by around 0.375 percentage points on average. On the other hand, the estimated degree of spatial dependence among yield spreads that are connected by cross-bank lending is lower: a $1 \%$ increase in any cross-bank lending linked yield spread is estimated to increase yield spreads by 0.293 percentage points on average. Cross-bank lending which, by its nature, is expected to be more suitable to financial assets pricing turns out to be statistically significant with the lowest estimated spatial degree. Finally, bilateral FDI flows stand for the longer term capital linkages and the estimated degree of spatial dependence among the yield spreads that share FDI flows equals 0.324. All in all, the movement of goods among advanced countries propagates the spatial dependence among the yield spreads the most.

In summary, these estimates confirm a highly significant spatial dependence in the sovereign yield spreads in the financial markets, after controlling for the country-specific fundamentals such as fiscal outlook indicators, economic growth and after allowing for common factors. Our results show that the domestic yield spreads are affected by the spreads of foreign countries. Regarding the propagation channels, economic connections between countries seem to shape such spatial dependence. Economic distance measured by trade volume registers the highest estimated degree of spatial dependence, followed by FDI flows and cross-bank lending while the geographic distance turns out to be insignificant in spreading spatial dependence across the sovereign interest rate differentials.

investment rather than generating profit from that particular investment. They seek safe havens, which are typically the risk-free government bonds of developed countries. Moreover, safe havens among government bonds would be determined by the economic fundamentals such as solid fiscal and monetary outlooks and dynamic economic growth performance, rather than by the geographical proximity. 


\subsection{Robustness analyses}

In this section, we investigate the sensitivity of our results for the normalization of the weighting matrices, the time series panel estimation methods and the sample of countries. First, we investigate whether the spatial dependence results are sensitive to the choice of the normalization method for the weighting matrices. Second, in our two-step approach, we initially establish consistent estimates between the sovereign yield spreads and the country-specific risks and then estimate a SAR model on the residuals from the first step, to investigate the presence of interdependence. We check whether the results are robust to the estimation methods that were used in the first step. Third, we investigate the presence of spatial dependence in interest rate differentials among EMU members, given that these economies are geographically closer and economically more connected within the common currency union.

\subsubsection{Sensitivity to the normalization techniques}

The benchmark results for the spatial dependence analysis are based on the min-max normalization. This measurement is in between the relative measurement, row-normalizations; and the absolute measurement, spectral-normalization. In this section, we analyze the presence of spatial dependence in the estimates from the CCEP estimation for all normalization methods.

The results for the spatial coefficients $(\psi)$ and their statistical tests are presented in Table 3.9. The benchmark results from Table 3.8 are also present in the middle of each network connection. The interpretation of $\psi$ changes across normalization methods. Row-normalization allows us to assess the spatial effects as the weighted average impacts of foreign spreads on domestic spreads since domestic yields are assessed through their direct connection with each foreign spread. For spectral-normalization, $\psi$ indicates "global spillover", changes in the domestic spread in the study domain are affected not only directly but also indirectly by foreign spreads.

Table 3.9: Spatial coefficients based on the residuals from the CCEP estimation

\begin{tabular}{|c|c|c|c|c|c|c|c|c|c|c|c|c|}
\hline \multirow{2}{*}{$\begin{array}{r}\text { Weight Matrix } \\
\text { Normalization type }\end{array}$} & \multirow[b]{2}{*}{ row } & \multicolumn{2}{|c|}{$\underline{\text { Distance }}$} & \multicolumn{3}{|c|}{ Trade volume } & \multicolumn{3}{|c|}{$\underline{\text { FDI }}$} & \multicolumn{3}{|c|}{ Cross-bank lending } \\
\hline & & min-max & spectral & row & $\min -\max$ & spectral & row & $\min -\max$ & spectral & row & $\min -\max$ & spectral \\
\hline$\psi$ & $\begin{array}{c}-0.338 \\
(0.091)\end{array}$ & $\begin{array}{l}-0.013 \\
(0.087)\end{array}$ & $\begin{array}{l}-0.015 \\
(0.088)\end{array}$ & $\begin{array}{c}-0.020 \\
(0.068)\end{array}$ & $\begin{array}{c}0.375 \\
(0.160)\end{array}$ & $\begin{array}{c}0.172 \\
(0.073)\end{array}$ & $\begin{array}{c}-0.024 \\
(0.065)\end{array}$ & $\begin{array}{c}0.324 \\
(0.123)\end{array}$ & $\begin{array}{c}0.187 \\
(0.071)\end{array}$ & $\begin{array}{c}0.062 \\
(0.053)\end{array}$ & $\begin{array}{c}0.293 \\
(0.138)\end{array}$ & $\begin{array}{c}0.145 \\
(0.068)\end{array}$ \\
\hline $\mathrm{p}$-value & $0.00^{* * *}$ & 0.239 & $0.09^{*}$ & 0.60 & $0.02^{* *}$ & $0.09^{*}$ & 0.40 & $0.00^{* * *}$ & $0.04^{* *}$ & 0.40 & $0.03^{* *}$ & $0.09^{*}$ \\
\hline Log-likelihood & -1420.2 & -1423.8 & -1344.2 & -1401.0 & -1421.2 & -1350.2 & -1450.1 & -1420.2 & -1450.1 & 1350.0 & -1421.0 & -1400.9 \\
\hline
\end{tabular}

The results in Table 3.9 are assessed in terms of the statistical significance of spatial coefficients, $\psi$, their signs and their magnitudes. The row-normalization method performs poorly across network connections and the presence of spatial dependence is rejected for all economic network connections. Spatial dependence is only statistically significant for the geographic distance measure, but 


\section{CHAPTER 3. INTERDEPENDENCE OF SOVEREIGN YIELD SPREADS: THE SPATIAL DIMENSION}

with a counter-intuitive sign. The row-normalization method is not suitable for our analysis. This is in line with Keiler and Eder (2013). The authors argue that row-normalization is problematic in an interest rate analysis since only direct effects of spillovers are considered, but not their indirect effects.

In terms of the statistical significance of spatial coefficients, $\psi$, both the minmax and spectral-normalization indicate the presence of spatial dependence, but the magnitudes are different. The min-max normalization performs best with the highest positive spatial autoregressive parameters, $\psi$, across all three economic distance measurements, ranging from 0.29 (cross-bank lending) to 0.38 (trade volume). The spectral, the absolute distance measurement, also registers statistically significant results over the economic distances, but with lower magnitudes, ranging from 0.15 (cross-bank lending) to 0.19 (FDI). For geographic distance, the spectral-normalization detects a spatial dependence of the yield spreads at $10 \%$ significance level with a negative sign. The spectral normalization methods also find statistically significant positive spatial dependence of the yield spreads across all economic distance measures. This is line with the benchmark results based on the min-max normalization. However, the magnitudes of the spatial coefficients are lower. Both the spectral and the min-max normalization methods point out the same trend in the data: trade channels propagate the interdependence of the sovereign yield spreads along with FDI flows.

\subsubsection{Sensitivity to the first step methods}

The benchmark results for the spatial dependence analysis is based on the CCEP estimation in the first step. In our two-step approach, the CCEP method that treats the coefficients homogeneously and factor loadings heterogeneously provides the best estimates for the long-run dynamics in the first step. The model explains $80 \%$ of the variation in the yield spreads. Among the six estimations, the AMG method explains $71 \%$ of the variation in the spreads and uses a different proxy to correct for the common factors while the DCCE estimation explains $51 \%$ of the variation. See Table 3.6.

In this sensitivity analysis, we fit a spatial model on the residuals from the AMG and the DCCE estimations, respectively. The aim is to check whether the spatial analysis is sensitive to the method used in the first step.

Table 3.10: Spatial coefficients based on the residuals from the AMG estimation

\begin{tabular}{|c|c|c|c|c|c|c|c|c|c|c|c|c|}
\hline \multirow{2}{*}{$\begin{array}{l}\text { Weight Matrix } \\
\text { Normalization type }\end{array}$} & \multicolumn{3}{|c|}{$\underline{\text { Distance }}$} & \multicolumn{3}{|c|}{$\underline{\text { Trade volume }}$} & \multicolumn{3}{|c|}{$\underline{\text { FDI }}$} & \multicolumn{3}{|c|}{ Cross-bank lending } \\
\hline & row & $\min -\max$ & spectral & row & min-max & spectral & row & $\operatorname{min-max}$ & spectral & row & $\min -\max$ & spectral \\
\hline$\psi$ & $\begin{array}{c}0.003 \\
(0.040)\end{array}$ & $\begin{array}{c}0.036 \\
(0.109)\end{array}$ & $\begin{array}{c}0.025 \\
(0.078)\end{array}$ & $\begin{array}{c}0.030 \\
(0.040)\end{array}$ & $\begin{array}{c}0.468 \\
(0.140)\end{array}$ & $\begin{array}{c}0.214 \\
(0.068)\end{array}$ & $\begin{array}{c}0.010 \\
(0.063)\end{array}$ & $\begin{array}{c}0.408 \\
(0.115)\end{array}$ & $\begin{array}{c}0.235 \\
(0.066)\end{array}$ & $\begin{array}{c}0.051 \\
(0.448)\end{array}$ & $\begin{array}{c}0.403 \\
(0.128)\end{array}$ & $\begin{array}{c}0.200 \\
(0.063)\end{array}$ \\
\hline p-value & 0.96 & 0.741 & 0.74 & 0.15 & $0.00^{* * *}$ & $0.00^{* * *}$ & 0.66 & $0.00^{* * *}$ & $0.00^{* * *}$ & 0.36 & $0.00^{* * *}$ & $0.00^{* * *}$ \\
\hline Log-likelihood & -1450.0 & -1350.0 & -1350.0 & -1445.0 & -1345.0 & -1345.6 & -1444.0 & -1344.0 & -1344.5 & -1444.5 & -1345.0 & -1345.5 \\
\hline
\end{tabular}


Table 3.10 summarizes the results for the spatial coefficients $(\psi)$ and their statistical tests. The results are derived from the AMG estimation via four network connections for all different normalization schemes. Regarding the propagation schemes, economic distance measurements are significant while the geographic distance measure continues to be statistically insignificant. Overall, the estimated degree of spatial dependence increases from 0.40 in the previous analysis to around 0.50. Among economic distance measures, the trade volume detects the highest degree of dependence (0.47) as the propagation scheme, followed by FDI flows with 0.41 . Finally, the degree of spatial dependence via crossbanking lending rises from 0.29 to 0.40 . In summary, we detect statistically positive spatial dependence of the yield spreads after estimating the long-run dynamics via the AMG estimation. The propagation channels are the trade connections, the FDI flows and cross-bank lending with higher estimated degree of spatial dependence.

Table 3.11: Spatial coefficients based on the residuals from the DCCE estimation

\begin{tabular}{|c|c|c|c|c|c|c|c|c|c|c|c|c|}
\hline \multirow{2}{*}{$\begin{array}{l}\text { Weight Matrix } \\
\text { Normalization type }\end{array}$} & \multicolumn{3}{|c|}{$\underline{\text { Distance }}$} & \multicolumn{3}{|c|}{ Trade volume } & \multicolumn{3}{|c|}{$\underline{\text { FDI }}$} & \multicolumn{3}{|c|}{ Cross-bank lending } \\
\hline & row & $\min -\max$ & spectral & row & $\min -\max$ & spectral & row & $\min -\max$ & spectral & row & $\min -\max$ & spectral \\
\hline$\psi$ & $\begin{array}{c}-0.583 \\
(0.099)\end{array}$ & $\begin{array}{l}-0.273 \\
(0.126)\end{array}$ & $\begin{array}{l}-0.195 \\
(0.905)\end{array}$ & $\begin{array}{c}-0.109 \\
(0.066)\end{array}$ & $\begin{array}{c}0.357 \\
(0.156)\end{array}$ & $\begin{array}{c}0.164 \\
(0.071)\end{array}$ & $\begin{array}{l}-0.012 \\
(0.064)\end{array}$ & $\begin{array}{c}0.376 \\
(0.119)\end{array}$ & $\begin{array}{c}0.216 \\
(0.068)\end{array}$ & $\begin{array}{l}-0.041 \\
(0.558)\end{array}$ & $\begin{array}{c}0.243 \\
(0.134)\end{array}$ & $\begin{array}{c}0.120 \\
(0.067)\end{array}$ \\
\hline p-value & 0.11 & $0.03^{* *}$ & $0.03^{* *}$ & 0.10 & $0.02^{* *}$ & $0.02^{* *}$ & 0.86 & $0.00^{* *}$ & $0.00^{* * *}$ & 0.46 & $0.07^{*}$ & $0.07^{*}$ \\
\hline Log-likelihood & -164.6 & -180.9 & -180.9 & -181.9 & -180.9 & -180.9 & -183.4 & -178.8 & -178.8 & -183.0 & -181.7 & -181.7 \\
\hline
\end{tabular}

Another time series panel estimation is the DCCE method which includes the lagged sovereign yield spreads. The results for the spatial coefficients $(\psi)$ and their statistical tests are presented in Table 3.11. The results are for four network connections for all different normalization schemes. The min-max normalization performs best with the highest positive spatial autoregressive parameters, $\psi$, across all three economic distance measurements, ranging from 0.24 (cross-bank lending) to 0.38 (FDI). The absolute distance measurement, the spectral, also registers statistically significant results over economic distances, but with lower magnitudes, ranging from 0.12 (cross-bank lending) to 0.21 (FDI). Row-standardization performs poorly across all schemes, registering insignificant p-values. In summary, we detect statistically positive spatial dependence of the yield spreads after estimating the long-run dynamics via the DCCE estimation. In terms of the estimated degree of spatial dependence, FDI channels register a slightly higher value than the trade channel. Still, in terms of the magnitudes, the difference between the benchmark results and these results are minor.

In summary, the statistically significant presence of positive spatial dependence in sovereign yield spreads is robust to the choice of the estimation methods in the first step. Changes in the spreads of foreign countries have a significant impact on the domestic yield spreads after taking into account country-specific risks and common factors. 


\subsubsection{Sensitivity to the sample of countries, the EMU members}

Our data set contains 11 EMU members prior to the 2004 expansion and 10 non-EMU countries. The EMU members share a common currency, have closer trade, FDI and banking sector ties. Also, sovereign yield spreads and their determinants follow different trends than the non-EMU members, see the descriptive statistics in Table 3.14 in appendix-A2. After 2008, the long-run borrowing rates of the EMU members were higher and more volatile compared to the non-EMU members. The European Central Bank has set the policy rate lower than the non-EMU countries. Fiscal outlook in terms of the debt ratio and the budget balance for the EMU members deteriorated more than the non-EMU members. In terms of economic growth rates, the non-EMU members caught up with the benchmark country while the EMU members under-performed by 0.5 percent points on average over the period 2008-2016.

Table 3.12: Model estimations for the EMU member countries (equation (3.8))

\begin{tabular}{|c|c|c|c|c|c|c|}
\hline $\begin{array}{r}\text { estimators } \\
\text { dependent variable }\end{array}$ & $\begin{array}{c}\mathrm{MG} \\
\text { Spreads }\end{array}$ & $\begin{array}{l}\text { CCEMG } \\
\text { Spreads }\end{array}$ & $\begin{array}{l}\text { CCEP } \\
\text { Spreads }\end{array}$ & $\begin{array}{c}\text { AMG } \\
\text { Spreads }\end{array}$ & $\begin{array}{l}\text { AMG-IMP } \\
\text { Spreads }\end{array}$ & $\begin{array}{l}\text { DCCE } \\
\text { Spreads }\end{array}$ \\
\hline Policy rate spread & $\begin{array}{c}0.208^{* * *} \\
{[0.054]}\end{array}$ & $\begin{array}{l}-0.012 \\
{[0.088]}\end{array}$ & $\begin{array}{c}0.03 \\
{[0.084]}\end{array}$ & $\begin{array}{c}0.323^{* * *} \\
{[0.053]}\end{array}$ & $\begin{array}{c}0.380^{* *} \\
{[0.049]}\end{array}$ & $\begin{array}{l}-0.336 \\
{[0.018]}\end{array}$ \\
\hline Budget balance/GDP spread & $\begin{array}{l}0.145 \\
{[0.782]}\end{array}$ & $\begin{array}{l}-0.53 \\
{[0.054]}\end{array}$ & $\begin{array}{c}-0.061^{* * *} * \\
{[0.015]}\end{array}$ & $\begin{array}{l}-0.009 \\
{[0.050]}\end{array}$ & $\begin{array}{l}-0.101 \\
{[0.088]}\end{array}$ & $\begin{array}{r}-0.030^{* *} \\
{[0.011]}\end{array}$ \\
\hline$\Delta$ Public debt/GDP spread (log) & $\begin{array}{l}6.757^{*} \\
{[2.664]}\end{array}$ & $\begin{array}{l}-2.579^{*} \\
{[1.305]}\end{array}$ & $\begin{array}{c}0.02 \\
{[0.990]}\end{array}$ & $\begin{array}{l}1.362 \\
{[0.734]}\end{array}$ & $\begin{array}{l}-1.824 \\
{[2.559]}\end{array}$ & $\begin{array}{c}0.407 \\
{[1.516]}\end{array}$ \\
\hline Real GDP growth spread & $\begin{array}{l}-0.009 \\
{[0.364]}\end{array}$ & $\begin{array}{l}0.101 \\
{[0.071]}\end{array}$ & $\begin{array}{c}-0.234^{* * *} \\
{[0.049]}\end{array}$ & $\begin{array}{c}-0.224^{* *} \\
{[0.079]}\end{array}$ & $\begin{array}{l}-0.270 \\
{[0.241]}\end{array}$ & $\begin{array}{l}-0.012 \\
{[0.045]}\end{array}$ \\
\hline Inflation spread & $\begin{array}{c}0.782 \\
{[0.438]}\end{array}$ & $\begin{array}{c}0.462 \\
{[0.289]}\end{array}$ & $\begin{array}{c}-0.327^{* *} \\
{[0.124]}\end{array}$ & $\begin{array}{c}0.161 \\
{[0.162]}\end{array}$ & $\begin{array}{l}0.574^{*} \\
{[0.224]}\end{array}$ & $\begin{array}{c}0.035 \\
{[0.098]}\end{array}$ \\
\hline CA/GDP spread & $\begin{array}{l}-0.014^{*} \\
{[0.019]}\end{array}$ & $\begin{array}{c}0.027 \\
{[0.035]}\end{array}$ & $\begin{array}{c}0.060^{* * *} \\
{[0.010]}\end{array}$ & $\begin{array}{c}0.046 \\
{[0.030]}\end{array}$ & $\begin{array}{c}0.066^{* *} \\
{[0.025]}\end{array}$ & $\begin{array}{l}-0.001 \\
{[0.007]}\end{array}$ \\
\hline$\Delta$ Liquidity indicator spread & $\begin{array}{l}-2.886^{*} \\
{[1.425]}\end{array}$ & $\begin{array}{l}2.730^{*} \\
{[1.207]}\end{array}$ & $\begin{array}{l}-0.119 \\
{[0.695]}\end{array}$ & $\begin{array}{c}0.593 \\
{[0.688]}\end{array}$ & $\begin{array}{l}1.189 \\
{[1.513]}\end{array}$ & $\begin{array}{c}0.679 \\
{[1.480]}\end{array}$ \\
\hline Exchange rate risk & $\begin{array}{l}-0.030 \\
{[0.018}\end{array}$ & $\begin{array}{l}0.041^{*} \\
0.016]\end{array}$ & $\begin{array}{c}0.009 \\
{[0.024]}\end{array}$ & {$[0.003$} & $\begin{array}{l}0.001 \\
{[0.016]}\end{array}$ & $\begin{array}{l}0.007 \\
{[0.015]}\end{array}$ \\
\hline Lagged dependent variable & & & & & & $\begin{array}{c}0.892^{* * *} \\
{[0.026]}\end{array}$ \\
\hline dummies/trends & included & included & included & included & included & included \\
\hline \# of observations & 935 & 935 & 935 & 935 & 935 & 902 \\
\hline \# of sign. Trends (at 5\%) & 6 & 8 & - & 8 & 3 & - \\
\hline R-squared & 0.57 & 0.85 & 0.87 & 0.60 & 0.75 & 0.47 \\
\hline RMSE & 1.30 & 0.56 & 0.76 & 0.61 & 1.06 & 0.39 \\
\hline CD Test (p-value) & $0.04^{* *}$ & 0.33 & 0.54 & 0.19 & 0.31 & 0.39 \\
\hline
\end{tabular}

Note: Standard deviations are in parenthesis. ${ }^{* * *} \mathrm{p}<0.01,{ }^{* *} \mathrm{p}<0.05,{ }^{*} \mathrm{p}<0.10$.

Note: The CD test statistic follows $\mathrm{N}(0,1)$ under the null hypothesis of no cross-sectional dependence.

In order to assess spatial dependence among the EMU members' yield spreads, we re-estimate equation (3.8) for the 11 EMU members. The results are reported in Table 3.12. In these estimations, the policy rate spread and exchange rate risk are observed common factors, rather than country-specific risk (as in Table 3.6). The policy rate is determined by the European Central Bank and is common for all members. Due to the adoption of the single currency by EMU members, the depreciation/appreciation against the US dollar is the same. Similar as in the previous analysis, the CCEP estimation registers the best fit to 
modeling the sovereign debt yield spreads for the EMU countries. The CCEP estimator explains $87 \%$ of the variation in the long-run yield spreads among the EMU members. No cross-sectional dependence in its residuals is detected and four out of eight explanatory variables are statistically significant. On the other hand, in this analysis, the fiscal indicator turns out to be significant for yield spreads. This is not the case for the whole sample.

The results of the CCEP estimation shows that the budget balance ratio spreads and real economic growth differences are the main determinants of the sovereign yield spreads. For instance, if the budget balance ratio is $5 \%$ higher than the US fiscal outlook, this leads to 0.3 percentage points decrease in the domestic long-run sovereign yield spreads. When European economies grow $1 \%$ faster than the US economy, this would reduce the long-run sovereign borrowing cost by 0.2 percentage points. In addition, the current account balance ratio and inflation differentials turn out to be statistically significant for determining sovereign yield spreads in the EMU.

\section{Testing for spatial autocorrelation}

To investigate the spatial patterns in the yield spreads of the EMU members, we fit a SAR model on the residuals from the CCEP estimation in the first step. Table 3.13 summarizes the results for the spatial coefficients $(\psi)$ and their statistical tests that are estimated via four network connections for the min-max normalization scheme.

In the benchmark analysis (see Table 3.8), we conclude for statistically significant spatial dependence in the sovereign yield spreads. Regarding the transmission channels, bilateral trade propagates the spatial dependence with the highest estimated degree, followed by the FDI flows and finally cross-bank lending. Geographic proximity is not the main channel of propagating the dependence.

The results for the sub-sample analysis in Table 3.13 supports the main findings of the benchmark results: sovereign yield spreads are related in the spatial dimension. Such dependence indicates that a change in the spreads of other members has a significant impact on the domestic yield spreads. Among the EMU members, transmission channels of interdependence cannot be explained via geographical closeness of members, but via economic distance measurements, in line with the previous analysis. The economic distance measurements, trade volume, FDI flows and cross-bank lending have statistically significant positive signs, supporting the previous results. Geographic distance is statistically insignificant.

The estimated degree of spatial dependence that uses the trade volume and the FDI as the weight are the highest for the spatial lag variable for the EMU countries. For instance, a 1\% increase in any sovereign yield spread is estimated to increase the yield spreads by around 0.382 percentage points on average. In terms of the magnitude of spatial dependence, the estimated degree of the 
dependence among the EMU members is the same as the degree of dependence among advanced countries in the benchmark sample.

Table 3.13: Spatial coefficients for the EMU countries based on the residuals from the CCEP estimation

\begin{tabular}{ccccc}
\hline \hline $\begin{array}{l}\text { Weight Matrix } \\
\text { Normalization type }\end{array}$ & $\begin{array}{c}\text { Distance } \\
\text { min-max }\end{array}$ & $\begin{array}{c}\text { Trade volume } \\
\text { min-max }\end{array}$ & $\begin{array}{c}\text { FDI } \\
\text { min-max }\end{array}$ & $\begin{array}{c}\text { Cross-bank lending } \\
\text { min-max }\end{array}$ \\
\hline \hline$\psi$ & -0.176 & 0.382 & 0.383 & 0.277 \\
p-value & $(0.084)$ & $(0.123)$ & $(0.108)$ & $(0.193)$ \\
0.11 & $0.03^{* *}$ & $0.00^{* * *}$ & $0.01^{* *}$ \\
\hline Log-likelihood & -780.0 & -777.9 & -776.6 & -778.1 \\
\hline Note: Standard deviations are in parenthesis. & $* * * \mathrm{p}<0.01,{ }^{* *} \mathrm{p}<0.05,{ }^{*} \mathrm{p}<0.10$
\end{tabular}

In a nutshell, these estimates indicate a highly significant spatial dependence in the sovereign yield spreads among the EMU members, after controlling for country-specific fundamentals such as the budget balance ratio, real economic growth and after allowing for common factors. The domestic yield spreads are affected by the spreads of other members of the EMU. Regarding the transmission channels, the mobility of goods and long-run capital among the EMU members propagate spatial dependence among sovereign interest rate differentials in the EMU.

The results indicate that there are spillovers across yield spreads within the EMU regardless of the country-specific economic fundamentals. The presence of spatial dependence in interest rate differentials can have implications for economies with a common currency such as the EMU. On the policy implications side, such dependence among its members backs the arguments of the common European bond market camp. A pan-European bond market can strengthen the monetary integration of the Union, enabling the European Central Bank to manage any upcoming financial crisis in the region.

\subsection{Concluding remarks}

Spreads on sovereign bonds are much larger than can be justified by the country-specific default risks and illiquidity. This raises the question whether this difference is due to the interdependence of the yield spreads. We investigate how this interdependence is propagated across countries and how the domestic yield spreads are affected by the spreads of foreign countries. We adopt a semi-parametric approach to address these issues to investigate the interdependence of the spreads.

First we establish the long-run relation between domestic sovereign yield spreads and country-specific risks such as exchange rate, default and liquidity risks. In the second step, we investigate the interdependence of yield spreads after extracting the country-specific risks and common factors from domestic yield 
spreads. We fit a spatial autoregressive (SAR) model in the residuals from the first step to investigate the presence of interdependence (see e.g. Holly et al. (2010)).

Regarding country-specific risks, the short-run policy rate spreads as well as relative real GDP growth rates are the main economic fundamentals that determine the long-run sovereign spreads. Consequently, when domestic short-run yields are higher than the US monetary policy stance, this leads to an increase in the domestic long-run sovereign borrowing cost differentials. Higher economic growth has a negative relationship with yield spreads. Among the EMU members, the budget balance ratio differentials and relative real GDP growth rates turn out to be statistically significant to explain the yield spreads. Budget balance ratios that are higher than the US fiscal outlook lead to a decrease in domestic long-term sovereign yield spreads. This finding indicates the importance of fiscal responsibility within a currency union. In the second step, we fit a spatial autoregressive model (SAR) on yields that cannot be explained by the country-specific risks and illiquidity. We find a highly significant spatial dependence in sovereign yield spreads. This implies that domestic yield spreads are affected by the spreads of foreign countries. Regarding the transmission channels, economic connections between countries shape such spatial dependence. Economic distance measured by trade volume shows the highest estimated degree of spatial dependence, followed by the FDI flows and crossbank lending while geographic distance turns out to be insignificant for spatial dependence.

Detecting spatial dependence can have serious implications for the EMU members in terms of policy implications. The debate on whether a common European bond market should be established receives public attention from time to time, and evidence from this study supports the pro-camp. The key point is that the importance of interdependence is detected after extracting the countryspecific risks and common factors. Even if each member country takes care of their fiscal responsibility individually, they are still vulnerable during a financial distress period due to spatial dependence. Introducing a common bond market can be one way of reducing this vulnerability. The supply-side of Eurodominated bonds remains fragmented across national states in the EMU, each with their own credit ratings. For instance, in a market structure similar to the US government bond market with federal and state levels, pan-European bond markets would make individual bonds more liquid and easier to trade, especially during a financial distress period. However, there are several strong arguments against pan-European bonds. First, a common bond contradicts the no-bail out principle which is essential for strengthening fiscal discipline in the Union. Second, burden sharing can lead to possible additional costs for the triple-A rated members. Nevertheless, while the political and fiscal integration of the EMU has a long way to go, a pan-European bond market can be another way of supporting the monetary integration of the union. 


\subsection{Appendices}

\subsubsection{The long-run sovereign yield spreads for selected countries}

Figure 3.1: Long-run yield spreads for selected countries

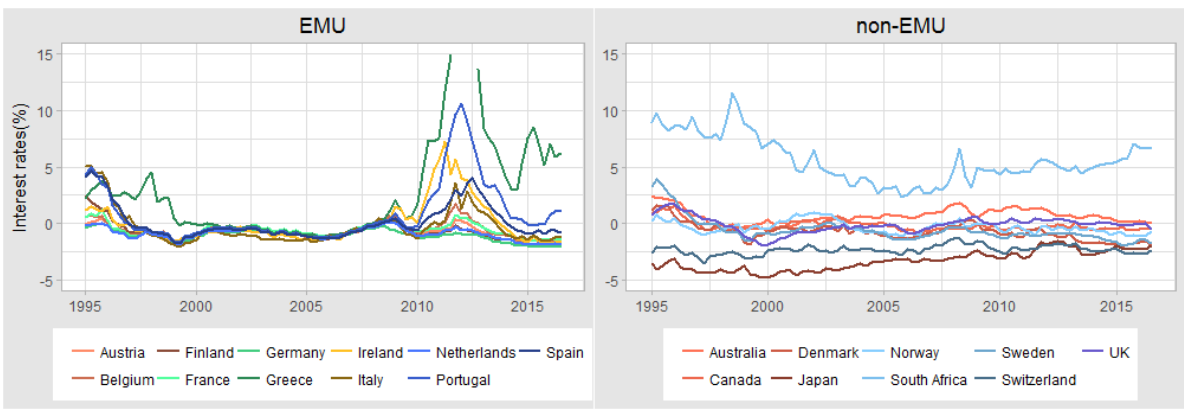

Source: Datastream

Note: The yield spreads for Greek bonds are above 15\% in 2011-2013.

\subsubsection{Data construction and descriptive statistics}

We have a total of $n=1680$ observations from $N=20$ countries. Time spans from $19961 \mathrm{Q}$ to $20164 \mathrm{Q}$ are covered by around 84 time series observations per country. The resulting panel is balanced and there are no gaps within individual country time series. Macro variables are realizations, we do not carry out any interpolation to expand the number of observations. Table 3.14 summarizes descriptive statistics for the variables in terms of sub-sample groups, EMU versus non-EMU members and in terms of the pre-crisis period and the postcrisis period. Before the crisis period, the sovereign yield spreads are lower than the spreads in the benchmark country and they become more volatile and positive after the final quarter of 2008. During the post-crisis period, the policy interest rate spreads become positive and higher while they are negative and minor during the pre-crisis period. The global risk factor is measured as the difference between the US private sector borrowing cost and the Fed policy rate. This particular spread increased from $2.4 \%$ in the previous period to $4 \%$ during post-crisis while it became less volatile later. The exchange rate risk premium was volatile in all periods. During the pre-crisis period, the US dollar per each domestic currency appreciated on average as the policy rates of other countries were lower. During the post-crisis period, the US dollar per each domestic currency depreciated as the Fed aggressively cut the policy rate. On the fiscal outlook, both the budget balance ratio and debt ratio became relatively more volatile after 2008, while they both improved. The main reason for that could be that the benchmark country's outlook has deteriorated significantly. For the external sector, the patterns are the same across the periods. Moreover, inflation also seems stable while economic growth performance is better for the benchmark country. After 2008, other economies 
have grown less compared to the USA. After 2008, the long-run borrowing rates among the EMU members were higher and more volatile compared to the non-EMU members. The European Central Bank's policy rate was lower and fiscal outlook in terms of the debt ratio and the budget balance for the EMU members was worse than for the non-EMU members. Finally, while non-EMU members caught up with the benchmark country in terms of economic growth, EMU members have under-performed by 0.5 percent points on average over 2008-2016.

Table 3.14: Descriptive statistics

\begin{tabular}{|c|c|c|c|c|c|c|c|c|}
\hline & \multicolumn{4}{|l|}{ Pre-crisis } & \multicolumn{4}{|l|}{ Post-crisis } \\
\hline & Avg & Max & Min & Std dev & Avg & $\operatorname{Max}$ & Min & Std dev \\
\hline \multicolumn{9}{|l|}{$E M U$} \\
\hline LRIR spread & -0.49 & 5.09 & -2.12 & 1.14 & 0.65 & 28.94 & -2.09 & 3.73 \\
\hline Policy rate & -0.54 & 1.92 & -2.61 & 1.37 & 0.65 & 2.34 & -0.38 & 0.67 \\
\hline Budget balance ratio & -0.29 & 9.34 & -6.80 & 3.10 & 2.21 & 10.02 & -21.66 & 4.15 \\
\hline Debt ratio & 0.47 & 71.98 & -63.55 & 29.93 & -19.52 & 57.43 & -74.36 & 33.32 \\
\hline Debt ratio (Log) & -0.08 & 0.69 & -1.70 & 0.46 & -0.25 & 0.38 & -1.42 & 0.37 \\
\hline GDP growth & 0.10 & 3.26 & -2.15 & 0.80 & -0.45 & 7.31 & -3.42 & 1.04 \\
\hline Inflation & -0.06 & 1.70 & -0.74 & 0.34 & -0.06 & 1.04 & -1.87 & 0.31 \\
\hline Opennes ratio & -5.74 & -4.69 & -6.68 & 0.44 & -5.79 & -4.74 & -6.46 & 0.44 \\
\hline $\mathrm{CA}$ ratio & 3.76 & 17.55 & -11.86 & 5.55 & 3.12 & 16.92 & -11.94 & 5.19 \\
\hline Liquidity indicator & -3.27 & -1.31 & -5.80 & 1.24 & -3.39 & -1.51 & -5.51 & 1.07 \\
\hline Global risk (Vix) & 0.66 & 50.32 & -49.13 & 22.24 & -0.88 & 95.96 & -43.25 & 29.45 \\
\hline Global risk factor 2 & 2.41 & 4.99 & 0.18 & 1.44 & 4.11 & 5.42 & 3.01 & 0.69 \\
\hline $\begin{array}{l}\text { Exchange rate risk } \\
\text { non-EMU }\end{array}$ & 0.28 & 7.85 & -8.54 & 3.94 & -0.93 & 5.13 & -13.27 & 4.39 \\
\hline LRIR spread & -0.12 & 11.54 & -4.85 & 2.73 & -0.21 & 7.07 & -3.15 & 2.16 \\
\hline Policy rate & 0.36 & 16.00 & -6.56 & 3.64 & 1.45 & 10.88 & -1.50 & 2.11 \\
\hline Budget balance ratio & 2.09 & 23.38 & -10.72 & 5.18 & 6.06 & 25.54 & -3.48 & 6.09 \\
\hline Debt ratio & -14.07 & 90.52 & -61.10 & 34.88 & -48.44 & 105.43 & -92.86 & 53.12 \\
\hline Debt ratio (Log) & -0.34 & 0.83 & -1.44 & 0.51 & -0.72 & 0.68 & -1.55 & 0.57 \\
\hline GDP growth & 0.04 & 3.87 & -2.03 & 0.94 & 0.01 & 2.72 & -1.88 & 0.81 \\
\hline Inflation & -0.13 & 2.43 & -1.09 & 0.51 & 0.09 & 2.10 & -0.93 & 0.51 \\
\hline Opennes ratio & -5.99 & -5.39 & -7.17 & 0.42 & -6.05 & -5.39 & -6.89 & 0.40 \\
\hline $\mathrm{CA}$ ratio & 6.28 & 26.65 & -4.02 & 5.92 & 5.14 & 21.65 & -4.52 & 6.27 \\
\hline Liquidity indicator & -3.35 & 0.02 & -5.21 & 1.37 & -3.58 & -0.40 & -5.44 & 1.41 \\
\hline Global risk (Vix) & 0.66 & 50.32 & -49.13 & 22.24 & -0.88 & 95.96 & -43.25 & 29.46 \\
\hline Global risk factor 2 & 2.41 & 4.99 & 0.18 & 1.44 & 4.11 & 5.42 & 3.01 & 0.69 \\
\hline \multicolumn{9}{|l|}{ Total } \\
\hline LRIR spread & -0.32 & 11.54 & -4.85 & 2.02 & 0.26 & 28.94 & -3.15 & 3.15 \\
\hline Policy rate & -0.14 & 16.00 & -6.56 & 2.68 & 1.01 & 10.88 & -1.50 & 1.55 \\
\hline Budget balance ratio & 0.78 & 23.38 & -10.72 & 4.33 & 3.94 & 25.54 & -21.66 & 5.46 \\
\hline Debt ratio & -6.07 & 90.52 & -63.55 & 33.04 & -32.54 & 105.43 & -92.86 & 45.66 \\
\hline Debt ratio (Log) & -0.20 & 0.83 & -1.70 & 0.50 & -0.46 & 0.68 & -1.55 & 0.53 \\
\hline GDP growth & 0.07 & 3.87 & -2.15 & 0.87 & -0.24 & 7.31 & -3.42 & 0.97 \\
\hline Inflation & -0.09 & 2.43 & -1.09 & 0.43 & 0.00 & 2.10 & -1.87 & 0.42 \\
\hline Opennes ratio & -5.85 & -4.69 & -7.17 & 0.45 & -5.90 & -4.74 & -6.89 & 0.44 \\
\hline $\mathrm{CA}$ ratio & 4.90 & 26.65 & -11.86 & 5.85 & 4.03 & 21.65 & -11.94 & 5.78 \\
\hline Liquidity indicator & -3.30 & 0.02 & -5.80 & 1.30 & -3.48 & -0.40 & -5.51 & 1.23 \\
\hline Global risk (Vix) & 0.66 & 50.32 & -49.13 & 22.23 & -0.88 & 95.96 & -43.25 & 29.43 \\
\hline Global risk factor 2 & 2.41 & 4.99 & 0.18 & 1.44 & 4.11 & 5.42 & 3.01 & 0.69 \\
\hline Exchange rate risk & 0.19 & 15.85 & -18.78 & 4.07 & -0.86 & 16.47 & -27.50 & 4.92 \\
\hline
\end{tabular}

Source: Datastream

* Note that all variables are spreads with the respect to the benchmark country (USA)

And Post-crisis period is after September 2008 till 2016.

\subsubsection{Panel unit root tests results}

The Pesaran (2007) test, CIPS, is the cross-sectionally augmented version of Im, Pesaran and Shin $(1997,2003)$ IPS test. These tests adopt the Common Correlated Effects (CCE) approach and incorporate cross-sectional dependence 
by augmenting the Augmented Dickey-Fuller (ADF) regressions with crosssectional means. The cross-sectional augmented ADF (CADF) regression for each panel/country is represented as:

$$
\Delta y_{i, t}=a_{i 0}+a_{i 1} t+a_{i 2} y_{i, t-1}+a_{i 3} \bar{y}_{t-1} \sum_{j=1}^{p} \delta_{i j} \Delta y_{i, t-j}+v_{i t}
$$

where $\bar{y}_{t}$ denotes the cross-sectional mean of $y_{i t}$. The CIPS statistic is the cross-sectional mean of $\tilde{t}_{t}$ which is the OLS t-ratio of $a_{i 2}$ in the above CADF regressions. The null hypothesis assumes that the series is non-stationary $\left(\mathcal{H}_{0}\right.$ : $\left.a_{i 2}=0\right)$ for all $\mathrm{i}$. The authors also suggest combining the p-values of the individual tests or the inverse normal test statistics.

Table 3.15 summarizes the CIPS test results for each variable in the data. The first row mainly focuses on the possible dependent variables like the yields, the yield spreads and adjusted yield spreads, referring to the spreads excluding exchange rate risks. We examine the properties of economic indicators for the default risk, one indicator for the liquidity risk and finally, one indicator for the exchange rate risk. We report lags, the inverse normal test statistic, $\mathrm{Z}$, and corresponding the p-values. The standard normal test, $Z[t-b a r]$, results are presented in the second columns while p-values are summarized in the third columns for each level of augmentation order till 3. The CIPS test results also take into account an intercept and a linear trend.

The null hypothesis is that the series is non-stationary $\left(\mathcal{H}_{0}: a_{i 2}=1\right)$ for all $i$ and homogeneous non-stationary across panel groups, N. We diagnose nonstationarity for adjusted yield spreads where the null is rejected while the yield spreads have stationary property. Among the explanatory variables, the government debt ratio and liquidity indicators also register non-stationary properties. For these variables, we work with their first differences in the analysis. Homogeneous non-stationarity is rejected for all other variables. Thus, we conclude that the government debt ratio spreads and the liquidity indicator spreads are integrated order of $\mathrm{I}(1)$ and the other series as stationary, $\mathrm{I}(0)$ variables. 
Table 3.15: Second generation panel unit roots tests-CIPS

\begin{tabular}{|c|c|c|c|c|c|c|c|c|c|c|c|}
\hline & \multirow{2}{*}{$\begin{array}{r}\text { Yields } \\
\mathrm{Z}[\mathrm{t}-\mathrm{bar}]\end{array}$} & \multirow[b]{2}{*}{ (p) } & \multirow[b]{2}{*}{ lags } & \multicolumn{2}{|c|}{ Swaps } & \multicolumn{3}{|c|}{ Yield spreads } & \multicolumn{3}{|c|}{ Adjusted yield spreads } \\
\hline lags & & & & $\mathrm{Z}[\mathrm{t}-\mathrm{bar}]$ & (p) & lags & $\mathrm{Z}[\mathrm{t}$-bar $]$ & $(\mathrm{p})$ & lags & $\mathrm{Z}[\mathrm{t}-\mathrm{bar}]$ & (p) \\
\hline \multicolumn{12}{|c|}{ in levels with an intercept and a linear trend } \\
\hline 0 & -3.28 & $0.00^{*}$ & 0 & -4.64 & $0.00 *$ & 0 & -2.29 & $0.01 *$ & 0 & -4.76 & $0.00^{*}$ \\
\hline 1 & -4.35 & $0.00^{*}$ & 1 & -5.08 & $0.00^{*}$ & 1 & -2.65 & $0.00^{*}$ & 1 & -1.20 & 0.12 \\
\hline 2 & -2.76 & $0.00^{*}$ & 2 & -5.54 & $0.00^{*}$ & 2 & -1.97 & $0.03^{*}$ & 2 & 0.85 & 0.80 \\
\hline 3 & -2.30 & $0.01^{*}$ & 3 & -4.84 & $0.00^{*}$ & 3 & -2.52 & $0.01^{*}$ & 3 & 2.10 & 0.98 \\
\hline \multicolumn{3}{|c|}{ Policy rate spreads } & \multirow{2}{*}{\multicolumn{3}{|c|}{$\begin{array}{l}\text { Budget balance to GDP spreads } \\
\text { lags Z[t-bar] (p) }\end{array}$}} & \multirow{2}{*}{\multicolumn{3}{|c|}{$\begin{array}{l}\text { Govern. debt to GDP spreads } \\
\text { lags } \quad \mathrm{t} \text { t-bar] } \quad(\mathrm{p})\end{array}$}} & \multirow{2}{*}{\multicolumn{3}{|c|}{$\begin{array}{l}\text { GDP growth rate spreads } \\
\text { lags } Z[\mathrm{t}-\mathrm{bar}] \quad \text { (p) }\end{array}$}} \\
\hline lags & $\mathrm{Z}[\mathrm{t}-\mathrm{bar}]$ & $(\mathrm{p})$ & & & & & & & & & \\
\hline \multicolumn{12}{|c|}{ in levels with an intercept and a linear trend } \\
\hline 0 & 0.37 & 0.65 & 0 & 1.64 & 0.95 & 0 & 4.91 & 1.00 & 0 & -6.46 & $0.00 *$ \\
\hline 1 & -5.06 & $0.00^{*}$ & 1 & -5.80 & $0.00^{*}$ & 1 & 3.38 & 1.00 & 1 & -6.14 & $0.00^{*}$ \\
\hline 2 & -4.77 & $0.00^{*}$ & 2 & -2.56 & $0.01 *$ & 2 & 2.84 & 1.00 & 2 & -6.48 & $0.00^{*}$ \\
\hline 3 & -6.37 & $0.00^{*}$ & 3 & -3.37 & $0.00^{*}$ & 3 & 3.95 & 1.00 & 3 & -10.77 & $0.00^{*}$ \\
\hline \multicolumn{3}{|c|}{ Inflation spreads } & \multicolumn{3}{|c|}{ Current Account ratio spreads } & \multicolumn{3}{|c|}{ Liquidity indicator spreads } & \multicolumn{3}{|c|}{ Fx per US } \\
\hline lags & $\mathrm{Z}[\mathrm{t}-\mathrm{bar}]$ & $(\mathrm{p})$ & lags & $\mathrm{Z}[\mathrm{t}-\mathrm{bar}]$ & (p) & lags & $\mathrm{Z}[\mathrm{t}-\mathrm{bar}]$ & $(\mathrm{p})$ & lags & $\mathrm{Z}[\mathrm{t}-\mathrm{bar}]$ & (p) \\
\hline \multicolumn{12}{|c|}{ in levels with an intercept and a linear trend } \\
\hline 0 & -2.09 & $0.02 *$ & 0 & -10.82 & $0.00^{*}$ & 0 & 4.58 & 1.00 & 0 & -21.58 & $0.00^{*}$ \\
\hline 1 & -6.02 & $0.00^{*}$ & 1 & -6.78 & $0.00^{*}$ & 1 & 3.22 & 0.99 & 1 & -17.47 & $0.00^{*}$ \\
\hline 2 & -7.46 & $0.00^{*}$ & 2 & -2.58 & $0.01 *$ & 2 & 2.49 & 0.99 & 2 & -14.07 & $0.00^{*}$ \\
\hline 3 & -7.78 & $0.00^{*}$ & 3 & 1.44 & 0.92 & 3 & 2.48 & 0.99 & 3 & -11.87 & $0.00^{*}$ \\
\hline
\end{tabular}

The panel unit root test based on cross section augmented ADF(CADF) regressions, separately run for each country is:

$$
\Delta y_{i, t}=a_{i 0}+a_{i 1} t+a_{i 2} y_{i, t-1}+a_{i 3} \bar{y}_{t-1} \sum_{j=1}^{p} \delta_{i j} \Delta y_{i, t-j}+v_{i t}
$$

where $\bar{y}_{t}$ denotes the cross section mean of $y_{i t}$. the CIPS statistic is simple cross section average of $\tilde{t}_{t}$ defined by CIPS $=N^{-1} \sum_{i=1}^{p} \tilde{t}_{i}$, where $\tilde{t}_{i}$ is the OLS t-ratio of $a_{i 2}$ in the above CADF regressions. So, the null hypothesis assumes that all series are non-stationary $\left(H 0: a_{i 2}=0\right.$ for all i). Pesaran (2017) also suggests combining the p-values of the individual tests. As such, the inverse chi-squared (or Fisher) test statistic is defined by $p=-2 \sum_{i=1}^{N} \ln \left(p_{i, t}\right)$, where $p_{i t}$ is the p-value corresponding to the unit root test of each cross section unit, that is each country in our sample. Another possibility would be to use the inverse normal test statistic defined by $Z=\frac{1}{\sqrt[2]{N}} \sum_{i=1}^{N} \phi^{-1}\left(p_{i, t}\right)$ 
CHAPTER 3. INTERDEPENDENCE OF SOVEREIGN YIELD SPREADS: THE SPATIAL DIMENSION 


\section{Chapter 4}

\section{Price discovery of European}

\section{equities traded on multiple}

\section{markets: Is the home market still}

\section{dominant?}

\subsection{Introduction}

In this chapter ${ }^{1}$ we discuss price discovery on stock markets. Price discovery is defined as the price adjustment process on the market when new information related to prices enters the market. Since trade in identical assets occurs on multiple market places, this raises the question of each market's contribution to the price discovery process. For instance, European equities are traded both on their national stock exchanges and on alternative trading venues such as

\footnotetext{
${ }^{1}$ This chapter is co-authored with Hande Karabıyı (Vrije Universiteit Amsterdam). The authors are grateful to those who provided insightful comments to earlier versions of this paper, in particular Tom Van Veen (Maastricht University). In addition, we would like to thank all participants at 2019 Royal Dutch Economic Association KVS new paper sessions in Den Haag, the Netherlands and all participants at the 12th International Workshop of Methods in International Finance in Louvain-la-Neuve, Belgium in 2018.
} 
a Multilateral Trading Facility $(\mathrm{MTF})^{2}$. However, little is known about which market in Europe is more influential in the price discovery process of European equities.

The dynamics of price discovery for stocks which are traded on multiple markets (cross-traded equities) have been studied extensively in the literature (AlhajYaseen et al. (2014); Chang et al. (2013); Eun and Sabherwal (2003); Frijns et al. (2010); Lok and Kalev (2006); Otsubo (2014); Chen et al. (2013)). It has become a stylized fact that the home market in which stocks have primary listings is dominant in terms of the adjustment process. This is due to larger trading volume (Hasbrouck (1995); Chen et al. (2013)) and more analyst coverage on stocks (Chang et al. (2013); Chen and Choi (2012)). Despite the rich literature on the price discovery of cross-traded stocks, some gaps in the empirical analyses still exist. Firstly, most of the studies investigate stocks that are listed ${ }^{3}$ and traded on two market venues only. However, a significant amount of company stocks are listed and traded on more markets (You et al. (2013)). Limited attention has been given to the price discovery of stocks that are traded on multiple markets. Secondly, most of the earlier analyses have focused on cross-listings with the US stock markets. Little attention has been given to assessing price discovery on non-US markets. Hence, this chapter aims to answer the following research question: which market places contribute most to the price discovery of European equities?

European exchanges provide an excellent opportunity to study price discovery. First, trading hours among European equity markets overlap longer compared to that of the US market as a foreign market. Second, as indicated by Werner and Kleidon (1996) and Grammig et al. (2005), stocks traded in different markets in different currencies are not perfect substitutes, because of the exchange rate risk. European stocks traded across European equity markets are perfect substitutes. Third, European stocks are traded both on national exchanges and on the MTFs. We refer to the MTFs as pan-European equity markets where all European stocks can be traded and are accessible to investors. For instance, the Dutch bank ING, the French bank BNP Paribas and the Belgian bank KBC Groups are traded on their local markets as well as in the MTFs, operated by the Chicago Board Options Exchange (CBOE) and by the London

\footnotetext{
${ }^{2}$ Following the introduction of the common currency, the European Commission adopted a legislative framework for financial markets to improve their efficiency, transparency and to protect investors. Under this framework, market operators or an investment firm can operate MTFs. Along with national exchanges which are registered as regulated markets, the MTFs are subject to permission from the appropriate regulatory body. The main difference between regulated markets and the MTFs is that former is run by market operators that also check whether firms meet all requirements such as disclosure requirements and other regulations. The MTFs do not have a standard listing process for firms. Apart from regulation differences, operating rules for both markets are the same: all the price quotas and trade volumes are made public in real-time.

${ }^{3}$ When a firm is cross-listed, it is obliged to meet all requirements of the host foreign stock exchange markets such as disclosure requirements and other regulations. When a firm is crosstraded, it is admitted to trade without meeting additional requirements. Nevertheless, both trading and listing make a firm's stock accessible to foreign investors.
} 


\subsection{INTRODUCTION}

Stock Exchange Group (LSEG) in the same currency. This structure provides a good opportunity to test whether the home market still remains dominant or whether a larger market (pan-European equity market) dominates the price discovery process.

We investigate the intra-day price discovery process for 73 Euronext stocks traded on three markets over the period September 2017 to March 2018. We focus on European stocks listed on the national stock exchanges with the largest market capitalization. In line with empirical evidence, our preliminary expectation is that the home markets dominate the price discovery process given that the largest volume of trade occurs in national stock exchanges and these stocks receive greater analyst coverage. We use panel data measures of price discovery developed by Karabiyik et al. (2018) to asses the contribution of trading venues to the price discovery process. Our contribution to the existing literature is twofold. First, instead of using individual stocks or aggregated data, we use a panel data approach to analyze price discovery properties of multiple markets in which the cross-section units consist of many stocks. Our panel data approach enables us to take into account heterogeneity across stocks. Using multiple stocks instead of a single stock increases the degrees of freedom, provides more accurate results and improves econometric estimates ${ }^{4}$. Rather than tracking the price discovery of the stocks individually, panel data modeling allows us to focus on the behavior of the markets for assessing the competitiveness of European equity markets. Secondly, previous empirical studies make limited attempts to conduct statistical tests on whether price discovery parameters are statistically significant or not. Our analysis contains the hypotheses tests which are not common in these empirical studies.

Contrary to our expectations, we find that the pan-European equity markets operated by the CBOE and the LSEG, contribute more to the price discovery process than the home market. Among the two pan-European markets, the CBOE contributes more to the price discovery process than the LSEG. These findings allow us to conclude that the CBOE has the biggest share in the price adjustment process. The home market has the smallest share. We obtain similar results by using higher frequency, 10-minute, data. In case of European equities, the introduction of MTFs not only spreads trading volume across the markets in the European Union but also shifts price discovery dominance. Moreover, the MTFs have increased competition and put pressure on the market shares of existing national stock exchanges in the Eurozone.

The chapter is organized as follows. Section 2 discusses price discovery. Section 3 summarizes related literature on price discovery in the context of market settings as well as the main factors that determine the adjustment process. Section 4 introduces the methodology we use to assess the research question. Section 5 describes the data. Section 6 reports the empirical results and section 7 concludes.

\footnotetext{
${ }^{4}$ Using panel data instead of a single time-series or aggregated data has many more advantages. Some of these advantages are summarized in Hsiao (2007).
} 


\subsection{Discussion of price discovery}

An identical asset may be traded on many markets. Spreading its trading across markets raises the question of the contribution of each market to the price adjustment process. In the price discovery literature, an asset price consists of a permanent component and a temporary component. The permanent component is determined by its fundamentals such as its expected returns and risks. The temporary component is determined by market conditions such as the number of buyers and sellers and non-public information that traders have.

The permanent component is derived from theory-based stock pricing models that are based on a company's fundamentals. Standard stock pricing models such as the Capital Asset Pricing Model (CAPM) and Arbitrage Pricing Theory (APT) focus on such fundamentals like expected returns, risks, and factors like a company's size and its stock's liquidity. The permanent component of the price is also termed the efficient price in the market efficiency literature. From the efficient market hypothesis, an asset trades at its fundamental value, incorporating all public and non-public information.

Theory-based pricing models consider market conditions as frictions, with no effects on an asset price in the long-run. Market frictions such as transaction costs and asymmetric information lead to deviations from the efficient price in the short-run. The number of buyers and sellers, the market share of each trader and the presence of non-public information among traders are market conditions that can affect daily price fluctuations. Moreover, differences in obligations of participants in trading (regulations and exchange rules), pricing methods, availability of funding, cost, availability of pricing information in executions also account for deviations from the efficient price.

The price discovery literature assumes first that on each market, prices for an identical asset follow a random walk, incorporating all available information and second, that on each market, prices for identical assets converge to a common efficient price. This efficient price is referred as the equilibrium price, the fundamental price and the fair price interchangeably in this literature. The price discovery process does not claim that the market price is the fundamental price, but this market price is driven by its implicit fundamental value. Analyses of the price discovery process have become popular in the financial economics literature with countless empirical applications on different asset categories such as commodities, equities, bonds and stock indices. In addition to multiple trades on different spot markets, the price discovery process across spot markets and derivative markets like future and options markets are studied to analyze which markets dominate the price discovery process.

How to measure price discovery?

To measure price discoveries, there are two modus operandi in the time series literature: the Information Share (IS) measure of Hasbrouck (1995) and the Permanent-Transitory (PT) measure of Harris et al. (2002a). Both methods 
have been studied extensively (The Journal of Financial Markets published a special issue on the topic of price discovery in 2002). Both methods assume that prices of an identical asset in different markets follow a random walk. This assumes that markets are efficient in the long-run. Given these two properties, following unpredictable patterns and approaching to the same efficient price in the long-run, the measures for the price discovery process are modeled by a Vector Error Correction Model (VECM). This implies that the price of a stock on each market is determined by the prices of this stock on all markets where it is traded.

Consider two markets, Market 1 and Market 2 and one asset $i$. In this VECM set-up, the price change of asset $i$ in Market 1 is related to the difference between its price in Market 1 and in Market 2 in the previous period, and to the price change of asset $i$ in each market in the previous period. Under the cointegration assumption, the price change of asset $i$ in Market 1 (and in Market 2) can then be modeled by long-run dynamics, the differences between the prices across different markets and short-run dynamics, the price changes in each market. Hasbrouck (1995) assumes that new information related to the efficient price is revealed by price volatility and suggests decomposing the variance of innovations caused by new information into its components. The Information Share (IS) measure is the ratio of the variance of price innovations of asset $i$ in a particular market over the total variance of the price innovations. A higher value of the IS measure indicates a greater contribution from that particular market.

The PT measure is based on the same VECM, but focuses on the permanent changes and is less parametrized in this sense. The PT is a function of the markets' speed of adjustment coefficients. In case of two markets and asset $i$, the price change of asset $i$ in Market 1, is modeled by the long-run dynamics along with the short-run dynamics in each market. The PT measure is calculated by the coefficient of the long-run dynamics. A PT of zero for Market 1 would imply that this market does not contribute to the price discovery of asset $i$. A higher value of the PT measure reflects a greater feedback or contribution from the Market 1. A PT of 1 for Market 1 implies that Market 1 is the only contributor to the process. Whether these contributions are statistically significant or not can be tested for the PT measure, but not for the IS measure. Moreover, when the correlation between different markets' innovations is high, the PT measure is more appropriate than the IS measure. However, the main advantage of the IS measure is its economic interpretation as it accounts for any differences in the variances across markets. Karabiyik et al. (2018) came up with an unifying panel framework to improve the properties of conventional IS and PT measures. The panel measures of price discovery are expected to improve estimation as well as inference for both measures. We use the panel methods of both measures to assess the price discovery process of European stocks. 


\subsection{Empirical literature on the price discovery of stocks}

A substantial body of empirical literature exists on where the price discovery of identical assets traded on multiple markets takes place. Empirical studies predominantly focus on stocks traded on various US exchanges. Preliminary studies analyzed internal US stock markets, while later studies focused on a US stock market as the foreign market ${ }^{5}$.

Studies concentrate on assets traded on US regional stock exchanges (Harris et al. (1995), Hasbrouck (1995), Harris et al. (2002b)), assets traded both in a home market and in the US as foreign market (Kehrle and Peter (2013), Chen and Choi (2012), Otsubo (2014), Lieberman et al. (1999)), and assets traded both in a home market and a non-US foreign market (Lok and Kalev (2006), Frijns et al. (2010), Ding et al. (1999), Kadapakkam et al. (2003)). The majority of these studies concluded that the home market is dominant. There are a few exceptions. Eun and Sabherwal (2003) examine 62 Canadian stocks listed on the Toronto Stock Exchange (TSE) and a US exchange over a 6-month period, from February 2 till June 31, 1998. They conclude that prices in both markets contribute to the price discovery process while the US adjusts more than the TSE. Frijns et al. (2015) study the price discovery processes of Canadian stocks traded in Toronto and on the New York Stock Exchange (NYSE). They conclude that price discovery shifts significantly towards the NYSE on days when macroeconomic news is announced.

There are fewer studies on European equities. Hupperets and Menkveld (2002) analyze seven Dutch blue chip stocks that are cross-listed on the Amsterdam Stock Exchange and the NYSE. They conclude that the home market contributes more to the price adjustment process. Pascual et al. (2006) study the price discovery process of the Spanish stocks listed on the Spanish Stock Exchange and cross-listed on the NYSE. They find that the home market dominates in terms of price discovery which is explained by the larger trading volume. Grammig et al. (2005) investigate 3 German firms traded on the NYSE and the Frankfurt Stock Exchange on the price discovery properties of these markets. They argue that most of the price discovery takes place in the home market. However, Grammig et al. (2005) criticize empirical applications in which exchange rate effects are treated exogenously. They argue that this leads to a biased conclusion because of the exchange rate risk and the authors add the exchange rate as another variable to their analysis. They also conclude that the home market dominates the process.

Empirical evidence further reveals that the main factors that determine the contribution of each market are trading volume, transaction costs and infor-

\footnotetext{
${ }^{5}$ Roosenboom and van Dijk (2009) argue that US stock exchanges are generally recognized to have the most liquid markets, the most stringent disclosure requirements, the largest shareholder bases and the strongest investor protection. For an international firm, being listed on a US stock market is attractive because of regional business motivations such as US business extension or US mergers and acquisitions or because of its dominant position in the global financial markets.
} 
mation asymmetry. Each market's contribution is positively related to its trading volume. Harris et al. (1995) link the NYSE's dominance among regional exchanges to its trading volume, which is supported by the findings of Chen et al. (2013), Eun and Sabherwal (2003), Frijns et al. (2010) . The trading cost hypothesis argues that price discovery occurs in the market with the lower trading costs. Eun and Sabherwal (2003), Frijns et al. (2010) and Korczak and Phylaktis (2010) conclude that each market's contribution to price discovery increases when its relative transaction costs decline. Another possible determinant of price discovery is information asymmetry due to concentration of informed traders in a particular market (Chen et al. (2009); Chen and Choi (2012)).

In terms of methodology, most of the empirical studies adapt an asset-byasset approach, focusing on the adjustment process of each individual asset separately. There are some exceptions. Narayan et al. (2014) investigate the price discovery between Credit Default Swap markets and stock markets by using data for 212 stocks. They adopt a panel data modeling and estimation approach to find price discovery parameters for these stocks. To the best of our knowledge this study is the first to use a panel data approach to price discovery. In their sector based analysis, they find that the stock market contributes most to price discovery in most of the sectors. The other exception is Karabiyik et al. (2017). They investigate the source of price discovery for Islamic Stocks listed on future markets and on spot markets with the help of panel data analysis. In their country based analysis, they find that for $63 \%$ of the countries price discovery is dominated by the spot markets.

\subsection{Methodology}

In this section, we first explain how price dynamics of the same asset/stock traded on multiple markets are modeled by an error-correction model. Then, we introduce the two workhorses of the price discovery literature which rely on the error correction model: the Information Share (IS) measure of Hasbrouck (1995) and the Permanent-Transitory (PT) measure of Harris et al. (2002a). Finally, we present the panel versions of these measures that have been introduced by Karabiyik et al (2018).

\subsubsection{Error Correction Model}

The price discovery literature assumes that in the long-run a single asset traded on different markets shares a common equilibrium price. The equilibrium price is also called the efficient price. In the short-run, market frictions such as transaction costs and asymmetric information lead to deviations from the equilibrium price. Market prices of the same stock traded on different markets are assumed to be driven by information related to the common efficient price of the stock. In statistical terms, this implies that prices are cointegrated. 
Let $p_{i, t}=\left[p_{1, i, t}, \ldots, p_{j, i, t} \ldots, p_{q, i, t}\right]^{\prime}$ denote $q \times 1$ vector of prices of stock $i$, where $p_{j, i, t}$ represents the price in market $j$ of stock $i$ at time $t$. Assume that we observe a sample of $N$ stocks, that are traded on $q$ markets over a time period of $T$, so that $j=1, . ., q ; i=1, \ldots N ; t=0, \ldots T$. We estimate an error correction model for each stock in which dimension is determined by $q$, markets. Panel data measures of price discovery are based on the estimation of these $N$ models.

A cointegrating system for the price of stock $i$ can be expressed by the following vector error correction model (VECM):

$$
\Delta p_{i, t}=\alpha_{i} \beta_{i}^{\prime} p_{i, t-1}+\sum_{\ell=1}^{k} A_{i, \ell} \Delta p_{i, t-\ell}+\epsilon_{i, t}
$$

where $\Delta p_{i, t}$ is a $q \times 1$ vector of first differences of the prices of stock $i . \alpha_{i}$, the speed of adjustment, and $\beta_{i}$, the cointegrating vectors, are $q \times r$ matrices and $A_{i, \ell}$ is a $q \times q$ matrix of coefficients of the short-run dynamics for the $\ell^{\text {th }}$ lag order. The initial values, $p_{i, 0}$, are assumed to be fixed and $\epsilon_{i, t}$ is a $q \times 1$ vector of stationary zero mean errors. The detailed assumptions on the parameters and the error process of this model can be found in Karabiyik et al. (2018). The first term on the right-hand side of equation (4.1) stands for the longrun dynamics between different markets while the second term stands for the short-run dynamics in each market.

In this setup, the cointegration assumption imposes a restriction on the matrix of cointegrating vectors $\beta_{i}$ : in case of $q$ markets, the number of cointegrating vectors, $r$, is $q-1$. Consider the VECM presentation in equation (4.1) for stock $i$ traded on two markets: Market 1 and Market 2. If two non-stationary price series, $\left(p_{1, i, t}, p_{2, i, t}\right)$ are cointegrated with a single cointegrating vector, $[1,-1]^{\prime}$, the difference between any two prices for one asset on two different markets, $p_{1, i, t}-p_{2, i, t}$, is stationary. Then, $\alpha_{i}$ becomes $2 \times 1$ matrix that measures the speed of adjustment in each market to the long-run equilibrium price of stock $i$, respectively. For two markets, the first row of equation (4.1) estimates the change in the price of stock $i$ in Market 1 by the gap between the prices of stock $i$ in both Market 1 and 2 in the previous period and the change in the price of stock $i$ in each market in the previous period. $\alpha_{1, i}$ estimates the speed at which the price of stock $i$ in Market 1 returns to the equilibrium price after a shock. The second row of equation (4.1) models the change in the price of stock $i$ in Market 2 with the long-run dynamics and short-run dynamics and $\alpha_{2, i}$ estimates the speed of adjustment in Market 2 .

In this setup, there might be $\left(\begin{array}{l}q \\ 2\end{array}\right)$ cointegrating relations. In line with Hasbrouck (1995), we assume that the difference between any two prices is stationary and one normalization assumption is sufficient for identification $\left(p_{1, i, t}\right.$ as numeraire). The cointegrating relations are considered as the price differences 
relative to $p_{1, i, t}$. In case of three markets, $\alpha_{i}$ becomes $3 \times 2$ matrix that measures the speed of adjustment in each market to the long-run equilibrium price of stock $i$ and there is not one single cointegrating vector, but two. Further assumptions are required for identification. As in Karabiyik et al. (2018), in this empirical study, we treat three markets as pairs for the price discovery process of European equities.

\subsubsection{Price discovery measures}

Rather than investigating the equilibrium price of a stock, price discovery analysis aims to investigate which markets efficiently and timely incorporate new information related to its efficient price. Changes in this information have their sources in different markets. Most of the empirical studies in the price discovery literature use two leading methods to assess the adjustment process: the Information Share (IS) measure of Hasbrouck (1995) and the Permanent-Transitory (PT) measure of Harris et al. (2002a).

Both methods are based on the parametrized VECM model in equation (4.1). The IS measure focuses on price volatility, captured by the efficient price innovations, based on the variance of $\epsilon_{i, t}$ in equation (4.1). The PT measure is a function of the speed of adjustment, $\alpha_{i}$ in equation (4.1). Both measures have their advantages and disadvantages, based on the properties of the data. However, as shown by Karabiyik et al. (2018) panel data measures of price discovery provide a uniform framework to improve the properties of the conventional IS and PT measures. We use the panel measures to assess whether, in line with empirical evidence, the price discovery process of European stocks traded on multiple markets is dominated by home markets. In the following section, we introduce technical details for both conventional IS and PT methods as well as their panel versions.

\section{Information share (IS) measure}

Hasbrouck (1995) assumes that new information related to the common efficient price is revealed by price volatility. The author suggests decomposing the total variance of the price innovations (error terms, $\epsilon_{i, t}$ in equation (4.1)) caused by the new information on shares, Information Share (IS), determined by each market. To investigate the IS measure, Hasbrouck (1995) works with the common trends representation of $p_{i, t}$. To derive this, we use the Beveridge-Nelson representation (Beveridge and Nelson (1981)) of the VECM of equation (4.1). Therefore, we rewrite equation (4.1) as

$$
p_{i, t}=\Pi_{i}(1) \sum_{s=1}^{t} \epsilon_{i, s}+\Pi_{i}^{*}(L) \epsilon_{i, t}+p_{i, 0}
$$


where $\Pi_{i}(1)$ is the sum of all moving average coefficients that represent the long-run impact of innovations and $\Pi_{i}^{*}(L)=\sum_{l=1}^{+\infty} \Pi_{i, l}^{*} L^{l}$ is the lag polynomial, which is stationary and converges to zero as $l \rightarrow \infty$. $p_{i, 0}$ is an initial price value. In line with Granger's representation theorem (Engle and Granger (1987)), the coefficients of equation (4.2) are determined by the parameters of the VECM in equation (4.1). For this, define $\Pi_{i}=\beta_{i, \perp} A_{i}^{+} \alpha_{i, \perp}^{\prime}$ with $A_{i}^{+}=\left[\alpha_{i, \perp}^{\prime} A_{i}(1) \beta_{i, \perp}\right]^{-1}$ is a scalar and $\alpha_{i, \perp}$ is the $q \times(q-1)$ orthogonal complement of $\alpha_{i}$ such that $\alpha_{i}^{\prime} \alpha_{i, \perp}=0_{(q-1) \times(q-1)}$. Under the cointegration assumption, $\beta_{i, \perp}$ is the orthogonal complement of $\beta_{i}$ satisfying $\beta_{i}^{\prime} \beta_{i, \perp}=0_{(q-1) \times 1}$, thus $\beta_{i, \perp}=\iota_{q}$, where $\iota_{q}=(1, \ldots, 1)^{\prime}$ is a $(q \times 1)$ vector of ones. Given that $\beta_{i}^{\prime} \Pi_{i}=0$, the common trends representation of the VECM in equation (4.1) is given by

$$
p_{i, t}=A_{i}^{+} \alpha_{i, \perp}^{\prime} \sum_{s=1}^{t} \epsilon_{i, s}+\Pi_{i}^{*}(L) \epsilon_{i, t}+p_{i, 0}
$$

where $\Pi_{i}(1)$ in equation (4.2) becomes $A_{i}^{+} \alpha_{i, \perp}^{\prime}$ in equation (4.3) given that $\beta_{i, \perp}=\iota_{q}$, where $\iota_{q}$ is a $(q \times 1)$ vector of ones. This long-run impact of innovations is determined by the parameters of the VECM in equation (4.1). Equation (4.3) is the basis for the calculation of the IS measure. Equation (4.3) indicates that each stock price follows a random walk. The influence of increments is represented by $A_{i}^{+} \alpha_{i, \perp}^{\prime} \epsilon_{i, t}$. The variance of the innovations in the equilibrium price is the total variance of the random walk increments of stock $i$, given by $\left(A_{i}^{+}\right)^{2} \alpha_{i, \perp}^{\prime} \Omega_{i} \alpha_{i, \perp}$ under the assumptions that $E\left(\epsilon_{i, t} \epsilon_{i, t}^{\prime}\right)=\Omega_{i}$ for all $\mathrm{t}$, where $\Omega_{i}$ is $q \times q$ positive definite matrix and $E\left(\epsilon_{i, t} \epsilon_{i, s}^{\prime}\right)=0_{q \times q}$.

Hasbrouck's IS measure decomposes $\left(A_{i}^{+}\right)^{2} \alpha_{i, \perp}^{\prime} \Omega_{i} \alpha_{i, \perp}$ into the contribution of each market's innovations to the total variance. This measure depends on $\Omega_{i}$. If $\Omega_{i}$ is diagonal, indicating that the innovations across different markets are uncorrelated, then $\left(A_{i}^{+}\right)^{2} \alpha_{i, \perp}^{\prime} \Omega_{i} \alpha_{i, \perp}$ is the sum of $q$ terms, representing the contribution from each market. Hasbrouck (1995) proposes a Cholesky decomposition of $\Omega_{i}$, thus $\Omega_{i}=C_{i} C_{i}^{\prime}$, where $C_{i}$ is a lower triangular matrix in which all the entries above the main diagonal are zero. This decomposition eliminates the correlation, assuming that $\Omega_{i}$ is diagonal. The information share of stock $i$ in market $j, I S_{i, j}$ is then given by:

$$
I S_{i, j}=\frac{\left(\alpha_{i, \perp}^{\prime} C_{i} \tau_{j}\right)^{2}}{\alpha_{i, \perp}^{\prime} \Omega_{i} \alpha_{i, \perp}}
$$

where $\tau_{j}=(0, \ldots, 0,1,0, \ldots, 0)^{\prime}$ is a $q \times 1$ selection vector with a 1 sitting in position $j$, corresponding to market $j$. The scalar, $\left(A_{i}^{+}\right)^{2}$ which appears at the denominator and numerator in equation (4.4) is canceled out. The IS measure in equation (4.4) is a ratio and the numerator stands for the variance of price innovations of asset $i$ in a particular market, market $j$, and the denominator 


\subsection{METHODOLOGY}

represents the total variance of the efficient price innovations of asset $i$.

The Cholesky decomposition helps to identify the contribution of each market to the total variance of the efficient price innovations. However, in this case the IS measure is sensitive to the ordering of the elements in $\epsilon_{i, t}$. In case of correlation between market $i$ and $j$, the IS measure for market $j$ is maximal (minimal) if $\epsilon_{i, t}^{\prime} \tau_{j}$ is the first (last) element of $\epsilon_{i, t}$. In order to overcome this, Hasbrouck (1995) suggests to calculate the upper, $I S_{U, i, j}$, and lower, $I S_{L, i, j}$, bound of the IS measure for each market and to work with the average of these upper and lower bound measures. Let $P_{U, j}\left(P_{L, j}\right)$ be a permutation matrix ${ }^{6}$ such that multiplication by a column vector leads to a column vector that has the $\mathrm{j}$-th element of the initial vector as the first (last) element and the rest are ordered as in the initial vector. Consider the case with two markets, then $\epsilon_{i, t}=\left(\epsilon_{1, i, t}, \epsilon_{2, i, t}\right)^{\prime}$ is a $2 \times 1$ matrix, $P_{U, 1} \epsilon_{i, t}=\left(\epsilon_{1, i, t}, \epsilon_{2, i, t}\right)^{\prime}$ in which Market 1 takes the first place and $P_{L, 1} \epsilon_{i, t}=\left(\epsilon_{2, i, t}, \epsilon_{1, i, t}\right)^{\prime}$ in which Market 1 takes the last place. In general notation, the upper and lower bounds of the IS measure of stock $i$ in market $j$ can be written as

$$
\begin{gathered}
I S_{U, i, j}=\frac{\left(\alpha_{i, \perp}^{\prime} P_{U, j}^{\prime} C_{i, U, j} \tau_{1}\right)^{2}}{\alpha_{i, \perp}^{\prime} \Omega_{i} \alpha_{i, \perp}} \\
I S_{L, i, j}=\frac{\left(\alpha_{i, \perp}^{\prime} P_{L, j}^{\prime} C_{i, L, j} \tau_{q}\right)^{2}}{\alpha_{i, \perp}^{\prime} \Omega_{i} \alpha_{i, \perp}}
\end{gathered}
$$

where $C_{i, U, j}\left(C_{i, L, j}\right)$ is such that $P_{U, j} \Omega_{i} P_{U, j}^{\prime}=C_{i, U, j} C_{i, U, j}^{\prime}\left(P_{L, j} \Omega_{i} P_{L, j}^{\prime}=C_{i, L, j} C_{i, L, j}^{\prime}\right)$. And its average is:

$$
I S A_{i, j}=\frac{\left(I S_{U, i, j}+I S_{L, i, j}\right)}{2}
$$

Yet there are disadvantages of the IS measure as indicated by Karabiyik et al (2018). First, the IS measure is based on a parametrized VECM which is vulnerable to estimation uncertainty compared to more parsimonious models such as in Hasbrouck (2002) and De Jong and Schotman (2010). Second, the IS measure requires some structure on the residuals and third, the Cholesky decomposition causes the measure to be sensitive of the order of markets. Note that the average of upper and lower bound of the IS measures, $I S A_{i, j}$ (equation (4.7)), was suggested as a remedy to the sensitivity issue. Finally, the standard errors of the IS measure are difficult to obtain, which makes statisti-

\footnotetext{
${ }^{6} \mathrm{~A}$ permutation matrix, $\mathrm{P}$, is a square binary matrix that has only one entry of 1 with 0s elsewhere for each row and in each column. It is nonsingular, having the determinants at $+/-1$ and $P P^{T}=I$. For instance, when $\mathrm{P}$ is multiplied with another matrix $A$ with $\mathrm{m}$ elements, then PA is formed by permuting the rows of the matrix A and AP is formed by permuting its columns.
} 
cal inference complicated. The panel version of the IS measures aims to address this point.

\section{Permanent-Transitory (PT) measure}

Given the drawbacks of the IS measure, Harris et al. (2002b) suggest using the permanent-transitory (PT) measure based on the decomposition considered in Gonzalo and Granger (1995). The PT measure tracks the contribution of each market to the permanent changes in the equilibrium price. It is constructed as a function of the market's speed of adjustment coefficients. The main advantage of the PT measure over the IS measure is the feasibility of carrying out inference on price discovery parameters. On the other hand, it is based on the same VECM as the information share measure, but less parametrized.

We start again with equation (4.3). In line with Gonzalo and Granger (1995), equation (4.3) can be expressed as the permanent-transitory decomposition. Consider two markets. Then the dimension of $\alpha_{i}$ is $2 \times 1$ and the dimension of $\alpha_{i, \perp}$ is $2 \times 1$ as well. Let $\alpha_{i}=\left(\alpha_{1, i}, \alpha_{2, i}\right)^{\prime}$ and $\alpha_{i, \perp}=\left(\alpha_{1, i, \perp}, \alpha_{2, i, \perp}\right)^{\prime}$. Now for Market 1 , equation (4.3) can be written as

$$
p_{1, i, t}=A_{i}^{+}\left[\alpha_{1, i, \perp} \sum_{s=1}^{t} \epsilon_{1, i, s}+\alpha_{2, i, \perp} \sum_{s=1}^{t} \epsilon_{2, i, s}\right]+\text { transitory part }
$$

Equation (4.8) shows that the permanent part consists of two terms, the accumulated innovations on Market 1 scaled by $\alpha_{1, i, \perp}$ and the accumulated innovations on Market 2 scaled by $\alpha_{2, i, \perp}$. The relative values of $\alpha_{1, i, \perp}$ and $\alpha_{2, i, \perp}$ determine which market efficiently and timely leads the price of stock $i$ to its new equilibrium price at time $t$ in Market 1. For instance, if $\alpha_{1, i, \perp}$ is larger than $\alpha_{2, i, \perp}$, then the price $p_{1, i, t}$ is dominated by shocks to Market 1 . Also, by definition we know that

$$
\alpha_{i}^{\prime} \alpha_{i, \perp}=\alpha_{1, i} \alpha_{1, i, \perp}+\alpha_{2, i} \alpha_{2, i, \perp}=0
$$

The relation between the weighting factors, $\left(\alpha_{1, i, \perp}, \alpha_{2, i, \perp}\right)$, and the speed of adjustments, $\left(\alpha_{1, i}, \alpha_{2, i}\right)$, depends on their magnitudes and their signs. For example, if $\left|\alpha_{1, i}\right|>\left|\alpha_{2, i}\right|$ and $\alpha_{1, i}<0<\alpha_{2, i}$, then $\alpha_{1, i, \perp}<\alpha_{2, i, \perp}$. This means that Market 2's innovations contribute more to the permanent component of prices, hence Market 2 dominates the price discovery process. In this case we say that Market 1 is a follower. Note the reverse relationship between the speed of adjustment, and the weighting factor which is the base of the PT measure. For instance, the lower the speed of adjustment $\alpha_{2, i}$, the higher the PT measure for Market 2.

In the general case, the PT measure of changes in the equilibrium price of stock 
$i$ on market $j$ is computed as follows:

$$
P T_{i, j}=\frac{\alpha_{j, i, \perp}}{\alpha_{1, i, \perp}+\ldots+\alpha_{q, i, \perp}}
$$

This ratio gives an indication of the degree of dominance of one market over the other market for stock $i$. A higher value of this ratio reflects greater feedback or contribution from market $j$. Therefore, a $P T_{i, j}$ of zero would imply that market $j$ does not contribute to the price discovery of stock $i$, whereas a $P T_{i, j}$ greater than zero implies feedback from market $j$ to the other markets.

\section{Panel versions of IS and PT measures}

Both the IS and PT measures discussed above have their advantages and disadvantages, based on the properties of the data that are investigated. The IS measure requires consistent estimation of the covariance matrix of the errors, the PT measure does not. It is not possible to derive statistical inference on the IS measure while the PT measure method overcomes this obstacle. When the correlation between different markets' innovations is high, the PT measure is more appropriate. On the other hand, the economic interpretation of the IS measure is easier as it accounts for any differences in the variance across markets. Baillie et al. (2002) argue that each measure tracks a different aspect of the price discovery process, so they are complementary, rather than substitutes. Karabiyik et al (2018) suggest a unifying panel framework to improve the properties of the conventional IS and PT measures. Considering panel measures of price discovery leads to improvements in the properties of the estimators for these measures and enables us to conduct inference on the estimated parameters.

In the previous section, we explained that the price discovery measures are functions of the VECM parameters. When we have a panel of multiple stocks traded on multiple markets, we can specify a VECM for the price of each stock (see equation (4.1)). Suppose that we have data on $N$ stocks. Then we have $N$ VECM models. Estimation of these models yields $N$ values for the $\alpha_{i}$ s. Pesaran and Smith (1995b) have shown that the simple average of these $N$ estimators is a consistent estimator for the mean of $\alpha_{i} \mathrm{~s}$. They further find that the variance of this estimator stems from the variation between the individual $\alpha_{i}$ s. For this result, the following assumption has to hold:

Assumption 1: $\quad \alpha_{i}=\alpha+\eta_{i}$ where $N^{1 / 2} \sum_{i=1}^{N}$ vec $_{i} \rightarrow_{d} N\left(0_{q(q-1) \times 1}, \Omega_{\eta}\right)$ as $N \rightarrow \infty$ and $\Omega_{\eta}$ is a $q(q-1) \times q(q-1)$ positive definite matrix satisfying $\left\|\Omega_{\eta}\right\|<\infty$.

This assumption allows $\alpha_{1}, \ldots, \alpha_{N}$ to be different but to have a constant mean and variance. Karabiyik et al (2018) use this result and propose using the 
mean-group estimator which can be formulated as

$$
\hat{\alpha}=\frac{1}{N} \sum_{i=1}^{N} \hat{\alpha}_{i}
$$

where $\hat{\alpha}_{i}$ is the OLS estimator obtained from the estimation of the individual VECM model for the $i^{\text {th }}$ stock. Combining the information from individual stocks allows us to exploit the variation in the behavior of different stock prices. This in turn enables us to carry out inference on our parameters.

In order to calculate the panel versions of the price discovery measures, we obtain the mean-group estimator, $\hat{\alpha}$, under Assumption 1 as well as the meanestimation of the covariance matrix of the errors, $\Omega$, in which we assume $N^{-1} \sum_{i=1}^{N} \Omega_{i} \rightarrow \Omega$ as $N \rightarrow \infty$. Here, $\alpha_{i, \perp}, \Omega_{i}=C_{i} C_{i}^{\prime}$ is replaced by $\alpha_{\perp}$ (the orthogonal complement of $\alpha$ ) and $\Omega=C C^{\prime}$, respectively. The panel version of the $I S_{i, j}$ (equation (4.4)) is

$$
P I S_{j}=\frac{\left(\alpha_{\perp}^{\prime} C_{j} \tau_{j}\right)^{2}}{\alpha_{\perp}^{\prime} \Omega \alpha_{\perp}}
$$

which stands for the ratio of the contribution of market $j$ 's innovations to the total variance, not for a specific stock, but for all stocks. It stands for the average contribution of market $j$ to the average total variance of all stock prices over all markets. The weakness of this measure in terms of the ordering of the markets is carried over to its panel version. In order to get the panel version of the ISA measure, we need to calculate $P I S_{U, j}$ and $P I S_{L, j}$. Consider $P_{U, j}\left(P_{L, j}\right)$, a permutation matrix, then multiplication with $\Omega$ and its transformation, $P_{U, j}^{T}\left(P_{L, j}^{T}\right)$, leads to market $j$ to be the first (last) element in the covariance matrix. In matrix notation, it is $P_{U, j} \Omega P_{U, j}^{\prime}=C_{U, j} C_{U, j}^{\prime}$. The panel versions of the $I S_{U, i, j}$ (equation (4.5)), measure is referred to as $P I S_{U, j}$ and is

$$
P I S_{U, j}=\frac{\left(\alpha_{\perp}^{\prime} P_{U, j}^{\prime} C_{U, j} \tau_{1}\right)^{2}}{\alpha_{\perp}^{\prime} \Omega \alpha_{\perp}}
$$

which stands for the average contribution of market $j$ to the average total variance of all stock prices over all markets where market $j$ is placed as the first element of the total variance. Next, consider the lower bound of the IS measure in which innovations from market $j$ is placed at the last element of the total variance, $P_{L, j} \Omega P_{L, j}^{\prime}=C_{L, j} C_{L, j}^{\prime}$. The panel version of $I S_{L, i, j}$ (equation (4.6)), 
measure is

$$
P I S_{L, j}=\frac{\left(\alpha_{\perp}^{\prime} P_{L, j}^{\prime} C_{L, j} \tau_{q}\right)^{2}}{\alpha_{\perp}^{\prime} \Omega \alpha_{\perp}}
$$

A similar interpretation holds: the average contribution of market $j$ to the average total variance of all stock prices in which market $j$ is placed as the last element of the total variance. To overcome the sensitivity of $P I S_{j}$ to the order of elements in the covariance matrix, we calculate the panel version of equation (4.7) as

$$
P I S A_{j}=\frac{P I S_{U, j}+P I S_{L, j}}{2}
$$

While the ISA measure focuses on the contribution of each market to the total variance of the efficient price innovations in terms of price volatility, the PT measure focuses on the permanent changes of the efficient price and tracks this via each market's speed of adjustments coefficients in the VECM. The panel version of $P T_{i, j}$ (equation (4.10)) is

$$
P P T_{j}=\frac{\tau_{j}^{\prime} \alpha_{\perp}}{\iota_{q}^{\prime} \alpha_{\perp}}
$$

Equation (4.16) indicates the dominance of market $j$ over the other markets. A $P P T_{j}$ of zero implies that market $j$ does not contribute to the price discovery process of the stocks. Narayan et al. (2014) and Karabiyik et al (2018) show that the cross-sectional variation of the individual PISA and PT measures is driven by the variation between $\alpha_{1}, \ldots, \alpha_{N}$. By restricting this variation, as with assumption 1, we can use this variation to find results for markets. Rather than focusing on a particular stock like most of the empirical studies in the literature, this methodology studies the behavior of the whole market: Which market dominates price discovery for all stocks?

\subsection{Data}

The aim of this study is to analyze where price discovery for European equities traded on multiple markets takes place. In the following section, we briefly elaborate on the nature of European equity markets and how we choose the stocks and market venues to be examined in this empirical study. 


\subsubsection{European stocks}

Table 4.1 summarizes the main European stock exchange groups with respect to the market capitalization. As of 2017, the London Stock Exchange Group (LSEG) is the largest European stock exchange with 2,498 listed companies (17\% of which are foreign companies) registering $€ 3.90$ trillion market capitalization of the companies along with $€ 2.04$ trillion trading volume in their stocks year-to-date. The LSEG is closely followed by the Euronext Group whose market capitalization is $€ 3.85$ trillion along with $€ 1.70$ trillion trading volume in stocks. There are 1,255 listed companies at the Euronext, $13 \%$ of which are foreign companies. It is interesting to note that the Spanish Exchange holds the highest number of companies listed, at 3,136. However, its foreign share is just $1 \%$ while the Irish Stock exchange registers the highest foreign company listing (21\%).

Each national stock exchange is operated by a particular market operator which is exclusively granted the right by the appropriate regulatory. Market operators have the absolute power to determine whether a company is eligible to be listed on the national stock exchange. Companies listed on the stock exchange are subject to listing criteria such as the number of shares that are publicly available, standards on how the financial accounts of a company should be maintained and clear rules on how company news is released to the market. For instance, the LSEG requires a company to have minimum market capitalization $(£ 700,000)$, three years of audited financial statements, minimum public float (25\%) and sufficient working capital (at least 12 months from the date of listing) in order to be listed at the LSE. We analyze the stocks listed in one particular group, the Euronext Group. The Euronext Group has the largest market capitalization and the highest trading volume in continental Europe.

Table 4.1: List of the Largest European Stock Exchanges

\begin{tabular}{|c|c|c|c|c|c|c|}
\hline \multirow[t]{2}{*}{ Indices } & \multirow{2}{*}{$\begin{array}{l}\text { Market Capitalization } \\
€ \text { Millions }\end{array}$} & \multicolumn{3}{|c|}{ Listed Companies } & \multirow[b]{2}{*}{ Foreign share } & \multirow{2}{*}{$\begin{array}{l}\text { Value of Share Trading } \\
€ \text { Millions- YTD }\end{array}$} \\
\hline & & Total & Domestic & Foreign & & \\
\hline LSEG & $3,908,253$ & 2498 & 2070 & 428 & $17 \%$ & $2,043,609$ \\
\hline Euronext Group & $3,853,504$ & 1255 & 1093 & 162 & $13 \%$ & $1,704,126$ \\
\hline Deutsche Borse AG & $1,984,406$ & 499 & 450 & 49 & $10 \%$ & $1,299,739$ \\
\hline Swiss Exchange & $1,479,383$ & 263 & 228 & 35 & $13 \%$ & 827,081 \\
\hline Nasdaq Nordic Exchanges & $1,345,173$ & 984 & 944 & 40 & $4 \%$ & 703,048 \\
\hline Irish Stock Exchange & 128,556 & 52 & 41 & 11 & $21 \%$ & 24,191 \\
\hline
\end{tabular}

Source: World Federation of Exchanges Monthly Report December 2017Excluding Investment funds and including SME MarketsLSEG: includes the London Stock Exchange and Borsa ItalianaEuronext: includes Belgium, England, France, Netherlands and PortugalNasdaq Nordic Exchanges includes the Copenhagen, Helsinki, Iceland, Stockholm, Tallinn, Riga and Vilnius stock exchanges

The Euronext Group was established in 2000 with the merger of three stock exchanges: Amsterdam, Brussels and Paris. The group acquired the Portuguese stock exchange Bolsa de Valores de Lisboa e Porto (BVLP) and renamed it as 
Euronext Lisbon in $2002^{7}$. For our research, we select 73 stocks out of 85 firms listed at the benchmark stock indices of Euronext Amsterdam (25 Dutch firms from the AEX Index), Euronext Paris (40 French firms from France CAC 40) and Euronext Brussels (20 Belgian firms from Belgium BEL 20). Price discovery analysis requires high frequency data, consisting of hourly and 10-minute transactions across different markets. Out of these 85 stocks, 73 stocks were traded hourly during the sample period. These were blue chip companies ${ }^{8}$ from 43 different sectors. Table 4.2 summarizes the firms whose stock price discoveries are examined. The total market capitalization of the selected stocks is $€ 2.5$ trillion, $63 \%$ of the total for the Euronext Group. In our analysis, we investigate the price discovery of the spot prices of stocks across different markets. Moreover, we pick stocks from the different sectors in order to represent the whole market. Rather than focusing on an individual stock, the features of the whole market can reveal more information on where price discovery takes place.

\subsubsection{European equity market places}

European equity markets consist of regulated exchange markets, Multilateral Trading Facility (MTF) and over-the-counter (OTC) equity markets ${ }^{9}$. National exchanges are registered as regulated markets while the MTFs are alternative trading venues to promote competition and to spread liquidity across multiple markets. The main difference between regulated markets and the MTFs is that the former have standard listing requirements while the MTFs do not have such requirements. The MTFs are trading venues supervised by the appropriate regulatory body and can be operated by an investment firm or a market operator. On the other hand, regulated markets are only run by market operators. Apart from differences in regulation, operating rules for these markets are the same: all the price quotas and trade volumes are public in real-time.

Figure 4.1 summarizes service providers as well as markets in Europe. Across the Europe, there are 24 regulated markets (in light color) and 20 MTFs (in darker color). Mergers and acquisitions stand out in the financial services sector. The Euronext Group consists of stock exchanges of Amsterdam, Brussels, Paris, Lisbon, London and continues to expand its pan-European model. In 2008, Nasdaq ${ }^{10}$ purchased OMX, the Swedish-Finnish financial company, which controlled 7 Nordic and Baltic stock exchanges. The London Stock Exchange (LSE) merged with Borsa Italia in 2007 and became the London Stock Exchange Group (LSEG).

\footnotetext{
${ }^{7}$ The group also acquired the Irish Stock Exchange in 2018 and the Oslo Stock Exchange in 2019 .

${ }^{8} \mathrm{~A}$ blue chip company is one that is able to generate profits in good as well as bad times (in any business cycle)

${ }^{9}$ Why equity markets matter. The Association for Financial Markets in Europe publications, December 2015.

${ }^{10}$ Nasdaq is an American stock exchange, the second-largest stock exchange in the world by market capitalization.
} 


\section{CHAPTER 4. PRICE DISCOVERY OF EUROPEAN EQUITIES TRADED ON MULTIPLE MARKETS: IS THE HOME MARKET STILL DOMINANT?}

Table 4.2: European Stocks from Euronext Amsterdam, Brussels and Paris

\begin{tabular}{|c|c|c|c|c|c|c|c|c|}
\hline \multirow{2}{*}{$\begin{array}{l}\text { September 2017-March } 2018 \\
\text { Company }\end{array}$} & \multirow[t]{2}{*}{ Euronext } & \multirow[b]{2}{*}{ Symbol } & \multirow[b]{2}{*}{ Sector } & \multirow{2}{*}{$\begin{array}{l}\text { Market Cap } \\
\text { Euro Mn }\end{array}$} & \multicolumn{4}{|c|}{ Average Daily Trading volume } \\
\hline & & & & & local market & $\mathrm{CBOE}$ & LSE & Frankfurt \\
\hline Altice N.V. Class A & A'dam & ATC-NL & Cable/Satellite TV & 10,408 & $8,542,719$ & $1,814,881$ & $1,018,039$ & 4,835 \\
\hline ASR Nederland NV & A'dam & ASRNL-NL & Multi-Line Insurance & 4,837 & 484,919 & 162,343 & 91,842 & 44 \\
\hline NN Group N.V. & A'dam & NN-NL & Life/Health Insurance & 12,069 & 974,893 & 305,978 & 152,687 & 1,121 \\
\hline Aalberts Industries N.V. & A'dam & AALB-NL & Industrial Machinery & 4,688 & 322,066 & 106,007 & 48,930 & 84 \\
\hline Gemalto N.V. & A'dam & GTO-NL & I.T.S. & 4,459 & 399,552 & 94,408 & 80,025 & - \\
\hline ArcelorMittal SA & A'dam & MT-NL & Steel & 27,655 & $5,519,575$ & $1,035,362$ & 561,234 & 51,176 \\
\hline Unilever NV Cert. of shs & A'dam & UNA-NL & Household/Personal Care & 128,604 & $4,711,960$ & $1,172,478$ & 635,660 & 33,919 \\
\hline Royal DSM NV & A'dam & DSM-NL & Food Retail & 13.914 & 722,962 & 187.646 & 106,498 & 1,469 \\
\hline Royal Dutch Shell Plc & A'dam & RDSA-MX & Integrated Oil & 127,274 & 9,987 & $2,060,282$ & 393,438 & 314,163 \\
\hline ING Groep NV & A'dam & INGA-NL & Financial Conglomerates & 59,535 & $15,557,193$ & $4,366,077$ & $1,710,862$ & 263,735 \\
\hline Heineken NV & A'dam & HEIA-NL & Beverages: Alcoholic & 49,567 & 726,293 & 196,892 & 129,757 & 1,533 \\
\hline Royal Philips NV & A'dam & PHIA-NL & Elec. Prod. Equip. & 29,358 & $3,277,217$ & 921,666 & 505,457 & 5,390 \\
\hline Royal KPN NV & A'dam & KPN-NL & Major Telecommunications & 12,195 & $14,562,439$ & $3,285,060$ & $2,227,780$ & 8 \\
\hline ASML Holding NV & A'dam & ASML-NL & Elec. Prod. Equip. & 62,036 & $1,428,572$ & 357,821 & 176,418 & 4,069 \\
\hline Royal Vopak NV & A'dam & VPK-NL & Other Transportation & 4,668 & 442.279 & 136.334 & 78,977 & 716 \\
\hline Wolters Kluwer NV & A'dam & WKL-NL & Publishing: Books/Magazines & 12,234 & 779,275 & 188,490 & 132,802 & 454 \\
\hline Akzo Nobel N.V. & A'dam & AKZA-NL & Industrial Specialties & 18,446 & 679,466 & 164,896 & 118,530 & 3 \\
\hline Roval Ahold Delhaize N.V. & A'dam & AD-NL & Food Retail & 22,508 & $6,270.951$ & $1,568,994$ & 919,678 & 19,485 \\
\hline Randstad Holding NV & A'dam & RAND-NL & Personnel Services & 9,369 & 649,978 & 156,928 & 99,636 & 679 \\
\hline Unibail-Rodamco SE & A'dam & UL-NL & Real Estate Development & 20,970 & 445,665 & 83,997 & 55,303 & 1,153 \\
\hline ABN AMRO Group N.V. & A'dam & ABN-NL & Major Banks & 25,286 & $2,062,164$ & 595,608 & 379,876 & 1,266 \\
\hline Philips Lighting NV & A'dam & LIGHT-NL & Electrical Products & 4,259 & 721.586 & 264,704 & 173,741 & 1,760 \\
\hline Galapagos NV & A'dam & GLPG-NL & Biotechnology & 4,023 & 416,210 & 47,908 & 25,535 & 4 \\
\hline Kering SA & Paris & KER-FR & Apparel/Footwear & 49,628 & 219,342 & 59,834 & 45,599 & 894 \\
\hline Carrefour SA & Paris & CA-FR & Food Retail & 13.764 & $3,367,485$ & 798,109 & 575,360 & 15,040 \\
\hline Atos SE & Paris & ATO-FR & I.T.S. & 12,755 & 364,903 & 79,355 & 67,326 & 642 \\
\hline Sanofi & Paris & SAN-FR & Pharmaceuticals: Major & 90,089 & $2,868,797$ & 665,642 & 461,924 & 32,805 \\
\hline Accor SA & Paris & AC-FR & Hotels/Resorts/Cruiselines & 12,475 & 894,330 & 274,612 & 186,210 & 865 \\
\hline STMicroelectronics NV & Paris & STM-FR & Semiconductors & 16,322 & $2,725,011$ & 779,753 & 456,500 & 6,068 \\
\hline Societe Generale S.A. & Paris & GLE-FR & Major Banks & 32,341 & $4,034,503$ & 961,830 & 559,818 & 9,178 \\
\hline Danone SA & Paris & BN-FR & Food: Major Diversified & 44,237 & $1,738,888$ & 456,358 & 287,518 & 8,686 \\
\hline AXA SA & Paris & CS-FR & Multi-Line Insurance & 58,954 & $8,337,409$ & $1,787,011$ & $1,319,110$ & 105.996 \\
\hline Peugeot SA & Paris & UG-FR & Motor Vehicles & 15,150 & $2,991,255$ & 898,966 & 614,821 & 9,425 \\
\hline Essilor International SA & Paris & EI-FR & Medical Specialties & 25,034 & 582,673 & 113,198 & 74,805 & 1,184 \\
\hline Credit Agricole SA & Paris & ACA-FR & Regional Banks & 37,673 & $6,396,250$ & $1,341,195$ & $1,066,740$ & 5,000 \\
\hline BNP Paribas SA Class A & Paris & BNP-FR & Major Banks & 77,701 & $3,867,599$ & $1,012,277$ & 665,255 & 15,648 \\
\hline C. Saint-Gobain & Paris & SGO-FR & Building Products & 25,325 & $1,919,434$ & 490,139 & 394,863 & 9,078 \\
\hline Sodexo SA & Paris & SW-FR & Misc. Comm. Services & 14,570 & 426,224 & 107,485 & 70,213 & 473 \\
\hline Legrand SA & Paris & LR-FR & Electrical Products & 17.123 & 538,912 & 151,166 & 88,474 & 311 \\
\hline ENGIE SA & Paris & ENGI-FR & Gas Distributors & 34,238 & $6,611,437$ & 986,286 & $1,218,886$ & 28,021 \\
\hline LafargeHolcim Ltd. & Paris & $\mathrm{LHN}-\mathrm{CH}$ & Construction Materials & 28,044 & $2,197,762$ & 55,242 & 201,027 & 3,605 \\
\hline TechnipFMC Plc & Paris & FTI-FR & Oilfield Services/Equipment & 12,125 & $1,600,012$ & 253,065 & 182,782 & 528 \\
\hline Bouygues SA & Paris & EN-FR & Engineering \& Construction & 15,855 & 879,031 & 224,149 & 166,889 & 1,072 \\
\hline Air Liquide SA & Paris & AI-FR & Chemicals: Specialty & 44,828 & $1,015,971$ & 180,802 & 156,468 & 2,381 \\
\hline Airbus SE & Paris & AIR-FR & Aerospace \& Defense & 64,277 & $1,905,010$ & 539,200 & 356,928 & 132,673 \\
\hline L'Oreal SA & Paris & OR-FR & Household/Personal Care & 103.525 & 644,488 & 129,362 & 97,989 & 2,450 \\
\hline LVMH & Paris & MC-FR & Apparel/Footwear & 123,378 & 665,831 & 138,180 & 95,784 & 4,332 \\
\hline Safran S.A. & Paris & SAF-FR & Aerospace \& Defense & 35,162 & 981.937 & 288,386 & 175,654 & 1,069 \\
\hline Capgemini SE & Paris & CAP-FR & I.T.S. & 16,593 & 510,728 & 150,252 & 122,431 & 639 \\
\hline Publicis Groupe SA & Paris & PUB-FR & Advertising/Marketing Services & 12,820 & 751,553 & 221,001 & 180,770 & - \\
\hline Michelin SCA & Paris & ML-FR & Automotive Aftermarket & 21,462 & 561,027 & 157,688 & 104,251 & 588 \\
\hline Pernod Ricard SA & Paris & RI-FR & Beverages: Alcoholic & 30,960 & 447,118 & 118,463 & 109,281 & 224 \\
\hline Renault SA & Paris & RNO-FR & Motor Vehicles & 24,276 & $1,058,036$ & 332,247 & 207,019 & 9,242 \\
\hline VINCI SA & Paris & DG-FR & Engineering \& Construction & 47,250 & $1,369,783$ & 300,557 & 201,600 & 5,207 \\
\hline Solvay SA & Paris & SOLB-BE & Chemicals: Specialty & 11,975 & 288,302 & $\# \mathrm{~N} / \mathrm{A}$ & 38,845 & 894 \\
\hline Schneider Electric SE & Paris & SU-FR & Electrical Products & 39,509 & $1,529,172$ & 365,394 & 229,343 & 3,913 \\
\hline Vivendi SA & Paris & VIV-FR & Movies/Entertainment & 28,174 & $4,669,362$ & $1,055,315$ & 876,602 & 18,532 \\
\hline Total SA & Paris & FP-FR & Integrated Oil & 116,062 & $6,545,340$ & $1,631,568$ & 944,091 & 49,674 \\
\hline Valeo SA & Paris & FR-FR & Auto Parts: OEM & 14,816 & 930,535 & 276,451 & 173,920 & 1,143 \\
\hline Aperam SA & Brussels & APAM-NL & Steel & 3,662 & 352,771 & 106,806 & 74,018 & 2 \\
\hline bpost SA & Brussels & BPOST-BE & Misc. Comm. Services & 5,077 & 667,204 & 157,923 & 81,083 & 1,841 \\
\hline Ablynx nv & Brussels & ABLX-BE & Biotechnology & 1,548 & 483,589 & 75,514 & 84,038 & 4 \\
\hline Ontex Group N.V. & Brussels & ONTEX-BE & Household/Personal Care & 2,241 & 291,835 & 76,565 & 48,423 & 213 \\
\hline Proximus SA & Brussels & PROX-BE & Major Telecommunications & 8,824 & 674,053 & 169,511 & 70,164 & 368 \\
\hline ageas $\mathrm{SA} / \mathrm{NV}$ & Brussels & AGS-BE & Multi-Line Insurance & 8,103 & 711,310 & 169,490 & 80,704 & 544 \\
\hline G.B. Lambert SA & Brussels & GBLB-BE & Construction Materials & 14,011 & 184,623 & 37,337 & $\# \mathrm{~N} / \mathrm{A}$ & 274 \\
\hline Franz Colruyt & Brussels & COLR-BE & Food Retail & 6.702 & 264.605 & 52,233 & 21,265 & 127 \\
\hline Ackermans\&van Haaren NV & Brussels & ACKB-BE & Engineering \& Construction & 4,809 & 32,336 & 5,213 & 1,978 & 1 \\
\hline Solvay SA & Brussels & SOLB-BE & Chemicals: Specialty & 11,975 & 288,302 & 49,774 & 38,845 & 256 \\
\hline Anheuser-Busch & Brussels & ABI-BE & Beverages: Alcoholic & 180,085 & $1,965,330$ & 561,757 & 235,861 & 15,967 \\
\hline KBC Groupe SA & Brussels & $\mathrm{KBC}-\mathrm{BE}$ & Regional Banks & 29,762 & 728,550 & 233,365 & 108,667 & 595 \\
\hline Cofinimmo SA & Brussels & COFB-BE & Real Estate Development & 2,339 & 34,628 & 10,244 & $\# \mathrm{~N} / \mathrm{A}$ & 16 \\
\hline Umicore & Brussels & UMI-BE & Other Metals/Minerals & 8,660 & 980,139 & 57,345 & 112,644 & 5,163 \\
\hline
\end{tabular}

Source: FactSet, June 2018.

C. Saint-Gobain- Compagnie de Saint-Gobain SA;LVMH-LVMH Moet Hennessy Louis Vuitton SE; Michelin SCA-Compagnie Generale des Etablissements Michelin SCA \& Paris ; G.B. Lambert- Groupe Bruxelles Lambert SA; Franz Colruyt-Etablissementen Franz Colruyt N.V. ; Anheuser-Busch- Anheuser-Busch InBev SA/NV; I.T.S.-Information Technology Services"; E.P.E.- Electronic Production Equipment; Misc. Comm.

Services-Miscellaneous Commercial Services. 
Figure 4.1: European trading market venues, 2014

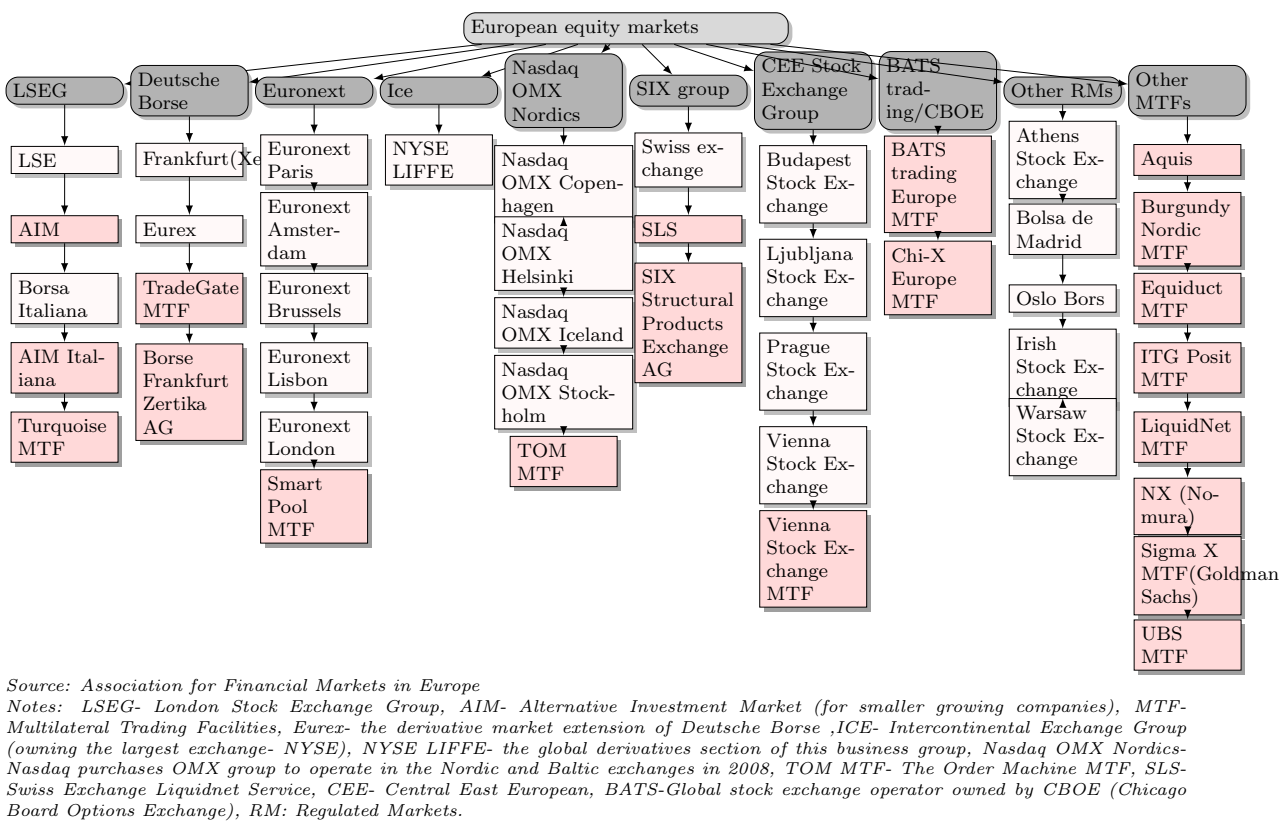

Multinational finance service corporations such as the ICE Group (Intercontinental Exchange owning the largest stock exchange (NYSE)), Nasdaq as well as CBOE (Chicago Board Option Exchange) have become active in the MTFs. New MTFs compete with existing trade venues like national exchanges in the region. Existing national stock exchanges such as Deutsche Borse and the Euronext Group also offer MTF services. Deutsche Borse remains national while the Euronext Group continues to expand its pan-European model via mergers and acquiring other national stock exchanges.

There are certain criteria to be fulfilled to study the price discovery process. The first is accessibility on the spot: markets need to be open to trading at the same time. The second is public information on pricing: all price quotas and trade volumes from these markets must be public in real-time. Finally, frequent transactions: active trading is needed to generate transaction prices on the spot at a high frequency, for example every hour and every 10 minutes.

The last three columns in Table 4.2 present the most active trading market venues for the selected Euronext stocks along with their home market: ChiX Europe MTF operated by the CBOE and Turquoise MTF operated by the LSEG and Frankfurt Stock Exchange. Frankfurt Stock Exchange is a national exchange and has the highest trade volume among all national exchanges in the EU. The effects of the European Commission's intention to improve financial integration are felt as trading activities in financial assets have spread across the EU. But, trading in the equity markets is still home-biased, mostly taking place 
in the home markets, for example, Euronext Amsterdam for Dutch securities. The largest trading volume still takes place in the home market, but the MTFs operated by the CBOE and by the LSEG have gained a considerable share of the trading ${ }^{11}$.

Within the European Monetary Union, what market is considered as the home market? We refer to the local/home market as the market in which the stocks have primary listings. This is one where a firm is listed to be public for the first time and also the market persistently with the highest volume of trading. We analyze selected stocks from the Euronext Group traded on three market venues: the local market (Euronext), Chi-X Europe MTF operated by the CBOE and Turquoise MTF operated by the LSEG.

\subsection{Empirical results}

We use the intra-day data of the stock prices of 73 firms over the time period 01/09/2017 - 29/03/2018 (see Table 4.2). The interval of hours within a day is 09:00 - 16:00. We analyze two frequencies: hourly data and 10 minute data. For the 10 minute data, we work with 55 firms since for some stocks there are no realized prices for the 10 minute frequency. We work with the logarithm of prices to smooth statistical properties such as high volatility of stock prices.

We start our empirical investigation with a preliminary analysis of cross-sectional dependence and panel time series properties of all series. Section 4.6.1 discusses the cross-sectional dependence tests while section 4.6.1 explores panel time series properties of the data and the presence of cointegration across the prices. Finally, section 4.6 .2 presents the panel measures of the conventional IS and PT measures.

\subsubsection{Cross-sectional dependence, unit root and cointegration tests}

\section{Cross-sectional dependence tests}

Common shocks such as oil price changes and fluctuations in global risk appetite affect asset prices. Pesaran (2007b) shows that the presence of crosssectional dependence in panel analysis due to common factors causes inaccurate estimates and misleading inference. We first investigate the cross-sectional properties of our data set before proceeding with the estimations. In case of the cross-sectional dependence, we proceed the analysis after extracting the dependence.

\footnotetext{
${ }^{11}$ Note that the British-Dutch oil company Royal Dutch Shell has a primary listing on the London Stock Exchange and secondary listings on Euronext Amsterdam and New York Stock Exchange and is also traded on the MTFs. In terms of trading volume, alternative venues register the highest volume for Shell.
} 
We examine the cross-sectional dependence by calculating the average crosssectional correlation coefficients for the prices of different stocks on each market. This value is obtained by

$$
\hat{\gamma}=\frac{1}{N(N-1)} \sum_{i=1}^{N-1} \sum_{j=i+1}^{N} \hat{\gamma}_{i, j}
$$

where

$$
\hat{\gamma}_{i, j}=\left(\sum_{t=1}^{T} p_{i, t}^{2}\right)^{-1 / 2}\left(\sum_{t=1}^{T} p_{j, t}^{2}\right)^{-1 / 2} \sum_{t=1}^{T} p_{i, t} p_{j, t}
$$

and where $i$ and $j$ are stocks. $\hat{\gamma}_{i, j}$ measures the cross-sectional correlation between stock $i$ and $j$ on a specific market. Next, we calculate $\hat{\gamma}$, which gives an indication about the average cross-sectional dependence across the logarithm of the original prices in the panel. The results are reported in Table 4.8 in the appendix. The "Not demeaned" section of this table gives the results for the levels of the logarithms of the original prices (hourly data) in the three markets. We find that $\hat{\gamma}$ is approximately equal to 0.5 for all markets. This suggests high levels of cross-sectional correlation. We also calculate $\hat{\gamma}$ for the first differences of the data in order to eliminate the effects of potential nonstationarity in the prices and find that the correlation varies between $0.12-0.14$. An average of approximately $13 \%$ suggests a moderate level of cross-sectional dependence. One way to correct for the presence of cross-sectional dependence is to consider demeaned prices which are defined as

$$
\tilde{p}_{i, t}=p_{i, t}-\frac{1}{N} \sum_{i=1}^{N} p_{i, t}
$$

where $\tilde{p}_{i, t}$ is a cross-sectionally demeaned price at time t. The second term on the right-hand side is the cross-sectional mean which is calculated by the sum of all asset prices at time $t$ divided by the number of assets. This mean is a proxy for the cross-sectional dependence that affects all prices ${ }^{12}$. However, cross-sectional demeaning can remove the dependence up to a certain extent. To see to which extent, we calculate $\hat{\gamma}$ for the cross-sectionally demeaned prices. The results are listed in the "Demeaned" panel of Table 4.8. The average pairwise correlation drops to approximately 0.00 for the crosssectionally demeaned data. This implies that, as expected, cross-sectional de-

\footnotetext{
${ }^{12}$ Suppose that the cross-sectional mean of stock prices is 80 at time $t$. During a bullish market, all prices are up and the mean increases, say to 100 in the next period. A change of 20 in each stock price is attributed to this common upward trend. The difference between a stock price and the cross-sectional mean at any time reveals individual stock price development.
} 
meaning eliminates cross-sectional dependence. In the remaining part of this chapter, cross-sectionally demeaned data are used for the estimation of price discovery parameters as well as cointegration tests. For the robustness check, we report the results for panel unit root tests for both not-demeaned and demeaned data.

\section{Panel unit root and cointegration tests}

The price discovery analysis is based on two assumptions: individual asset prices on each market follow a unit root process and the prices of each asset across different markets are bound by its own common efficient price, thus they are cointegrated. In this section we test for these assumptions and we investigate the unit root and cointegration properties of our data set. We consider three tests for testing unit roots: the test developed by Moon and Perron (2004) which is robust to cross-sectional dependence, IPS test of Im et al. (2003) which allows for heterogeneity across panel units and the CIPS test of Pesaran (2007b) ${ }^{13}$ which considers cross-sectional dependence.

\section{Panel unit root tests}

Moon and Perron (2004) consider the unit root tests that are robust to general forms of cross-sectional dependence and have no assumptions on the relative magnitude of $\mathrm{N}$ and $\mathrm{T}$. They allow for cross-sectional correlation and assume that there is a dynamic factor structure that generates this cross-sectional dependence. They start with the idea that an asset price can be expressed as

$$
p_{i, t}=\rho_{i} p_{i, t-1}+u_{i, t}
$$

where

$$
u_{i, t}=\lambda_{i}^{\prime} f_{t}+e_{i, t}
$$

Here $f_{t}$ is an $r \times 1$ vector of unobserved common factors. $\lambda_{i}$ is an $r \times 1$ vector of factors, $r$ is the number of factors that are affecting the panel. The idea behind the Moon and Perron (2004) test is to eliminate the common components of the series and then use defactored data that allow for more than one common factor. The null hypothesis is the existence of a unit root, $\mathcal{H}_{0}: \rho_{i}=1$ for all $i=1,2 \ldots N$ against the heterogeneous alternative, $\mathcal{H}_{a}:\left|\rho_{i}\right|<1$ for some $i$. Moon and Perron (2004) show that as $N$ and $T \rightarrow \infty$, with $N / T \rightarrow 0$, the unit root test statistics, $t_{a}^{*}$ and $t_{b}^{*}$, have a limiting standard normal distribution under the null hypothesis. However, under the alternative hypothesis they have a different distribution. The Moon and Perron unit root test results are presented in Table 4.9 in the appendix. We consider the model with fixed

\footnotetext{
${ }^{13}$ Pesaran (2007) suggest the cross-sectionally augmented version of Im, Pesaran and Shin $(1997,2003)$ IPS test, CIPS thereafter.
} 
effects only and the model with fixed effects and trend. We report the results for the cases with $r=1$ factor, $r=2$ factors and $r=3$ factors. The results in Table 4.9 show that the estimated $\rho,(\hat{\rho})$, is approximately equal to 1 for all cases and for all markets. The test statistics do not reject the null hypothesis of a unit root even at $1 \%$ significance level since all values are below the critical value of 2.58 . The only exception is for the cross-sectionally demeaned prices in local markets for the case with fixed effects and trend and $r=3$.

The second and the third unit root tests that we consider are the IPS and CIPS tests ${ }^{14}$. The IPS test was developed by Im et al. (2003). They propose a unit root test for dynamic heterogeneous panels. The test is based on the mean of the individual augmented Dickey-Fuller statistics. They consider the model

$$
\Delta p_{i, t}=\alpha_{i}+\phi_{i} p_{i, t-1}+u_{i, t}
$$

where $\Delta p_{i, t}=p_{i, t}-p_{i, t-1}$ and $\phi_{i}=-\left(1-\rho_{i}\right)$. Equation (4.21) is further augmented with the lagged first differences of $p_{i, t}$ up to a certain lag level for possible alternative models. The null hypothesis of unit roots becomes $\mathcal{H}_{0}: \phi_{i}=0$ for all $i^{15}$. The CIPS test is a variant of the IPS test in which crosssectional dependence is taken into account and the model and the estimators are modified accordingly. This test was proposed by Pesaran (2007b) and extended to a multifactor error structure by Pesaran et al. (2013). Both the IPS test and the CIPS test follow nonstandard distributions ${ }^{16}$. The critical values are reported in Table 4.3 for our sample.

Table 4.3: Critical values of IPS and CIPS tests for $\mathrm{N}=73$ and $\mathrm{T}=1716$

\begin{tabular}{l|r|r|r|r}
\hline \hline & & $1 \%$ & $5 \%$ & $10 \%$ \\
\hline \multirow{2}{*}{ IPS } & Intercept only & -1.73 & -1.67 & -1.64 \\
& Intercept and trend & -2.36 & -2.44 & -2.28 \\
\hline \multirow{2}{*}{ CIPS } & Intercept only & -2.21 & -2.10 & -2.04 \\
& Intercept and trend & -2.67 & -2.59 & -2.54 \\
\hline \hline
\end{tabular}

Notes: IPS critical values are taken from Im et al. (2003), CIPS critical values are taken from Pesaran (2007b).

We report the results of our tests in Table 4.10 in the appendix. We report the estimated auto-regressive coefficients, $\rho_{i}$. We consider three different lag specifications. In Table $4.10, \ell_{1}$ corresponds to a lag order of $1, \ell_{2}$ corresponds

\footnotetext{
${ }^{14}$ Compared with Moon and Perron (2004) tests, these two tests assume the joint asymptotics, $N, T \rightarrow \infty$, jointly and sequential asymptotics, $N \rightarrow \infty$, then $T \rightarrow \infty$.

${ }^{15}$ Note that $\phi_{i}=0$ is equivalent to $\rho_{i}=1$ for all $i$ in equation (4.19)

${ }^{16}$ The finite sample critical values for the test statistics are given in the corresponding papers.
} 
to a lag order $\left\lfloor\left(\frac{2 T}{100}\right)^{2 / 9}\right\rfloor$, where $\lfloor x\rfloor$ indicates the highest integer value that is smaller than $x$. For example, for $T=1716$ (hourly data), the lag order is 2 . Finally, $\ell_{3}$ corresponds to a lag order that is selected by the Akaike Information Criterion (AIC). We consider the case with intercepts only and the case with an intercept and a trend. Furthermore, we obtain the CIPS and IPS test results for the cross-sectionally not-demeaned data and the demeaned data. These different specifications aim to check for the robustness of our conclusions about the unit root properties of the prices. In all cases, the estimated autoregressive coefficient $\left(\hat{\rho}_{i}\right)$ is approximately equal to 0.99 . The IPS tests on the raw data indicate the severity of not taking into account the cross-sectional dependence in the panel data. The IPS test results for the not-demeaned data (with specification of intercept only) conclude the rejection of the null hypothesis of unit roots: the $t$-statistics across different lag orders (the fourth column, the upper part in Table 4.10) are higher than the critical value of -1.64 at $10 \%$ significance level. The prices on each market do not follow unit roots. However, we conclude to opposite results with the CIPS statistics for the not-demeaned data in which the tests incorporate cross-sectional dependence. For the demeaned data, both the CIPS and IPS indicate the existence of unit roots. The CIPS test results for both model specifications (only intercepts and intercepts \& time trends) across different lag orders fail to reject the null hypothesis. This allows us to conclude that the prices follow a unit root in all markets.

The analysis is conducted on the price levels. If the prices follow unit root process, then their first differences are stationary. To test for this stationarity, we compute the coefficient estimates and $t$-statistics for the first differences. The results are reported in Table 4.11 and Table 4.12 in the appendix. The coefficient estimates for the first differences are close to zero and the null hypothesis of a unit root for the first differences is strictly rejected.

\section{Cointegration tests}

Given that the prices of assets follow a unit root process, the next step is to check whether prices of each asset across different markets converge to their own efficient price in the long-run. Therefore, we need to investigate the cointegration properties of bi-market prices before proceeding with estimating the price discovery parameters. For this purpose we consider the market pairs: (i) Local and CBOE, (ii) Local and LSEG (London), (iii) London and CBOE. We investigate the cointegration relation between these market pairs. The statistical method we use for this purpose was developed by Westerlund (2007). The two tests developed in Westerlund (2007) are residual based tests. The null hypothesis is "no cointegration". To formulate the residual based cointegration tests, consider the following cointegrating regression for market pairs of prices:

$$
p_{1, i, t}=\beta_{i} p_{2, i, t}+e_{i, t}
$$

In the previous section, we have concluded that the prices are nonstationary. If 
$p_{1, i, t}$ and $p_{2, i, t}$ are cointegrated with the cointegrating vector $\left(1,-\beta_{i}\right)$ then the error term of the cointegrating regression must be stationary. Residual based tests use this property and test for a unit root in the residuals of the cointegration regression. A unit root in these residuals means there is no cointegration between $p_{1, i, t}$ and $p_{2, i, t}$. So the test regression is

$$
\hat{e}_{i, t}=\delta_{i} \hat{e}_{i, t-1}+u_{i, t}
$$

where $\hat{e}_{i, t}$ are the error terms from equation (4.22) with $\mathcal{H}_{0}: \delta_{i}=1$. Westerlund (2007) proposes two variance ratio test statistics for $\delta_{i}$. The first test statistic, $v r_{g}$ restricts $\delta_{i}$ to be equal to a $\delta$ for each asset $i$, the second test statistic, $v r_{p}$, allows for heterogeneity in $\delta_{i}$. This test does not incorporate cross-sectional dependence, hence we need to use this test on the cross-sectionally demeaned data. All reported statistics have standard normal distributions. The test statistic results are reported in Table 4.4. We list the results for 60 minute and 10 minute frequency data. We check whether the results are robust to the choice of no (linear) trend or a (linear) trend in the cointegrating relation. For all specifications, for all frequencies and for all market pairs, the null hypothesis of no cointegration is rejected. Therefore, we conclude that the prices of each asset across different markets converge to the same price, its own efficient price in the long-run.

Table 4.4: Cointegration test results.

\begin{tabular}{l|l|l|r|r|r|r}
\hline \hline & & & 60 minutes & \multicolumn{2}{|c}{10 minutes } \\
\hline \multirow{2}{*}{ Demeaned } & \multirow{2}{*}{ No trend } & Pairs & $v r_{g}$ & $v r_{p}$ & $v r_{g}$ & $v r_{p}$ \\
\cline { 3 - 6 } & & Local \& CBOE & -3.402 & -5.958 & -4.72 & -5.948 \\
& & Local \& London & -2.990 & -6.021 & -9.731 & -8.886 \\
& \multirow{2}{*}{ Trend } & London \& CBOE & -11.186 & -8.837 & -10.754 & -9.556 \\
\hline & & Local \& CBOE & -3.253 & 7.403 & -6.313 & 7.459 \\
& & Local \& London & -3.473 & 7.312 & -12.935 & -9.255 \\
& & London \& CBOE & -14.984 & -11.821 & -13.528 & -12.84 \\
\hline \hline
\end{tabular}

Notes: $v r_{g}$ (homogeneous) and $v r_{p}$ (heterogeneous) refers to the tests of panel cointegration suggested by Westerlund (2007), following a standard normal distribution. Pairs tell between which market we are testing for a cointegrating relation. At $10 \%$ the critical value is 1.64 , at $5 \%$, the critical value is 1.96 and at $1 \%$ it is 2.58 . As all tests are one-sided, a calculated statistic (in absolute terms) larger than the critical value leads to the rejection of the null hypothesis of no cointegration. 


\subsubsection{Estimation of price discovery parameters}

\section{$V E C M$ and the speed of adjustment}

The main contribution of this empirical study is to analyze price discovery for $N$ assets. The panel framework allows to combine the information from each asset to improve the statistical inference. However, pooling the information requires some commonality to exploit. We introduce this commonality by restricting the variation of the speed of the adjustment coefficients, $\alpha_{i}$, see Assumption 1. We are concerned about the price discovery which is determined by $\alpha_{1}, \alpha_{2}, \ldots, \alpha_{N}$ in equation (4.3). To estimate the panel measure of price discovery, we first investigate the statistical significance of the speed of adjustment coefficients.

Based on cointegration relations, we consider three market pairs for the price discovery process of European equities: (i) Local and CBOE, (ii) Local and London, (iii) London and CBOE. As we have discussed in section 4.4, both measures, PIS (PISA) and PPT, depend on the estimated speed of adjustment coefficients $\left(\alpha_{1}, \alpha_{2}\right)$ of the long-run dynamics in an error correction model, equation (4.3). We first estimate the error correction model and focus on the estimated speed of adjustment coefficients for each market.

To this end, we estimate the following models for our market pairs

$$
\begin{aligned}
& \left.\Delta p_{1, i, t}=\alpha_{1, i}\left(p_{1, i, t-1}-p_{2, i, t-1}\right)+A_{11, i} \Delta p_{1, i, t-1}+A_{12, i} \Delta p_{2, i, t-1}+\xi 4, i, i 4\right) \\
& \left.\Delta p_{2, i, t}=\alpha_{2, i}\left(p_{1, i, t-1}-p_{2, i, t-1}\right)+A_{21, i} \Delta p_{1, i, t-1}+A_{22, i} \Delta p_{2, i, t-1}+\notin 4, i, 25\right)
\end{aligned}
$$

This is a standard VECM presentation for asset $i$ traded on Market 1 and Market 2 . The changes in asset prices in each market are affected by their long-run dynamics as well as their short-run dynamics. Equation (4.24) models that the change in the price of asset $i$ in Market 1 is related to the gap between the prices of asset $i$ in both Market 1 and 2 in the previous period as well as to the change in the price of asset $i$ in each market in the previous period. $\alpha_{1, i}$ estimates the speed at which the price of asset $i$ in Market 1 returns to the equilibrium price after a shock.

According to the terminology of the cointegration theory, the differences between the prices across markets are deviations from the long-run equilibrium. However, one needs to be careful in interpreting this. The counterpart of the term "long-run equilibrium" in price discovery analysis is "fair price". The differences between the prices are actually deviations from the fair price. Consequently, the "speed of adjustment parameter", $\alpha_{j},,_{i}$ gives the speed at which the prices are adjusting back to the the fair price level. Consider equation (4.24) and suppose we have $\left(p_{1, i, t-1}-p_{2, i, t-1}\right)>0$ : this means that the actual value of $p_{1, i}$ was greater than its fair price in the previous period. If the error correction continues, then $p_{1, i}$ should fall, declining towards the fair price. Consider 
$\left(p_{1, i, t-1}-p_{2, i, t-1}\right)<0$ : this means that the actual value of $p_{1, i}$ was less than its fair price in the previous period. Then, $p_{1, i}$ should increase, heading towards the equilibrium. With this notation in which Market 1 is placed at the first position in the VECM, we expect $\alpha_{1, i}$ to be negative. For equation (4.25), exactly the opposite argument is valid, thus we expect $\alpha_{2, i}$ to be positive. Furthermore, we assume that $\alpha_{1, i}$ and $\alpha_{2, i}$ have fixed mean group estimators, $\alpha_{1}$ and $\alpha_{2}$ which are obtained by:

$$
\hat{\alpha}_{j}=\frac{1}{N} \sum_{i=1}^{N} \hat{\alpha}_{j, i}
$$

where $\hat{\alpha}_{j, i}$ is the OLS estimator obtained from the ECM models (equation (4.24) and (4.25)) for $j=1,2$. We also calculate the $t$-values for the test of the significance of the error correction term in the error correction models. Finally, we report "STD", the standard deviation of the firm specific error correction parameters which is defined as

$$
S T D_{j}=\sqrt{\frac{1}{N-1} \sum_{i=1}^{N}\left(\hat{\alpha}_{j, i}-\hat{\alpha}_{j}\right)^{2}}
$$

We report this value as an indicator of the variation of the speed of adjustment coefficient across firms. A sufficient amount of variation is necessary for $\hat{\alpha}_{j}$ to be a valid estimator for the mean of the speed of adjustment coefficients.

Table 4.5: Mean group estimation results for $\alpha_{1}$ and $\alpha_{2}$.

\begin{tabular}{l|l|r|r|r|r|r|r}
\hline \hline & & $\hat{\alpha}_{1}$ & $S T D_{1}$ & $t$-statistic & $\hat{\alpha}_{2}$ & $S T D_{2}$ & $t$-statistic \\
\hline \multirow{3}{*}{60 minutes } & Local \& CBOE & -0.488 & 0.193 & -21.584 & 0.026 & 0.071 & 3.096 \\
& Local \& London & -0.490 & 0.193 & -21.714 & 0.027 & 0.068 & 3.340 \\
& London \& CBOE & -0.783 & 0.589 & -11.354 & 0.243 & 0.546 & 3.795 \\
\hline \multirow{2}{*}{10 minutes } & Local \& CBOE & -0.172 & 0.039 & -32.990 & 0.004 & 0.012 & 2.245 \\
& Local \& London & -0.172 & 0.039 & -32.797 & 0.005 & 0.013 & 3.005 \\
& London \& CBOE & -0.756 & 0.168 & -33.396 & 0.091 & 0.147 & 4.599 \\
\hline \hline
\end{tabular}

Notes: $\hat{\alpha}_{1}$ and $\hat{\alpha}_{2}$ are the mean group estimators of $\alpha_{1}$ and $\alpha_{2}$, respectively. "ST $D_{j}$ " refers to the standard deviation of the firm-specific error correction parameters that make up $\hat{\alpha}_{j}$, for $j=1,2$. The reported $t$-tests test the null hypothesis that there is no error correction. At $10 \%$ the critical value is 1.64 , at $5 \%$, the critical value is 1.96 and at $1 \%$ it is 2.58 .

Table 4.5 summarizes the mean group estimators $\left(\hat{\alpha}_{1}, \hat{\alpha}_{2}\right)$, their standard deviations and t-statistics for each market pair for two different data frequencies. The first market pair that we investigate is the Local Market - CBOE pair. 
Estimation of the VECM equation (4.24) - (4.25) model for this pair yields $\hat{\alpha}_{\text {local }}=-0.488$ and $\hat{\alpha}_{C B O E}=0.026$. Both coefficient estimates are highly significant. By looking at the $S T D$ results we see that there is enough variation among the speed of adjustment coefficient estimates across stocks, this confirms the validity of our estimators. These results confirm that the prices in the local market are cointegrated with the prices of the CBOE market. A value of -0.488 for the speed of adjustment coefficient implies that any deviation of the prices in the local market from the fair price adjusts back in approximately two periods, corresponding to two hours in our sample. For the adjustment process in the CBOE market, the coefficients (0.026) are positive, but smaller. This means that the adjustment process of the prices in the CBOE markets to the fair price takes longer. These conclusions are for the 60 minute frequency prices. As a robustness check we report the results for 10 minute frequency prices. In this case we have $\hat{\alpha}_{\text {local }}=-0.172$ and $\hat{\alpha}_{C B O E}=0.004$. Both coefficient estimates are significant. These findings are in accordance with the previous findings for the 60 minute prices. However, the decline in the magnitude of the coefficients, from -0.488 to -0.172 , is due to switching to higher frequency data. Any deviation of the prices in the local markets from the fair price adjusts back in approximately five periods, corresponding to 50 minutes for this frequency, which is still lower than two hour adjustment period with the 60 minute data. The second market pair that we investigate is the Local Market - LSEG (London) pair. The VECM estimation of this pair yields $\hat{\alpha}_{\text {local }}=-0.490$ and $\hat{\alpha}_{\text {London }}=0.027$. Both coefficient estimates are highly significant. Having $\hat{\alpha}_{\text {local }}$ equal to -0.490 is expected as the estimation of the Local Market - CBOE pair gives approximately the same result and the interpretation of $\alpha_{\text {local }}$ is the same in both cases. So, this implies that any deviation of the prices in the local market from the fair price adjusts back in approximately two hours. Furthermore, $\hat{\alpha}_{\text {London }}=0.027$ implies that the prices in London go very slowly back to the fair price over time, similar to the prices in the CBOE market. Using higher frequency data yields similar results for the markets' dominance in the price discovery process.

Finally, we comment on the results for the third market pair, London - CBOE, which are two main MTFs for the European equities. Estimation of the VECM (4.24) - (4.25) model for this pair yields $\hat{\alpha}_{\text {London }}=-0.783$ and $\hat{\alpha}_{C B O E}=0.243$. Both coefficient estimates are highly significant despite the fact that the standard deviation of the individual coefficient estimates is higher. The result that $\hat{\alpha}_{\text {London }}=-0.783$ implies that the prices in London adjusts to the fair price faster than the prices in the CBOE market and the result that $\hat{\alpha}_{C B O E}=0.243$ means that the prices in the CBOE move back to the fair price longer compared to London. The results for the 10 minute frequency prices are in line with the previous analysis: both coefficient estimates are statistically significant and their signs are as expected. This concludes our investigation of the statistical significance of the speed of adjustment coefficients for the markets. We proceed with estimating the panel measures of price discovery for European equities traded on multiple markets. 


\section{Price discovery parameters}

Having interpreted the estimation results for the ECM models in (4.24) - (4.25), we can move on to the price discovery parameter estimation results. In line with Karabiyik et al (2018), we estimate panel measures of price discovery parameters, (see equations (4.12), equation (4.15) and (4.16)). We report the estimates of three different measures: PIS, PISA and PPT. In order to assess the validity of the PIS measures, we report the estimated residual correlations for all market pairs in Table 4.6. The last column of this table shows that correlations between the residuals of the first pair (Local and CBOE) and the second pair (Local and London) are both around 0.3. This is a moderate value and might validate the PIS measure. The correlation between the residuals of the third pair (London and CBOE) is, however, is around 0.85, which is substantial. These high correlations results imply that the PISA measure should be preferred to the PIS measure and the PPT measure over the PISA measure.

Table 4.6: Estimated residual correlation structure.

\begin{tabular}{l|l|r|r|r|r}
\hline \hline & & $\hat{\Omega}_{11}$ & $\hat{\Omega}_{22}$ & $\hat{\Omega}_{12}$ & CORR \\
\hline \multirow{3}{6}{60 minutes } & Local \& CBOE & 0.018 & 0.011 & 0.004 & 0.291 \\
& Local \& London & 0.018 & 0.011 & 0.004 & 0.292 \\
& London \& CBOE & 0.012 & 0.011 & 0.010 & 0.849 \\
\hline \multirow{2}{*}{10 minutes } & Local \& CBOE & 0.002 & 0.002 & 0.001 & 0.313 \\
& Local \& London & 0.002 & 0.002 & 0.001 & 0.305 \\
& London \& CBOE & 0.002 & 0.002 & 0.002 & 0.979 \\
\hline \hline
\end{tabular}

Notes: $\hat{\Omega}$ is obtained as the estimated covariance matrix of the VECM residuals, where $\hat{\Omega}_{11}$ $\left(\hat{\Omega}_{22}\right)$ denote the estimated variance of the first market (second market). $\hat{\Omega}_{12}$ is the covariance between the two markets. "CORR" refers to the correlation between the residuals.

Table 4.7 summarizes the price discovery parameters' estimates of each market pair for the 60 minute as well as the 10 minute data set. The PIS (Local) stands for the average contribution of the local market to the average total variance of all stock prices. A higher value of this ratio reflects a greater contribution from the local market. Recall from Section 4.4 that since the PIS measure relies on the Cholesky decomposition of the error covariance matrix, this measure is sensitive to the ordering of the markets. In addition, in case of high correlation among the errors of the VECM across markets, the PISA performs better than the PIS. The PPT (Local) indicates the dominance of the local market over other market. A PPT (Local) of 1 implies that only the local market contributes to the price discovery process. We also check the statistical significance of the PPT measure.

We first comment on the results obtained by using hourly data for the local 
market and the CBOE market on the first row. The PIS measure gives more discovery power to the $\mathrm{CBOE}$ and leaves the local market out of the discovery process, with a price discovery effect that is not significantly different from zero. However, given the residual correlation results we discussed above, we believe that it is safer to use the PISA measure, which is estimated to be equal to $93.6 \%$ for the CBOE and $6.4 \%$ for the local market, both significant. The PPT measure implies that $95.0 \%$ of the price discovery occurs in the CBOE, whereas the $5.0 \%$ of the price discovery occurs in the local market. Both markets contribute to the discovery of the efficient price since their estimates are highly significant. However, the CBOE dominates the discovery process. The 10 minute frequency results are in accordance with these results. The PISA measure is $94.5 \%$ for the CBOE and $5.5 \%$ for local markets, both significantly different from zero. The PPT measure in this case is higher, $97.9 \%$ for the CBOE and $2.1 \%$ for the local markets. Overall, these results can be summarized as follows. The CBOE, as an away market, substantially dominates the price discovery process. The local markets still contribute to this process but with a really small share, roughly around $5 \%$. 
Table 4.7: PIS, PISA and PPT estimation results.

\begin{tabular}{|c|c|c|c|c|c|c|c|}
\hline & & $P \hat{I} S$ & $t$ & $\hat{P I S A}$ & $t$ & $P \hat{P} T$ & $t$ \\
\hline & & \multicolumn{6}{|c|}{ Local \& CBOE } \\
\hline \multirow[t]{9}{*}{60 minutes } & Local & 0.005 & 1.47 & 0.064 & 7.57 & 0.050 & 3.09 \\
\hline & $\mathrm{CBOE}$ & 0.995 & 311.21 & 0.936 & 110.68 & 0.950 & 58.80 \\
\hline & & \multicolumn{6}{|c|}{ Local \& London } \\
\hline & Local & 0.005 & 1.59 & 0.065 & 8.00 & 0.051 & 3.33 \\
\hline & London & 0.995 & 316.23 & 0.935 & 114.70 & 0.949 & 61.50 \\
\hline & & \multicolumn{6}{|c|}{ London \& CBOE } \\
\hline & London & 0.099 & 1.62 & 0.426 & 23.36 & 0.237 & 3.82 \\
\hline & $\mathrm{CBOE}$ & 0.901 & 14.76 & 0.575 & 31.54 & 0.763 & 12.34 \\
\hline & & \multicolumn{6}{|c|}{ Local \& CBOE } \\
\hline \multirow[t]{8}{*}{10 minutes } & Local & 0.001 & 1.11 & 0.056 & 17.16 & 0.021 & 2.27 \\
\hline & $\mathrm{CBOE}$ & 1.000 & 212.58 & 0.944 & 290.64 & 0.979 & 104.40 \\
\hline & & \multicolumn{6}{|c|}{ Local \& London } \\
\hline & Local & 0.001 & 1.49 & 0.056 & 15.96 & 0.030 & 3.07 \\
\hline & London & 0.999 & 142.49 & 0.944 & 267.21 & 0.970 & 99.30 \\
\hline & & \multicolumn{6}{|c|}{ London \& CBOE } \\
\hline & London & 0.014 & 2.22 & 0.484 & 541.21 & 0.107 & 4.91 \\
\hline & $\mathrm{CBOE}$ & 0.986 & 156.41 & 0.516 & 577.94 & 0.893 & 40.79 \\
\hline
\end{tabular}

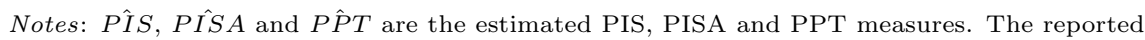
$t$ is the test statistic for the null hypothesis of no price discovery in the corresponding market and following standard normal distribution. At $10 \%$ the critical value is 1.64 , at $5 \%$, the critical value is 1.96 and at $1 \%$ it is 2.58. As all tests are one-sided, a calculated statistic larger than the critical value leads to the rejection of the null hypoithesis of no price discovery.

Next, we consider the local market and the LSEG (London). The results are similar to the case for local market and the CBOE. The results show that price discovery occurs in both markets with the LSEG having a substantially larger share than the local markets. This result and the result for the local market - CBOE pair, show that pan-European equity markets dominate the home markets for stocks.

When we investigate the price discovery process in two pan-European equity markets, the CBOE and the LSEG, we obtain interesting results. First thing to note is the contrast with the analysis of local - pan-European market pairs: The PPT measures are substantially different from the PIS and PISA measures. Secondly, the higher frequency price data, 10 minute prices in our study, affect the estimation results considerably. Third, the PIS measure estimates are materially different from the PISA measure estimates. This was expected due to the high level of correlation between the residuals of the two markets. The 
PPT measure estimates obtained by using hourly data suggest that $76.3 \%$ of the price discovery occurs in the CBOE market and $23.7 \%$ of the price discovery occurs in the LSEG. The dominance of the CBOE is more pronounced and increases up to $89.3 \%$, in the estimates for 10 minute frequency data. Given the high level of correlation between the residuals of these markets, we refrain from commenting on the PIS results as they can be assumed to be invalid. Compared to the PPT estimates, PISA indicate less dominance for the CBOE. Using hourly data, the CBOE dominates the price discovery process by $57.5 \%$. Using 10 minute frequency data, the PISA of the CBOE drops to 51.6\%. Both PPT and PISA measures are highly significant.

The overall conclusion is threefold. First, pan-European markets contribute to the price discovery process more than the local markets. Second, between the two pan-European markets, the CBOE seems to contribute more to the price discovery process than the LSEG. This difference is more pronounced with the PPT measure. The results allow us to conclude that the CBOE has the biggest share in the adjustment process to the fair price followed by the LSEG. Finally, the local markets have the smallest share. Third, our results are robust to different frequencies. This can be seen from the similarities in the results obtained by using hourly data and 10 minute data. The findings are consistent with previous empirical evidence, showing that both the home market and the foreign markets contribute to the price discovery process (Eun and Sabherwal (2003), Frijns et al. (2015)).

\subsection{Conclusion}

In this chapter we study where the price discovery of European stocks traded on multiple markets takes place. Price discovery is defined as the adjustment process of each market venue after new information related to the fundamental price of a stock has appeared on the market. It is well documented in the empirical finance literature that the home market dominates the price discovery process due to its larger trade volume and greater analyst coverage of stocks. However, we argue that there are some gaps in the empirical literature and aim to fill in these gaps. Empirical studies are mainly centered on US markets, focus on two markets and adopt the asset-by-asset approach. We study the competitiveness of European equity markets for European stocks by estimating the price discovery process via panel modeling. We investigate the intra-day adjustment of the price discovery for 73 Euronext stocks traded in three markets over the period September 2017 to March 2018. We contribute to the existing literature in terms of market settings and methodology. First, we study price discovery for more than two market venues. Secondly, we focus on the competitiveness of European stock exchange markets in terms of price discovery for European firms, rather than internationally listed companies in the US market. Finally, rather than tracking the price discovery of European stocks individually, panel data modeling allows us to focus on the behavior of 


\subsection{CONCLUSION}

the markets to assess the competitiveness of European equity markets.

We find that the pan-European equity markets operated by the CBOE and the LSEG contribute more to the price discovery process than the home market. Among the two pan-European markets, the CBOE contributes to the price discovery process more than the LSEG. These findings allow us to conclude that the $\mathrm{CBOE}$ has the biggest share in the price adjustment process. The home market has the smallest share. Finally, we obtain the same results by using higher frequency, 10 minute data. With these findings, we contribute to the literature by showing that the mainstream consensus on the dominance of the home market in price discovery does not hold for our sample. In the case of European equities, the introduction of MTFs not only spread trading volume across the markets in the European Union but also shifted the price discovery dominance. Moreover, the MTFs have increased competition and put pressure on existing national stock exchanges in the Eurozone.

Our results raise the question of what the implications are of the pan-European markets being dominant in the price discovery process. Pan-European markets seem to be better at processing information. Regulators aim to spread equity trading across the markets in the Union in order to improve financial integration. When they succeed in this, the price discovery dominance also shifts away from the home markets. Moreover, the MTFs have increased competition and put pressure on existing regulated markets to improve their services.

National stock exchange markets consider price discovery as a measure of the relative efficiency and competitiveness between markets, affecting trading activity. Increased competition has reduced their trade volume. National stock exchange markets seem to be reluctant to modify their business models while non-European based multinational corporations are more active in alternative trading markets. Finally, from traders' perspective, our findings indicate that the MTFs lead the home market and information is processed immediately at alternative markets. 


\subsection{Appendices}

\subsubsection{Pairwise correlation coefficients}

Table 4.8: Average pairwise correlation coefficients- Equation (4.17)

\begin{tabular}{l|r|r|r|r}
\hline \hline \multirow{2}{*}{ Not demeaned } & & $\hat{\gamma}$ & $C D$ & $L M$ \\
& Local & 0.500 & 1877.667 & 45454.552 \\
& CBOE & 0.500 & 1877.600 & 45451.313 \\
& London & 0.500 & 1877.597 & 45451.155 \\
& $\Delta$ Local & 0.128 & 480.273 & 3681.851 \\
& $\Delta$ CBOE & 0.134 & 503.244 & 4040.058 \\
& $\Delta$ London & 0.132 & 496.604 & 3937.936 \\
\hline \multirow{2}{*}{ Lemeaned } & Local & -0.006 & -23.760 & 40284.183 \\
& CBOE & -0.006 & -22.734 & 38637.682 \\
& London & -0.006 & -23.256 & 39508.009 \\
& $\Delta$ Local & -0.004 & -14.749 & 451.686 \\
& $\Delta$ CBOE & -0.002 & -8.611 & 465.767 \\
& $\Delta$ London & -0.002 & -6.512 & 469.617 \\
\hline \hline
\end{tabular}

Notes: $\hat{\gamma}$ refers to the average pairwise correlation coefficients defined in Pesaran 2004. ' $C D$ refers to the cross-sectional dependence test statistic defined in Pesaran 2004. See Chapter 3 for the full formula. $L M$ is the Lagrange multiplier test statistic considered by Baltagi et al. (2012). "Demeaned" refers to cross-sectionally demeaned data. The results are for the hourly prices. $\mathrm{CD} \sim \mathrm{N}(0,1)$ and $\mathrm{LM}$ is distributed as $\chi^{2}$. 


\subsection{APPENDICES}

\subsubsection{Panel unit root tests}

Table 4.9: Moon and Perron unit root test results for levels- Equation (4.21)

\begin{tabular}{|c|c|c|c|c|c|c|c|c|}
\hline & & & \multicolumn{3}{|c|}{ fixed effects only } & \multicolumn{3}{|c|}{ fixed effects and trend } \\
\hline & \# of factors & Market & $\hat{\rho}$ & $t_{a}^{*}$ & $t_{b}^{*}$ & $\hat{\rho}$ & $t_{a}^{*}$ & $t_{b}^{*}$ \\
\hline \multirow[t]{9}{*}{ Not demeaned } & \multirow[t]{3}{*}{1} & Local & 1.000 & -0.095 & -1.391 & 1.000 & 0.597 & 0.645 \\
\hline & & $\mathrm{CBOE}$ & 1.000 & 0.040 & 0.766 & 1.000 & 0.481 & 0.536 \\
\hline & & London & 1.000 & 0.010 & 0.188 & 1.000 & 0.490 & 0.532 \\
\hline & \multirow[t]{3}{*}{2} & Local & 1.000 & 0.025 & 0.362 & 1.000 & 0.894 & 0.988 \\
\hline & & $\mathrm{CBOE}$ & 1.000 & -0.035 & -0.480 & 1.000 & 0.653 & 0.720 \\
\hline & & London & 1.000 & -0.094 & -1.475 & 1.000 & 0.526 & 0.567 \\
\hline & \multirow[t]{3}{*}{3} & Local & 1.000 & -0.048 & -0.746 & 1.000 & 1.459 & 1.463 \\
\hline & & $\mathrm{CBOE}$ & 1.000 & 0.049 & 0.712 & 1.000 & 1.031 & 1.158 \\
\hline & & London & 1.000 & 0.048 & 0.701 & 1.000 & 1.233 & 1.364 \\
\hline \multirow[t]{9}{*}{ Demeaned } & \multirow[t]{3}{*}{1} & Local & 1.000 & 0.147 & 1.233 & 1.000 & 0.557 & 0.609 \\
\hline & & $\mathrm{CBOE}$ & 1.000 & 0.058 & 0.455 & 1.000 & 0.541 & 0.592 \\
\hline & & London & 1.000 & 0.049 & 0.377 & 1.000 & 0.572 & 0.608 \\
\hline & \multirow[t]{3}{*}{2} & Local & 1.000 & 0.022 & 0.194 & 1.000 & 0.849 & 0.843 \\
\hline & & $\mathrm{CBOE}$ & 1.000 & 0.169 & 1.427 & 1.000 & 0.768 & 0.853 \\
\hline & & London & 1.000 & 0.177 & 1.497 & 1.000 & 0.952 & 1.041 \\
\hline & \multirow[t]{3}{*}{3} & Local & 1.000 & 0.035 & 0.321 & 1.001 & 3.492 & 3.356 \\
\hline & & $\mathrm{CBOE}$ & 1.000 & 0.042 & 0.368 & 1.000 & 1.263 & 1.266 \\
\hline & & London & 1.000 & 0.055 & 0.483 & 1.000 & 1.522 & 1.509 \\
\hline
\end{tabular}

Notes: $t_{a}^{*}$ and $t_{b}^{*}$ are the unit root test statistics of Moon and Perron (2004), both have standard normal asymptotic distributions. " $\hat{\rho}$ " is the pooled OLS estimator of the AR(1). At $10 \%$ the critical value is 1.64 , at $5 \%$, the critical value is 1.96 and at $1 \%$ it is 2.58 . As all tests are one-sided, a calculated statistic (in absolute terms) larger than the critical value leads to the rejection of the null hypothesis of a unit root. 
CHAPTER 4. PRICE DISCOVERY OF EUROPEAN EQUITIES TRADED ON MULTIPLE MARKETS: IS THE HOME MARKET STILL

DOMINANT?

Table 4.10: CIPS and IPS unit root test results for levels- Equation (4.21)

\begin{tabular}{|c|c|c|c|c|c|c|c|c|c|c|}
\hline & \multirow[b]{2}{*}{ Lag } & \multirow[b]{2}{*}{ Market } & \multicolumn{4}{|c|}{ only intercepts } & \multicolumn{4}{|c|}{ intercepts and time trends } \\
\hline & & & $\hat{\rho}_{\text {cips }}$ & CIPS & $\hat{\rho}_{i p s}$ & IPS & $\hat{\rho}_{\text {cips }}$ & CIPS & $\hat{\rho}_{i p s}$ & IPS \\
\hline \multirow[t]{9}{*}{ Not demeaned } & \multirow[t]{3}{*}{$\ell_{1}$} & Local & 0.994 & -1.676 & 0.994 & -2.264 & 0.991 & -2.358 & 0.989 & -0.344 \\
\hline & & CBOE & 0.994 & -1.682 & 0.994 & -2.353 & 0.991 & -2.357 & 0.989 & -0.380 \\
\hline & & London & 0.994 & -1.682 & 0.994 & -2.353 & 0.991 & -2.357 & 0.989 & -0.380 \\
\hline & \multirow[t]{3}{*}{$\ell_{2}$} & Local & 0.994 & -1.659 & 0.994 & -2.149 & 0.991 & -2.340 & 0.989 & -0.076 \\
\hline & & CBOE & 0.994 & -1.666 & 0.994 & -2.236 & 0.991 & -2.344 & 0.989 & -0.135 \\
\hline & & London & 0.994 & -1.666 & 0.994 & -2.236 & 0.991 & -2.344 & 0.989 & -0.135 \\
\hline & \multirow[t]{3}{*}{$\ell_{3}$} & Local & 0.994 & -1.719 & 0.994 & -2.551 & 0.991 & -2.419 & 0.989 & -0.709 \\
\hline & & CBOE & 0.994 & -1.722 & 0.994 & -2.623 & 0.991 & -2.409 & 0.989 & -0.736 \\
\hline & & London & 0.994 & -1.722 & 0.994 & -2.623 & 0.991 & -2.409 & 0.989 & -0.736 \\
\hline \multirow[t]{9}{*}{ Demeaned } & \multirow[t]{3}{*}{$\ell_{1}$} & Local & 0.995 & -1.599 & 0.995 & -0.831 & 0.990 & -2.202 & 0.990 & -0.470 \\
\hline & & CBOE & 0.995 & -1.584 & 0.995 & -0.857 & 0.990 & -2.184 & 0.990 & -0.430 \\
\hline & & London & 0.995 & -1.584 & 0.995 & -0.857 & 0.990 & -2.184 & 0.990 & -0.430 \\
\hline & \multirow[t]{3}{*}{$\ell_{2}$} & Local & 0.995 & -1.589 & 0.995 & -0.668 & 0.990 & -2.189 & 0.990 & -0.169 \\
\hline & & CBOE & 0.995 & -1.592 & 0.995 & -0.729 & 0.990 & -2.195 & 0.990 & -0.205 \\
\hline & & London & 0.995 & -1.592 & 0.995 & -0.729 & 0.990 & -2.195 & 0.990 & -0.205 \\
\hline & \multirow[t]{3}{*}{$\ell_{3}$} & Local & 0.995 & -1.645 & 0.995 & -1.118 & 0.990 & -2.267 & 0.990 & -1.015 \\
\hline & & $\mathrm{CBOE}$ & 0.995 & -1.649 & 0.995 & -1.167 & 0.990 & -2.266 & 0.990 & -0.951 \\
\hline & & London & 0.995 & -1.649 & 0.995 & -1.167 & 0.990 & -2.266 & 0.990 & -0.951 \\
\hline
\end{tabular}

Notes: CIPS and IPS are the unit root test statistics of Pesaran (2004) and Im et al. (2003), both have standard normal asymptotic distributions. "AR coeff" is the pooled OLS estimator of the $\operatorname{AR}(1)$. 


\subsection{APPENDICES}

Table 4.11: Moon and Perron unit root test results for first differences- Equation $(4.21)$

\begin{tabular}{|c|c|c|c|c|c|c|c|c|}
\hline & & & \multicolumn{3}{|c|}{ Without trend } & \multicolumn{3}{|c|}{ With trend } \\
\hline & \# of factors & Market & $\hat{\rho}$ & $t_{a}$ & $t_{b}$ & $\hat{\rho}$ & $t_{a}$ & $t_{b}$ \\
\hline \multirow[t]{9}{*}{ Not demeaned } & \multirow[t]{3}{*}{1} & Local & 0.008 & -3915.0 & -161.2 & 0.508 & -1426.1 & -160.8 \\
\hline & & CBOE & -0.012 & -3785.5 & -156.2 & 0.486 & -1411.1 & -159.6 \\
\hline & & London & -0.011 & -3596.5 & -147.8 & 0.491 & -1327.5 & -149.5 \\
\hline & \multirow[t]{3}{*}{2} & Local & 0.008 & -4472.3 & -185.0 & 0.504 & -1641.5 & -185.9 \\
\hline & & CBOE & -0.012 & -3878.8 & -160.2 & 0.485 & -1450.7 & -164.2 \\
\hline & & London & -0.011 & -3789.5 & -156.7 & 0.485 & -1415.3 & -160.4 \\
\hline & \multirow[t]{3}{*}{3} & Local & 0.008 & -5196.0 & -216.7 & 0.497 & -1927.5 & -219.9 \\
\hline & & CBOE & -0.012 & -4687.6 & -193.3 & 0.486 & -1752.0 & -198.0 \\
\hline & & London & -0.011 & -4709.1 & -194.6 & 0.485 & -1765.7 & -200.0 \\
\hline \multirow[t]{9}{*}{ Demeaned } & \multirow[t]{3}{*}{1} & Local & 0.008 & -4512.3 & -186.6 & 0.503 & -1656.6 & -187.6 \\
\hline & & CBOE & -0.012 & -3878.1 & -160.1 & 0.486 & -1448.5 & -163.9 \\
\hline & & London & -0.009 & -3559.2 & -147.1 & 0.487 & -1328.3 & -150.4 \\
\hline & \multirow[t]{3}{*}{2} & Local & 0.008 & -5282.0 & -220.2 & 0.496 & -1959.2 & -223.4 \\
\hline & & $\mathrm{CBOE}$ & -0.012 & -4703.2 & -194.0 & 0.487 & -1754.2 & -198.2 \\
\hline & & London & -0.010 & -4732.9 & -195.7 & 0.486 & -1773.4 & -200.9 \\
\hline & \multirow[t]{3}{*}{3} & Local & 0.008 & -6071.8 & -254.0 & 0.493 & -2268.7 & -259.7 \\
\hline & & CBOE & -0.012 & -5467.6 & -226.9 & 0.482 & -2048.1 & -232.6 \\
\hline & & London & -0.009 & -5462.9 & -227.4 & 0.481 & -2053.4 & -233.9 \\
\hline
\end{tabular}

Notes: See the notes under Table 4.9 . 
CHAPTER 4. PRICE DISCOVERY OF EUROPEAN EQUITIES TRADED ON MULTIPLE MARKETS: IS THE HOME MARKET STILL

DOMINANT?

Table 4.12: CIPS and IPS unit root test results for first differences- Equation $(4.21)$

\begin{tabular}{|c|c|c|c|c|c|c|c|c|c|c|}
\hline & \multirow[b]{2}{*}{ Lag } & \multirow[b]{2}{*}{ Market } & \multicolumn{4}{|c|}{ Without trend } & \multicolumn{4}{|c|}{ With trend } \\
\hline & & & $\hat{\rho}_{\text {cips }}$ & CIPS & $\hat{\rho}_{\text {ips }}$ & IPS & $\hat{\rho}_{\text {cips }}$ & CIPS & $\hat{\rho}_{i p s}$ & IPS \\
\hline \multirow[t]{9}{*}{ Demeaned } & \multirow[t]{3}{*}{$\ell_{1}$} & Local & -0.040 & -24.7 & -0.034 & -237.4 & -0.042 & -24.8 & -0.035 & -255.2 \\
\hline & & CBOE & -0.041 & -24.7 & -0.034 & -237.8 & -0.043 & -24.8 & -0.035 & -255.5 \\
\hline & & London & -0.041 & -24.7 & -0.034 & -237.8 & -0.043 & -24.8 & -0.035 & -255.5 \\
\hline & \multirow[t]{3}{*}{$\ell_{2}$} & Local & -0.022 & -17.2 & -0.032 & -157.8 & -0.025 & -17.3 & -0.034 & -167.3 \\
\hline & & CBOE & -0.019 & -17.2 & -0.027 & -157.4 & -0.022 & -17.2 & -0.029 & -166.9 \\
\hline & & London & -0.019 & -17.2 & -0.027 & -157.4 & -0.022 & -17.2 & -0.029 & -166.9 \\
\hline & \multirow[t]{3}{*}{$\ell_{3}$} & Local & -0.023 & -35.2 & -0.025 & -333.8 & -0.024 & -35.2 & -0.025 & -361.5 \\
\hline & & CBOE & -0.020 & -35.1 & -0.024 & -329.7 & -0.021 & -35.1 & -0.024 & -356.9 \\
\hline & & London & -0.020 & -35.1 & -0.024 & -329.7 & -0.021 & -35.1 & -0.024 & -356.9 \\
\hline \multirow[t]{9}{*}{ Not demeaned } & \multirow[t]{3}{*}{$\ell_{1}$} & Local & -0.035 & -24.7 & -0.034 & -235.4 & -0.036 & -24.8 & -0.035 & -252.7 \\
\hline & & CBOE & -0.034 & -24.8 & -0.034 & -235.4 & -0.035 & -24.8 & -0.035 & -252.7 \\
\hline & & London & -0.034 & -24.8 & -0.034 & -235.4 & -0.035 & -24.8 & -0.035 & -252.7 \\
\hline & \multirow[t]{3}{*}{$\ell_{2}$} & Local & -0.033 & -17.2 & -0.031 & -159.3 & -0.035 & -17.3 & -0.034 & -168.8 \\
\hline & & $\mathrm{CBOE}$ & -0.027 & -17.2 & -0.028 & -158.7 & -0.030 & -17.2 & -0.030 & -168.2 \\
\hline & & London & -0.027 & -17.2 & -0.028 & -158.7 & -0.030 & -17.2 & -0.030 & -168.2 \\
\hline & \multirow[t]{3}{*}{$\ell_{3}$} & Local & -0.028 & -35.1 & -0.024 & -337.1 & -0.028 & -35.1 & -0.024 & -365.0 \\
\hline & & $\mathrm{CBOE}$ & -0.024 & -35.1 & -0.023 & -335.3 & -0.024 & -35.1 & -0.023 & -363.0 \\
\hline & & London & -0.024 & -35.1 & -0.023 & -335.3 & -0.024 & -35.1 & -0.023 & -363.0 \\
\hline
\end{tabular}

Notes: See the notes under Table 4.10. 


\section{Chapter 5}

\section{Summary and conclusions}

This dissertation examines the price determination and price movements in government bonds and equity markets within the EMU. We use a panel modeling approach. Most empirical studies boil down to either time series analysis or cross-sectional analysis, depending on the question at hand. Each method of analysis has its own pros and cons. Panel modeling aims to improve estimation by combining both types of analysis. In this thesis, we report the results of three empirical studies, each employing relevant tools from the panel framework to gain more insight in the price determination and price movements of the financial assets within the union.

In Chapter 2, we examine the main drivers of long-run government borrowing cost differentials among EMU members and how the introduction of the EMU and the financial crisis in 2008 have had an impact on bond pricing. The results of our study suggest that the differential government debt ratio, differential economic growth rates, liquidity and governance quality significantly explain the sovereign yield spreads. We identify a significant positive effect for the differential government debt ratio and a significant negative effect for relative economic growth rates. The more liquid the public bond markets are, the lower the liquidity risk premiums. A positive market perception of governance effectiveness reduces sovereign yield spreads. Moreover, the non-linear dynamic panel estimates indicate that markets seemed to have ignored country-specific economic fundamentals after the emergence of the EMU while the markets revalued these risk factors after the 2008 financial crisis. We also investigate whether the relations between the main drivers and bond yield spreads change with membership of the EMU. The results show that markets price fiscal indebtedness higher among EMU members than among non-EMU members. Finally, the results of the dynamic panel model are robust to different estimation techniques and to sample selection. 


\section{CHAPTER 5. SUMMARY AND CONCLUSIONS}

The main implication of this study for policy makers is to keep prioritizing fiscal responsibility while introducing structural reforms to boost economic growth in the long-run. As the European Commission prioritizes investment, fiscal responsibility and structural reforms, promoting economic growth via reforms can thus reduce borrowing costs. Structural reforms refer to changes in the way an economy works. For instance, addressing the challenges facing the welfare state such as an aging population, introducing more flexible labor markets, a simpler and fairer tax system can improve the overall business environment. Regarding fiscal responsibility, regulation to keep the debt stock ratio at a certain level or at least avoiding upward momentum in the public debt ratio is vital for strengthening the currency union. Finally, the perception of whether the government will implement policies that support the private sector is also important in shaping the trend of long-term borrowing cost differentials. This relation is captured via the governance indicator which measures government effectiveness in terms of its ability to implement policies that boost private sector development. The countries that have postponed taking such actions due to social and political opposition are likely to face higher risk premiums in the bond markets in the future.

Chapter 3 studies the spatial interdependence of sovereign yield spreads. First, we establish the long-run relation between the domestic sovereign yield spreads (defined as the difference between the long-run interest rate on a domestic sovereign bond and the long-run interest rate for a US bond) and the countryspecific risks such as exchange rate, default and liquidity risks. In the secondstep, we investigate the interdependence of yield spreads after extracting the country-specific risks and common factors from the domestic yield spreads. To investigate the presence of interdependence, we fit a spatial autoregressive (SAR) model in the residuals from the first-step. Regarding country-specific risks, the short-run policy rate spreads as well as relative real GDP growth rates are the main economic fundamentals that determine the long-run sovereign spreads. Consequently, when domestic short-run yields are higher than the US monetary policy stance, this leads to an increase in the domestic long-run sovereign borrowing cost differentials. Higher economic growth has a negative relationship with yield spreads. Among EMU members, the budget balance ratio differentials and relative real GDP growth rates turn out to be statistically significant for explaining yield spreads. Budget balance ratios that are higher than the US fiscal outlook lead to a decrease in the domestic long-term sovereign yield spreads. This finding indicates the importance of fiscal responsibility within a common currency union. Regarding interdependence, we find a highly significant spatial dependence in the sovereign yield spreads. This implies that the domestic yield spreads are affected by the spreads of foreign countries. Regarding transmission channels, economic connections between countries shape spatial dependence. Economic distance measured by trade volume shows the highest estimated degree of spatial dependence, followed by FDI flows and cross bank lending while geographical distance turns out to be insignificant for spatial dependence. 
On the policy implications side, detecting spatial dependence can have serious implications for EMU members. The debate on common European bonds receives public attention from time to time, and the evidence in this study supports the pro-camp. The key point is that the importance of interdependence is detected after extracting the country-specific risks and common factors. Even if each member country takes care of their fiscal responsibility individually, they are still vulnerable during a financial distress period due to spatial dependence. Introducing a common bond market can be one way to go to reduce this vulnerability. For instance, in a market structure similar to the US government bond market with federal and state levels, pan-European bond markets would make individual bonds more liquid and easier to trade, especially during a financial distress period. However, there are several strong arguments against pan-European bonds. First, a common bond contradicts the no-bail out principle which is essential to strengthening fiscal discipline in the Union. Second, burden sharing can lead to possible additional costs for the triple-A rated members. Nevertheless, while the political and fiscal integration of the EMU has a long way to go, a pan-European bond market can be another way of supporting the monetary integration of the union.

Chapter 4 takes a closer look at the competitiveness of European equity markets for European stocks within the price discovery context, to figure out whether the home market still dominates the price adjustment process. We find that pan-European equity markets, the CBOE and the LSEG, contribute to the price discovery process more than the local markets. Among the two panEuropean markets, the CBOE seems to dominate the process compared to the LSEG. Thus, the CBEO registers the biggest share in the determination of the fair price followed by the LSEG and the local markets. We find a decline in the importance of home markets during the process. Pan-European markets seem to be better at processing information. The introduction of pan-European markets not only spreads trading volume across the markets in the union but also shifts price discovery dominance. Policy makers aim to spread the trade volume in equity markets across the Union to improve financial integration. A decline in the home market dominance in the price discovery process seems to be by-product of these policies. Moreover, Multilateral Trading Facility (MTFs) have increased competition and put pressure on existing regulated markets to reduce service fees. From the perspective of national exchange markets, increasing competition has reduced their market shares. On the other hand, being better at processing information is costly. From the traders' perspective, our findings indicate that the MTFs lead the home market and that information is processed immediately at alternative markets. In order to make a possible profit from trading, trading on the alternative markets could be more beneficial. 
CHAPTER 5. SUMMARY AND CONCLUSIONS 


\section{Bibliography}

Alesina, A., Broeck, M. D., Prati, A., Tabellini, G., Obstfeld, M., and Rebelo, S. (1992). Default risk on government debt in OECD countries. Economic Policy, 7(15):427-463.

Alhaj-Yaseen, Y. S., Lam, E., and Barkoulas, J. T. (2014). Price discovery for cross-listed firms with foreign IPOs. International Review of Financial Analysis, 31:80 - 87.

Amato, J. D. and Remolona, E. M. (2012). The credit spread puzzle. Financial Market Research, (3):15-20.

Anselin, L., Le Gallo, J., and Jayet, H. (2008). Spatial panel econometrics. Springer, Berlin.

Ardagna, S., Caselli, F., and Lane, T. (2004). Fiscal discipline and the cost of public debt service: Some estimates for OECD countries. National Bureau of Economic Research, Working paper(10788).

Arellano, M. and Bond, S. (1991). Some tests of specification for panel data: Monte carlo evidence and an application to employment equations. Review of Economic Studies, 58(2):277-97.

Arellano, M. and Bover, O. (1995). Another look at the instrumental variable estimation of error-components models. Journal of Econometrics, 68(1):2951.

Arnold, I. and Lemmen, J. (2001). The vulnerability of banks to government default risk in the EMU. International Finance, 4(1):101-25.

Bae, K.-H., Karolyi, G. A., and Stulz, R. M. (2003). A new approach to measuring financial contagion. Review of Financial Studies, 16(3):717-763.

Baillie, R. T., Booth, G. G., Tse, Y., and Zabotina, T. (2002). Price discovery and common factor models. Journal of Financial Markets, 5(3):309 - 321.

Balassone, F., Franco, D., and Giordano, R. (2004). Market induced discipline: Is there fall-back solution for rule-failure. Banca dItalia Mimeo. 


\section{BIBLIOGRAPHY}

Barrios, S., Iversen, P., Lewandowska, M., and Setzer, R. (2009). Determinants of intra-euro area government bond spreads during the financial crisis. European Economy - Economic Papers 388, Directorate General Economic and Monetary Affairs, European Commission.

Bayoumi, T., Goldstein, M., and Woglom, G. (1995). Do credit markets discipline sovereign borrowers? evidence from U.S. states. Journal of Money, Credit and Banking, 27(4):1046-1059.

Beine, M. and Candelon, B. (2011). Liberalisation and stock market comovement between emerging economies. Quantitative Finance, 11(2):299312.

Bernoth, K. and Erdogan, B. (2012). Sovereign bond yield spreads: A timevarying coefficient approach. Journal of International Money and Finance, $31(3): 639-656$.

Bernoth, K., von Hagen, J., and Schuknecht, L. (2012). Sovereign risk premiums in the european government bond market. Journal of International Money and Finance, 31(5):975 - 995.

Beveridge, S. and Nelson, C. R. (1981). A new approach to decomposition of economic time series into permanent and transitory components with particular attention to measurement of the 'business cycle'. Journal of Monetary Economics, 7(2):151 - 174 .

Blanco, R. (2001). The euro-area government securities markets. recent developments and implications for market functioning. Banco de España Working Papers 0120, Banco de España.

Blasques, F., Koopman, S. J., Lucas, A., and Schaumburg, J. (2016). Spillover dynamics for systemic risk measurement using spatial financial time series models. Journal of Econometrics, 195(2):211 - 223.

Blatt, D., Candelon, B., and Manner, H. (2015). Detecting contagion in a multivariate time series system: An application to sovereign bond markets in Europe. Journal of Banking \& Finance, 59:1 - 13.

Booth, L., Georgopoulos, G., and Hejazi, W. (2007). What drives provincialCanada yield spreads? Canadian Journal of Economics, 40(3):1008-1032.

Canzoneri, M., Cumby, R., and Diba, B. (2002). Should the european central bank and the federal reserve be concerned about fiscal policy? Proceedings - Economic Policy Symposium - Jackson Hole, pages 333-389.

Chang, E. C., Luo, Y., and Ren, J. (2013). Cross-listing and pricing efficiency: The informational and anchoring role played by the reference price. Journal of Banking \&6 Finance, 37(11):4449 - 4464.

Chen, H. and Choi, P. M. S. (2012). Does information vault niagara falls? cross-listed trading in New york and Toronto. Journal of Empirical Finance, $19(2): 175-199$. 
Chen, H., Choi, P. M. S., and Hong, Y. (2013). How smooth is price discovery? evidence from cross-listed stock trading. Journal of International Money and Finance, 32:668 - 699 .

Chen, J., Tse, Y., and Williams, M. (2009). Trading location and equity returns: Evidence from US trading of british cross-listed firms. Journal of International Financial Markets, Institutions and Money, 19(5):729 - 741.

Claeys, P., Moreno, R., and Suriñach, J. (2012). Debt, interest rates, and integration of financial markets. Economic Modelling, 29(1):48 - 59.

Claeys, P. and Vasicek, B. (2014). Measuring bilateral spillover and testing contagion on sovereign bond markets in Europe. Journal of Banking E Finance, 46(0):151 - 165 .

Codogno, L., Favero, C., and Missale, A. (2003). Yield spreads on EMU government bonds. Economic Policy, 18(37):503-532.

De Grauwe, P. and Ji, Y. (2013). Self-fulfilling crises in the eurozone: An empirical test. Journal of International Money and Finance, 34(0):15 - 36.

De Grauwe, P. and Ji, Y. (2014). Disappearing government bond spreads in the Eurozone back to normal? CEPS Working Document No. 396.

De Grauwe, P. and Ji, Y. (2015). Market sentiments and the sovereign debt crisis in the eurozone. Technical Report 28, Collaborative EU Project FinMaP Financial Distortions and Macroeconomic Performance: Expectations, Constraints and Interaction of Agents.

De Grauwe, P., Ji, Y., and Macchiarelli, C. (2017). Fundamentals versus market sentiments in the euro bond markets: implications for QE. LSE Research Online Documents on Economics 85127, London School of Economics and Political Science, LSE Library.

De Jong, F. and Schotman, P. C. (2010). Price discovery in fragmented markets. Journal of Financial Econometrics, 8(1):1-28.

Diebold, F. X. and Yilmaz, K. (2009). Measuring financial asset return and volatility spillovers, with application to global equity markets. The Economic Journal, 119(534):158-171.

Diebold, F. X. and Yilmaz, K. (2012). Better to give than to receive: Predictive directional measurement of volatility spillovers. International Journal of Forecasting, 28(1):57 - 66 .

Ding, D. K., Harris, F. H., Lau, S. T., and McInish, T. H. (1999). An investigation of price discovery in informationally-linked markets: equity trading in Malaysia and Singapore. Journal of Multinational Financial Management, $9(3): 317-329$.

Dominik, M. (2012). Determinants of sovereign yield spreads in the Eurozone: 


\section{BIBLIOGRAPHY}

A bayesian approach. Journal of International Money and Finance, 31(3):657 -672 .

Dungey, M., Fry, R., González-Hermosillo, B., and Martin, V. L. (2005). Empirical modelling of contagion: a review of methodologies. Quantitative finance, $5(1): 9-24$.

Eberhardt, M. and Teal, F. (2011). Econometrics for grumblers: a new look at the literature on cross-country growth empirics. Journal of Economic Surveys, 25(1):109-155.

Eichengreen, B. and Mody, A. (1998). What explains changing spreads on emerging-market debt: Fundamentals or market sentiment? NBER Working Papers 6408, National Bureau of Economic Research.

Elmendorf, D. W. and Mankiw, N. (1999). Government debt. Scholarly Articles 2643866, Harvard University Department of Economics.

Engle, R. F. and Granger, C. W. (1987). Co-integration and error correction: representation, estimation, and testing. Econometrica: Journal of the Econometric Society, pages 251-276.

Eun, C. S. and Sabherwal, S. (2003). Cross-border listings and price discovery: Evidence from u.s.-listed canadian stocks. The Journal of Finance, 58(2):549-575.

Faini, R. (2006). Fiscal policy and interest rates in europe. Economic Policy, 21(47):443-489.

Favero, C., Giavazzi, F., and Spaventa, L. (1998). High yields: The spread on German interest rates. NBER Working Papers 5408, National Bureau of Economic Research.

Favero, C. and Missale, A. (2010). Eu public debt management and eurobonds.

Favero, C. and Missale, A. (2012). Sovereign spreads in the eurozone: which prospects for a eurobond? Economic Policy, 27(70):231-273.

Favero, C. A. (2013). Modelling and forecasting government bond spreads in the euro area: A GVAR model. Journal of Econometrics, 177(2):343 - 356.

Favero, C. A. and Giavazzi, F. (2002). Is the international propagation of financial shocks non-linear?: Evidence from the ERM. Journal of International Economics, 57(1):231 - 246.

Favero, C. A. and Missale, A. (2016). Contagion in the EMU-the role of eurobonds with OMTs. Review of Law $\&$ Economics, 12(3):555-584.

Forbes, K. J. and Chinn, M. D. (2004). A decomposition of global linkages in financial markets over time. Review of economics and statistics, 86(3):705722 . 
Forbes, K. J. and Rigobon, R. (2002). No contagion, only interdependence: Measuring stock market comovements. The Journal of Finance, 57(5):22232261.

Frijns, B., Gilbert, A., and Tourani-Rad, A. (2010). The dynamics of price discovery for cross-listed shares: Evidence from australia and new zealand. Journal of Banking $\&$ Finance, 34(3):498 - 508.

Frijns, B., Gilbert, A., and Tourani-Rad, A. (2015). The determinants of price discovery: Evidence from us-canadian cross-listed shares. Journal of Banking \& Finance, 59(1):457 - 468.

Gale, W. G. and Orszag, P. R. (2004). Budget deficits, national saving, and interest rates. Brookings Papers on Economic Activity, 2004(2):101-210.

Gomez-Puig, M. (2008). Monetary integration and the cost of borrowing. Journal of International Money and Finance, 27(3):455 - 479.

Gonzalo, J. and Granger, C. (1995). Estimation of common long-memory components in cointegrated systems. Journal of Business 85 Economic Statistics, $13(1): 27-35$.

Grammig, J., Melvin, M., and Schlag, C. (2005). Internationally cross-listed stock prices during overlapping trading hours: price discovery and exchange rate effects. Journal of Empirical Finance, 12(1):139 - 164.

Gruber, J. W. and Kamin, S. B. (2012). Fiscal positions and government bond yields in OECD countries. Journal of Money, Credit and Banking, 44(8):1563-1587.

Gupta, M. S., Mati, A., and Baldacci, M. E. (2008). Is it (still) mostly fiscal? Determinants of sovereign spreads in emerging markets. International Monetary Fund.

Hagen, J. V., Schuknecht, L., and Wolswijk, G. (2011). Government bond risk premiums in the eu revisited: The impact of the financial crisis. European Journal of Political Economy, 27(1):36 - 43.

Harris, F. H., McInish, T. H., Shoesmith, G. L., and Wood, R. A. (1995). Cointegration, error correction, and price discovery on informationally linked security markets. The Journal of Financial and Quantitative Analysis, 30(4):563-579.

Harris, F. H., McInish, T. H., and Wood, R. A. (2002a). Security price adjustment across exchanges: an investigation of common factor components for dow stocks. Journal of Financial Markets, 5(3):277 - 308.

Harris, F. H., McInish, T. H., and Wood, R. A. (2002b). Security price adjustment across exchanges: an investigation of common factor components for dow stocks. Journal of Financial Markets, 5(3):277 - 308. 


\section{BIBLIOGRAPHY}

Hasbrouck, J. (1995). One security, many markets: Determining the contributions to price discovery. The Journal of Finance, 50(4):1175-1199.

Hasbrouck, J. (2002). Stalking the efficient prices in market microstructure specifications: an overview. Journal of Financial Markets, 5(3):329 - 339.

Haugh, D., Ollivaud, P., and Turner, D. (2009). What drives sovereign risk premiums?: An analysis of recent evidence from the euro area. OECD Economics Department Working Papers 718.

Heppke-Falk, K. H. and Hüfner, F. P. (2004). Expected budget deficits and interest rate swap spreads - evidence for France, Germany and Italy. Discussion Paper Series 1: Economic Studies 2004,40, Deutsche Bundesbank, Research Centre.

Holly, S., Pesaran, M. H., and Yamagata, T. (2010). A spatio-temporal model of house prices in the $\{\mathrm{USA}\}$. Journal of Econometrics, 158(1):160 - 173.

Hsiao, C. (2007). Panel data analysis-advantages and challenges. Test: An Official Journal of the Spanish Society of Statistics and Operations Research, 16(1):1-22.

Huang, J.-C., Ates, A., and Brahmasrene, T. (2006). Measuring emerging stock market correlations utilizing the gravity model. Journal of Economics \& Economic Education Research, 7(3).

Hupperets, E. C. and Menkveld, A. J. (2002). Intraday analysis of market integration: Dutch blue chips traded in Amsterdam and New york. Journal of Financial Markets, 5(1):57 - 82.

Im, K. S., Pesaran, M. H., and Shin, Y. (2003). Testing for unit roots in heterogeneous panels. Journal of econometrics, 115(1):53-74.

Kadapakkam, P.-R., Misra, L., and Tse, Y. (2003). International price discovery for emerging market stocks: Evidence from Indian GDRs. Review of Quantitative Finance and Accounting, 21(2):179-199.

Kallestrup, R., Lando, D., and Murgoci, A. (2016). Financial sector linkages and the dynamics of bank and sovereign credit spreads. Journal of Empirical Finance, 38:374 - 393 .

Kamin, S. B. and von Kleist, K. (1999). The evolution and determinants of emerging markets credit spreads in the 1990s. BIS Working Papers 68, Bank for International Settlements.

Karabiyik, H., Narayan, P. K., Phan, D. H. B., and Westerlund, J. (2017). Islamic spot and index futures markets: Where is the price discovery? PacificBasin Finance Journal.

Karabiyik, H., Westerlund, J., and Narayan, P. (2018). Panel data measures of price discovery. Working paper. 
Kehrle, K. and Peter, F. J. (2013). Who moves first? an intensity-based measure for information flows across stock exchanges. Journal of Banking \& Finance, 37(5):1629 - 1642 .

Keiler, S. and Eder, A. (2013). Cds spreads and systemic risk: A spatial econometric approach. Discussion Papers 01/2013, Deutsche Bundesbank, Research Centre.

Kelejian, H. H. and Prucha, I. R. (2010). Specification and estimation of spatial autoregressive models with autoregressive and heteroskedastic disturbances. Journal of Econometrics, 157(1):53 - 67.

Koop, G., Pesaran, M., and Potter, S. M. (1996). Impulse response analysis in nonlinear multivariate models. Journal of Econometrics, 74(1):119 - 147.

Korczak, P. and Phylaktis, K. (2010). Related securities and price discovery: Evidence from NYSE-listed non-U.S. stocks. Journal of Empirical Finance, $17(4): 566-584$.

Laubach, T. (2009). New evidence on the interest rate effects of budget deficits and debt. Journal of the European Economic Association, 7(4):858-885.

Lemmen, J. et al. (1999). Managing government default risk in federal states. Financial Markets Group, London School of Economics.

Lemmen, J. J. and Goodhart, C. A. (1999). Credit risks and european government bond markets: A panel data econometric analysis. Eastern Economic Journal, 25(1):77.

Lieberman, O., Ben-Zion, U., and Hauser, S. (1999). A characterization of the price behavior of international dual stocks: an error correction approach. Journal of International Money and Finance, 18(2):289 - 304.

Linnemann, L. and Schabert, A. (2010). Debt nonneutrality, policy interactions, and macroeconomic stability. International Economic Review, 51(2):461-474.

Lok, E. and Kalev, P. S. (2006). The intraday price behaviour of Australian and New Zealand cross-listed stocks. International Review of Financial Analysis, 15(4):377 - 397 .

Looning, I. (2000). Default premia on european government debt. Review of World Economics, 136:259-283.

Manganelli, S. and Wolswijk, G. (2009). What drives spreads in the euro area government bond market? Economic Policy, 24(58):191-240.

Manner, H. and Candelon, B. (2010). Testing for asset market linkages: A new approach based on time-varying copulas. Pacific Economic Review, 15(3):364-384.

Metiu, N. (2012). Sovereign risk contagion in the eurozone. Economics Letters, $117(1): 35-38$. 


\section{BIBLIOGRAPHY}

Moon, H. R. and Perron, B. (2004). Testing for a unit root in panels with dynamic factors. Journal of econometrics, 122(1):81-126.

Narayan, P. K., Sharma, S. S., and Thuraisamy, K. S. (2014). An analysis of price discovery from panel data models of cds and equity returns. Journal of Banking \& Finance, 41:167 - 177.

Nickell, S. (1981). Biases in dynamic models with fixed effects. Econometrica: Journal of the Econometric Society, pages 1417-1426.

Oliveira, L., Curto, J. D., and Nunes, J. P. (2012). The determinants of sovereign credit spread changes in the euro-zone. Journal of International Financial Markets, Institutions and Money, 22(2):278-304.

Otsubo, Y. (2014). International cross-listing and price discovery under trading concentration in the domestic market: Evidence from japanese shares. Journal of Empirical Finance, 25:36 - 51.

Pascual, R., Pascual-Fuster, B., and Climent, F. (2006). Cross-listing, price discovery and the informativeness of the trading process. Journal of Financial Markets, 9(2):144 - 161 .

Pesaran, H. (2004). General diagnostic tests for cross section dependence in panels. CESifo Working Paper Series No. 1229, CESifo.

Pesaran, M. and Smith, R. (1995a). Estimating long-run relationships from dynamic heterogeneous panels. Journal of Econometrics, 68(1):79 - 113.

Pesaran, M. H. (2007a). A pair-wise approach to testing for output and growth convergence. Journal of Econometrics, 138(1):312 - 355.

Pesaran, M. H. (2007b). A simple panel unit root test in the presence of crosssection dependence. Journal of applied econometrics, 22(2):265-312.

Pesaran, M. H. and Pick, A. (2007). Econometric issues in the analysis of contagion. Journal of Economic Dynamics and Control, 31(4):1245 - 1277.

Pesaran, M. H., Smith, L. V., and Yamagata, T. (2013). Panel unit root tests in the presence of a multifactor error structure. Journal of Econometrics, 175(2):94-115.

Pesaran, M. H. and Smith, R. (1995b). Estimating long-run relationships from dynamic heterogeneous panels. Journal of econometrics, 68(1):79-113.

Pesaran, M. H. and Tosetti, E. (2011). Large panels with common factors and spatial correlation. Journal of Econometrics, 161(2):182 - 202.

Poterba, J. and Rueben, K. (1999). State fiscal institutions and the u.s. municipal bond market. Fiscal institutions and fiscal performance, National Bureau of Economic Research.

Rigobon, R. (2016). Contagion, spillover and interdependence. ECB Staff Working Paper No.607, European Central Bank. 
Roosenboom, P. and van Dijk, M. A. (2009). The market reaction to crosslistings: Does the destination market matter? Journal of Banking $\&$ Finance, $33(10): 1898$ - 1908.

Rowland, P. and Torres, J. L. (2004). Determinants of spread and creditworthiness for emerging market sovereign debt: A panel data study. Borradores de Economía; No. 295.

Schuknecht, L., von Hagen, J., and Wolswijk, G. (2009). Government risk premiums in the bond market: EMU and Canada. European Journal of Political Economy, 25(3):371 - 384 .

Sgherri, S. and Zoli, E. (2009). Euro area sovereign risk during the crisis. IMF Working Papers 09/222, International Monetary Fund.

Thomas, L. and Wu, D. (2009). Long-term interest rates and expected future budget deficits: evidence from the term structure. Applied Economics Letters, 16(4):365-368.

Tsuji, C. (2005). The credit-spread puzzle. Journal of International Money and Finance, 24(7):1073-1089.

Werner, I. M. and Kleidon, A. W. (1996). U.k. and u.s. trading of british cross-listed stocks: An intraday analysis of market integration. The Review of Financial Studies, 9(2):619-664.

Westerlund, J. (2007). Testing for error correction in panel data. Oxford Bulletin of Economics and statistics, 69(6):709-748.

You, L., Lucey, B. M., and Shu, Y. (2013). An empirical study of multiple direct international listings. Global Finance Journal, 24(1):69 - 84. 


\section{BIBLIOGRAPHY}




\section{The impact statement}

In this thesis, we discuss the different aspects of joining the common currency union such as reducing default risks of its members, interdependence of government bond markets and increasing competitiveness in the financial markets. The topics are concerns not only to the academic community but also to public policy makers as well as private decision makers.

During the corona recovery package discussion in Summer 2020, the members of the European Monetary Union (EMU) discussed the option of establishing a Eurobond, but it did not come to reality as fiscally strong members object. This Eurobond is a jointly guaranteed debt instrument in which each member has full responsibility for repayment regardless its contribution to the common budget. Due to the no bailout principle, the Eurobonds face higher legal obstacles within the EU Treaty and second they face far less politically acceptance by the member states. The main arguments against jointly guaranteed debt instruments are that they can create moral hazard for the weaker members and discourage fiscal discipline for these members. The arguments that support the Eurobonds are that they promote further market integration, increase liquidity and reduce the risk of crises propagation. We find empirical evidence that supports the last argument. Providing insurance to weaker members would benefit all participating members. A second important impact of this thesis will be pointing out the possible consequences of Brexit on European capital markets, especially on equity markets. Next, I will outline the impact of each chapter.

In Chapter 2, we find that, despite the fact that financial markets have become more integrated, country-specific economic fundamentals do matter for European government bond pricing. Among the country-specific fundamentals, fiscal strength, ability to generate taxes to cover its expenses, is important, but relative real economic growth is the most robust across the different estimations. Fiscal consolidation is preferable to improve governments' credibility. On the other hand, if fiscal consolidation has a strong negative effect on economic growth, rather than bringing the government yield spreads down it can 
put push them up. The policy makers can continue to prioritize fiscal responsibility while promoting economic growth via structural reforms such as investments in education and infrastructure.

In Chapter 3, we focus on the interdependence of government bond markets in the EMU and how the domestic yield spreads are affected by the spreads of other member countries. The importance of interdependence is detected after extracting the country-specific risks and common factors. We find that bilateral trade connections as well as FDI flows are the main propagation channels. Even if each member country takes care of their fiscal responsibility individually, they are still vulnerable during a financial distress period due to the interdependence. The results of this chapter have profound implications on the discussion whether Eurobonds are essential to prevent the crisis propagation due to interdependence in the bond markets in the EMU. In addition, Eurobond instruments can be another way of strengthening the monetary integration of the union.

In Chapter 4, we investigate the intra-day adjustment of the price discovery of Euronext stocks traded in three markets: the home market in which the firms become public for the first time and in which the highest volume of trade occurs and two Multi Trading Facilities (MTFs) operated by the international financial service providers. For this, we introduce a new estimator that measures the contribution of each market to price adjustments. We find that the integration of European equity markets has had the effect that home market dominance no longer holds in Europe. Second, the influence of the MTFs in the price discovery process has increased. The key implication of our results is to pay attention to the possible consequences of Brexit on financial markets, particularly on equity markets. The, MTFs for European stocks operate in London and are subject to U.K regulations and their legal status is unclear after Brexit. Generally, London as a financial center has been the main channel for European financial markets to access the global financial markets, not just for equity, but also for other financial instruments. European policy makers either need to introduce a European capital market union or boost a new financial capital center to be an alternative to London.

In conclusion, this thesis elaborates on topics that are important to prevent crises propagation in the EMU due to interdependence in the bond markets and to improve integration of financial markets in the union. First of all, regarding the question whether jointly backed debt instruments are essential, we provide empirical evidence for the bond markets and arguments to public policy makers to support the debt instruments, the Eurobonds. Second, concerning the question whether financial integration in European equity markets would be affected after Brexit, we find the evidence for the increasing importance of U.K. regulated MTFs served by international financial service providers in London. This requires actions from European policy makers to boost a new financial capital center in the Continental Europe. 


\section{Curriculum vitae}

Seher Fazlıŏlu was born and raised in Istanbul, Turkey. She obtained her B.A. in economics from Boğaziçi University in 2001. Her background includes six years of professional experience in performing economic analysis and modeling at Boutique investment house in Istanbul. She has also studied and worked at several universities around the world like Maastricht, Paris and Istanbul.

Her adventure in Maastricht began in 2012 when she obtained a MSc in Economic and Financial Research with specialization in Econometrics from Maastricht University. She continued her academic career by enrolling into the $\mathrm{PhD}$ Program at the same university. She ran for the position of the scientific staff representative at the University Council in 2013 and served till 2015. Her research interests are monetary economics, financial economics and panel data.

She is a member of the Istanbul Culture and Art Foundation and The Netherlands Bach Society, a dark chocolate connoisseur and a beginner surfer. 